Juliana Isa Beraldo

\title{
A inibição da dipeptidil peptidase IV reduz os níveis de angiotensina II e atenua o remodelamento e a disfunção cardíaca em ratos com doença renal crônica
}

Dissertação apresentada à Faculdade de Medicina da Universidade de São Paulo para obtenção do título de Mestre em Ciências

Programa de Ciências Médicas

Área de concentração: Distúrbios Genéticos de Desenvolvimento e Metabolismo

Orientadora: Profa. Dra. Adriana Castello Costa Girardi

São Paulo 


\author{
Juliana Isa Beraldo
}

\title{
A inibição da dipeptidil peptidase IV reduz os níveis de angiotensina II e atenua 0 remodelamento e a disfunção cardíaca em ratos com doença renal crônica
}

Dissertação apresentada à Faculdade de Medicina da Universidade de São Paulo para obtenção do título de Mestre em Ciências

Programa de Ciências Médicas Área de concentração: Distúrbios Genéticos de Desenvolvimento e Metabolismo

Orientadora: Profa. Dra. Adriana Castello Costa Girardi

(Versão corrigida. Resolução CoPGr 6018/11, de 1 de novembro de 2011. A versão original está disponível na Biblioteca da FMUSP)

São Paulo

2017 
Dados Internacionais de Catalogação na Publicação (CIP)

Preparada pela Biblioteca da

Faculdade de Medicina da Universidade de São Paulo

Creprodução autorizada pelo autor

Beraldo, Juliana Isa

A inibição da dipeptidil peptidase IV reduz os níveis de angiotensina II e atenua o remodelamento e

a disfunção cardíaca em ratos com doença renal crônica

/ Juliana Isa Beraldo. -- São Paulo, 2017.

Dissertação(mestrado)--Faculdade de Medicina da Universidade de São Paulo.

Programa de Ciências Médicas. Área de

Concentração Distúrbios Genéticos de Desenvolvimento

e Metabolismo.

Orientadora: Adriana Castello Costa Girard.

Descritores: 1.Doença renal crônica 2.Inibidores

da dipeptidil peptidase IV 3.Sitagliptina

4.Albuminúria 5.Remodelamento cardíaco 6.Ratos

Wistar

$\mathrm{USP} / \mathrm{FM} / \mathrm{DBD}-403 / 17$ 
Dedicatória 
Dedico este trabalho à minha família, que foi meu porto seguro ao longo desta trajetória. 
Agradecimentos 


\section{Agradecimentos}

À Deus, pela vida, saúde, bênçãos e por mostrar o caminho nas horas incertas. Eu Ihe sou tão grata.

Aos meus pais, Maurílio e Márcia, que mesmo à distância transmitiram muito amor, compreensão e apoio. Obrigada por fazerem o melhor que podem pelos seus filhos e por terem me ensinado valores, pelos quais me fazem encarar os desafios com dignidade. A vocês todo meu amor e gratidão.

Aos meus irmãos, Hélen e Diógenes, obrigada por toda força, companheirismo e verdadeira "irmandade".

À minha orientadora, Prof. Dra. Adriana Girardi, por ter me recebido de portas abertas e confiado este trabalho a mim. Agradeço também pelo apoio, dedicação, ensinamentos e pelos desafios impostos, que contribuíram para $o$ meu crescimento. Muito obrigada.

Ao Mauro, por todos os momentos de aprendizados, discussões, amizade e principalmente pelo apoio.

Às minhas amigas Cecília, Camila, Miriam e Bruna, que foram fonte de força durante esses anos.

A todos os integrantes do Laboratório de Genética e Cardiologia Molecular, em especial aos colegas do grupo renal, Acaris, Flávia, Flávio, Daniel, Renato, Gabriela, Juliano e Carla. Obrigada por todos os conhecimentos compartilhados, amizade e apoio.

Aos amigos do ICESP, Igor, Jânio e José, que conseguiam deixar tudo mais leve quando os dias eram difíceis.

Ao prof. Dr. José Eduardo Krieger, pela oportunidade de executar o trabalho em um laboratório de excelência.

Aos professores que compuseram a banca de qualificação, Prof. Dra. Luciana Rossoni, Prof. Dr. Bruno Caramelli e Prof. Dr.Carlos Seguro. Obrigada pelas sugestões que tanto contribuíram para a evolução desse trabalho.

Ao Leonardo e Rafael, pela realização dos estudos ecocardiográficos. 
Ao Prof. Dr. Gerhard Malnic, que gentilmente disponibilizou seu laboratório para realização das análises plasmáticas.

Ao Márcio pela ajuda com as análises histológicas.

Aos funcionários da divisão de experimentação do Incor, Leno, Rafa, Dario, Pedro, Vicente, dentre tantos outros que muito me ajudaram com os animais.

À CAPES e FAPESP pelo suporte financeiro.

A todos aqueles que mesmo não estando citados aqui fazem parte da minha vida. 
Epígrafe 
"Afinal, aquilo que amamos sempre será parte de nós." Harry Potter 


\section{SUMÁRIO}

\section{LISTA DE ABREVIATURAS, SIGLAS E SÍMBOLOS}

\section{LISTA DE FIGURAS}

\section{LISTA DE TABELAS}

\section{RESUMO}

\section{ABSTRACT}

1. INTRODUÇÃO

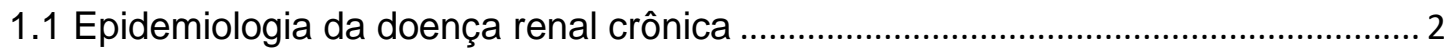

1.2 Definição e classificação da DRC .......................................................................... 3

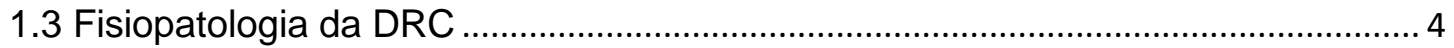

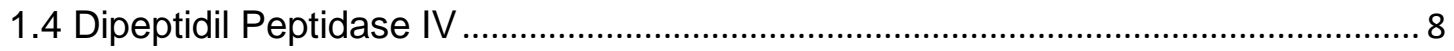

1.5 Efeitos renais dos inibidores da dipeptidil peptidase IV ........................................ 10

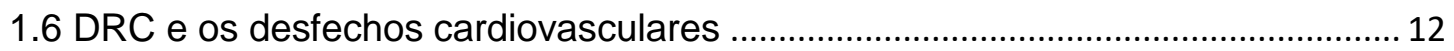

2. OBJETIVOS

3. MATERIAIS E MÉTODOS .................................................................... 21

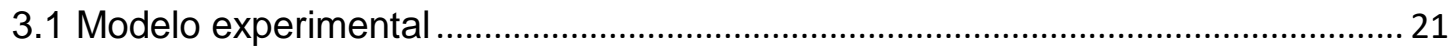

3.2 Indução da Doença Renal Crônica ......................................................................... 21

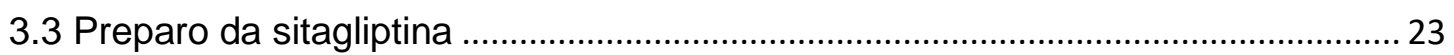

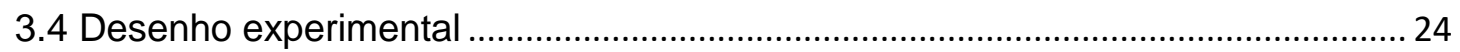

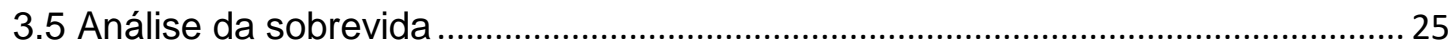

3.6 Determinação das concentrações plasmáticas de creatinina, ureia, glicose, sódio, potássio, cálcio e hemoglobina ……………………....................................... 26

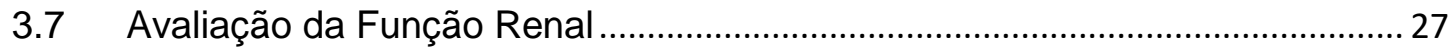

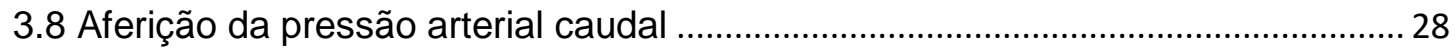


3.9 Determinação da atividade da DPPIV circulante e cardíaca .................................. 29

3.10 Determinação da concentração plasmática de BNP .............................................. 29

3.11 Avaliação da função cardíaca por ecodopplercardiograma.................................. 30

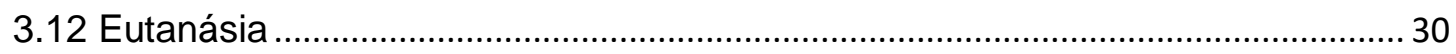

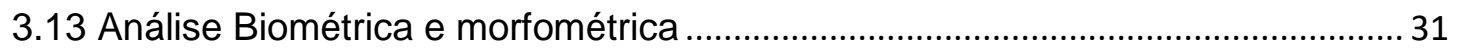

3.14 Preparação do homogenato de tecido cardíaco .................................................... 32

3.15 Determinação da concentração de proteínas ........................................................ 33

3.16 Análise da atividade da enzima conversora de angiotensina (ECA) ....................33

3.17 Análise da atividade da enzima conversora de angiotensina 2 (ECA2) .............. 34

3.18 Eletroforese em gel de poliacrilamida (SDS - PAGE) ....................................... 35

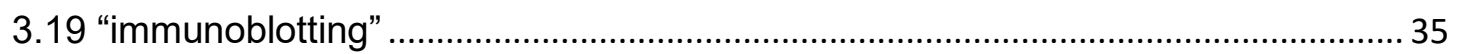

3.20 Reação em cadeia de polimerase em tempo real .................................................. 38

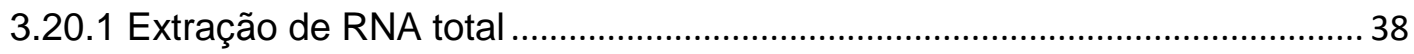

3.20.2 Transcrição do DNA complementar .............................................................. 39

3.20.3 Reação em cadeia de polimerase em tempo real (Qrt-PCR) ........................ 40

3.21 Determinação dos níveis de nitrotirosina........................................................... 42

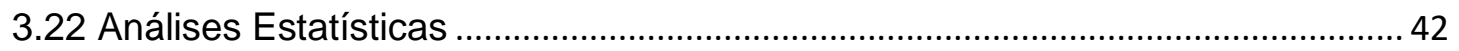

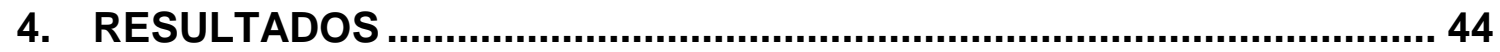

4.1 Parâmetros biométricos, metabólicos e atividade da DPPIV plasmática em ratos sham, $\mathrm{Nx}$ e Nx+IDPPIV

4.2 Efeitos da sitagliptina sobre a função renal e níveis pressóricos em ratos com DRC

4.4 Parâmetros biométricos e BNP cardíaco e circulante em ratos sham, Nx e Nx +IDPPIV

4.5 Efeitos da sitagliptina sobre o remodelamento cardíaco ......................................... 55

4.6 Expressão do NHE1 em ratos sham, Nx e Nx + IDPPIV ......................................... 58

4.7 Avaliação da função cardíaca em ratos sham, Nx e Nx+IDPPIV ........................... 59 
4.8 Atividade e expressão dos componentes do sistema renina angiotensina (SRA) em ratos sham, $\mathrm{Nx}$ e $\mathrm{Nx}+$ IDPPIV

4.9 Expressão gênica dos mediadores inflamatórios cardíacos e infiltração de macrófagos em ratos sham, Nx e Nx+IDPPIV 65

4.10. Avaliação do estresse oxidativo em ratos sham, $\mathrm{Nx}$ e Nx + IDPPIV 67

5. DISCUSSÃO 69

6. CONCLUSÕES 
Lista de Abreviaturas e Siglas 
$\mathrm{ACTb}$ - beta actina

AGT - angiotensinogênio

Ang I - angiotensina I

Ang II - angiotensina II

AT1 - receptor tipo I da angiotensina II

AT2 - receptor tipo II da angiotensina II

BNP - peptídeo natriurético cerebral

BSA- albumina de soro bovino

${ }^{\circ} \mathrm{C}$ - grau Celsius

$\mu \mathrm{g}$ - microgramas

$\mu \mathrm{l}-$ microlitros

Ca ${ }^{2+}$ - cálcio

Cdna - ácido desoxirribonucleico complementar

CD26: dipeptidil peptidase IV

COBEA - Colégio Brasileiro de Experimentação Animal

Cyclo - ciclofilina

D - diâmetro nuclear mais longo

D2 - diâmetro nuclear mais curto

DM2 - diabetes melittus tipo 2

DO - densidade óptica

DPPIV - dipeptidil peptidase IV

DRC - doença renal crônica

ECA - enzima conversora de angiotensina 
ECA2 - Isoforma 2 da enzima conversora de angiotensina

ECL - "Enhanced chemiluminescence"

EDTA - Ácido etilenodiamino tetra-acético

EUA - Estados Unidos da América

E/A - Relação onda E por onda A

ELISA - ensaio imunoenzimático

EndMT - transição endotelial-mesenquimal

EPM - Erro padrão da média

EROs - espécies reativas de oxigênio

GIP - peptídeo gástrico insulinotrópico

GLP-1 - peptídeo 1 semelhante ao glucagon

$\mathrm{h}$ - hora

$\mathrm{H}^{+}$- Íon hidrogênio

HC-FMUSP - Hospital das Clínicas - Faculdade de Medicina da Universidade de

São Paulo

HRP - Anticorpo secundário conjugado à peroxidase

IC - insuficiência cardíaca

IDPPIV - inibidor da dipeptidil peptidase IV

IgG - Imunoglobulina G

IgM - Imunoglobulina M

IL-6 - interleucina 6

IL-1 $\beta$ - interleucina 1 beta

IL-10 - interleucina 10

$\mathrm{kg}$ - quilogramas

$\mathrm{M}-$ molar 
Mas - receptor Mas

MCP1 - Monocytechemoattractant

$\mathrm{mg}$ - miligramas

$\min -$ minuto

$\mathrm{ml}$ - mililitro

$\mathrm{mM}$ - milimolar

$\mathrm{Na}^{+}-$Íon sódio

$\mathrm{NaCl}$ - Cloreto de sódio

NHE3 - isoforma 3 do trocador $\mathrm{Na}^{+} / \mathrm{H}^{+}$

ng - nanogramas

nm - nanômetros

$\mathrm{nM}$ - nanomolar

PBS - tampão fosfato-salino

PA - Pressão arterial

$\mathrm{P}_{\mathrm{cr}}$ - concentração plasmática de creatinina

PCR - reação em cadeira pela polimerase

$\mathrm{Pg}$ - picogramas

PH - potencial Hidrogeniônico

PVDF - Polímero de Fluoreto de Polivinilideno

NPY - neuropeptídeo Y

PYY - peptídeo YY

$r$ - Coeficiente de determinação de correlação de Pearson

RFG - Ritmo de filtração glomerular

RNA - Ácido ribonucleico

RNAm - RNA mensageiro 
RPM - Rotações por minuto

SDF-1 $\alpha$ - Fator derivado do estroma-1 alfa

SDS - Dodecil sulfato de sódio

SDS-PAGE - Eletroforese em gel de poliacrilamida

SRA - sistema renina angiotensina

SRAA - sistema renina angiotensina aldosterona

TGF- $\beta 1$ - Fator beta 1 de crescimento transformante

TRIV - Tempo de relaxamento isovolúmico

U - Unidade internacional para quantificação de atividade enzimática

UCr - Concentração urinária de creatinina

V - Fluxo urinário

VD - Ventrículo direito

VE - Ventrículo esquerdo

v/v - volume/volume 
Lista de Figuras 


\section{LISTA DE FIGURAS}

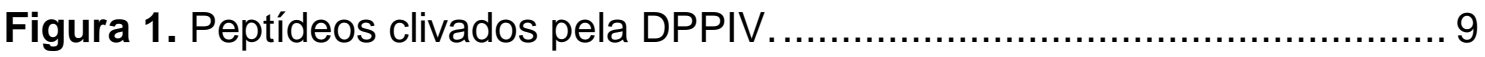

Figura 2. Esquematização do sistema renina angiotensina aldosterona......... 15

Figura 3. Cirurgia de nefrectomia $5 / 6$ em ratos Wistar para indução da DRC. 22

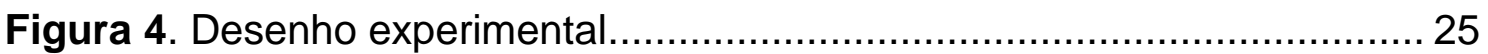

Figura 5. Curva da sobrevida global dos animais sham, $\mathrm{Nx}$ e Nx+IDPPIV...... 44

Figura 6. Avaliação da função renal em ratos sham, $\mathrm{Nx}$ e Nx+IDPPIV........... 48

Figura 7. Consumo de água e fluxo urinário em ratos sham, $\mathrm{Nx}$ e Nx + IDPPIV.

Figura 8. Consumo, excreção e balanço de sódio e níveis pressóricos em ratos

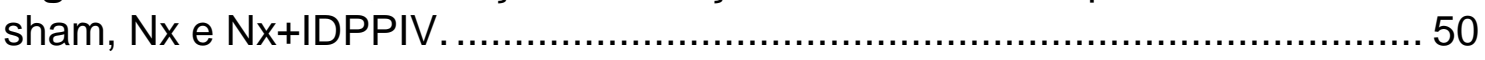

Figura 9. Determinação da atividade e abundância da DPPIV cardíaca em

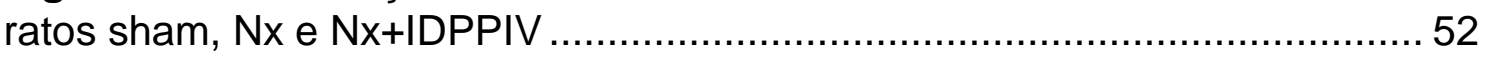

Figura 10. Parâmetros biométricos e BNP circulante e cardíaco em ratos sham,

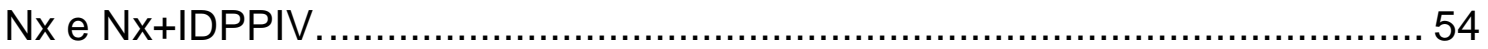

Figura 11. Efeitos da sitagliptina sobre a fibrose intersticial. ......................... 56

Figura 12. Efeitos da sitagliptina sobre a hipertrofia cardíaca........................ 57

Figura 13. Expressão proteica de NHE1 em ratos sham, Nx e Nx+IDPPIV. ... 58

Figura 14. Análise da função cardíaca em ratos sham, $\mathrm{Nx}$ e Nx+IDPPIV. ....... 60

Figura 15. Expressão gênica dos componentes do sistema renina angiotensina

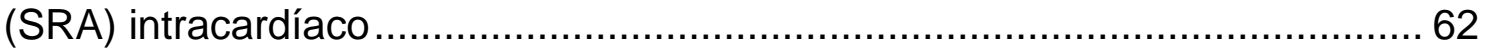

Figura 16. Expressão proteica e atividade de ECA e ECA2 ….........................63

Figura 17. Níveis de angiotensina II e angiotensina 1-7 em ratos sham, $\mathrm{Nx} e$

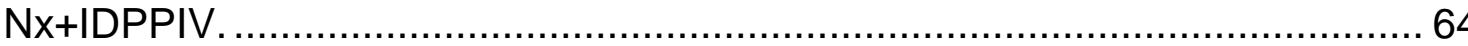

Figura 18. Avaliação dos marcadores inflamatórios e anti-inflamatórios em homogenato de coração de ratos com DRC tratados com sitagliptina ou veículo

Figura 19. Avaliação dos níveis de nitrotirosina em homogenato de coração de

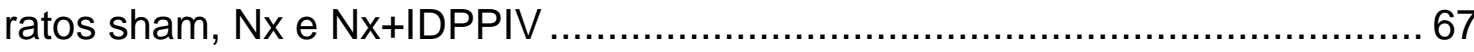

Figura 20. Efeitos da inibição da DPPIV em ratos com DRC ......................... 79 
Lista de Tabelas 


\section{LISTA DE TABELAS}

Tabela 1. Classificação da DRC e risco cardíaco associado com base no ritmo de filtração glomerular e excreção urinária de albumina.

Tabela 2. Lista de anticorpos primários e secundários utilizados nos experimentos de "immunoblotting".

Tabela 3. Oligonucleotídeos utilizados para PCR em tempo real................... 41

Tabela 4. Biometria, consumo de água e ração e parâmetros metabólicos em ratos sham, $\mathrm{Nx}$ e $\mathrm{Nx}+$ IDPPIV 46 
Resumo 


\section{RESUMO}

Beraldo Jl. A inibição da dipeptidil peptidase IV reduz os níveis de angiotensina II e atenua o remodelamento e a disfunção cardíaca em ratos com doença renal crônica [Dissertação]. São Paulo: Faculdade de Medicina, Universidade de São Paulo; 2017.

A disfunção cardíaca é um dos principais desfechos da doença renal crônica, sendo que o eixo sistema renina angiotensina (SRA) é um mediador chave nessa condição. Estudos têm demonstrado que os inibidores da dipeptidil peptidase IV (IDPPIV), uma classe de drogas utilizadas no tratamento do diabetes tipo II, são capazes de exercer efeitos renoprotetores e cardioprotetores, entretanto, os efeitos dos IDDPIV sobre o tecido cardíaco frente a uma injúria renal ainda não foram descritos. Assim, esse estudo teve como objetivo investigar se a inibição da DPPIV atenua a disfunção e o remodelamento cardíaco em ratos com DRC e se esses efeitos se associam a alterações no SRA. Para este fim, ratos Wistar $(\mathrm{N}=37)$ com idade entre 2-3 meses, foram submetidos à nefrectomia $5 / 6$ para indução da DRC. Após a cirurgia, os ratos foram randomizados em 2 grupos: Nx (tratados com veículo) e Nx + IDPPIV (tratados com sitagliptina - 200 mg/Kg/dia). Ratos submetidos à cirurgia fictícia foram utilizados como controles (sham). Como esperado, após oito semanas de seguimento, o grupo Nx apresentou acentuada disfunção renal. Por outro lado, nos ratos tratados com sitagliptina, a queda do ritmo de filtração glomerular (RFG) foi significativamente atenuada, bem como a creatinina sérica, albuminúria e pressão arterial caudal em relação ao grupo Nx. Curiosamente, tanto a atividade quanto a expressão proteica e gênica da DPPIV cardíaca estavam aumentadas em ratos Nx comparado aos ratos controles. As análises histológicas mostraram que os cardiomiócitos de ratos Nx apresentaram maior volume nuclear e fibrose intersticial cardíaca em relação ao sham. Por outro lado, nos ratos tratados com sitagliptina o volume nuclear dos cardiomiócitos e fibrose estavam reduzidos em relação aos ratos $\mathrm{Nx}$. A função sistólica não se mostrou distinta entre os três grupos de ratos. Todavia, o tempo de relaxamento isovolumétrico (TRIV) foi maior em Nx do que em sham, como sugestivo de disfunção diastólica associada à DRC e o tratamento com sitagliptina foi capaz de atenuar o TRIV. A concentração de angiotensina II cardíaca estava aumentada nos ratos $\mathrm{Nx}$ em relação aos ratos sham e o tratamento com sitagliptina foi capaz de impedir sua elevação. Em conjunto, os nossos dados sugerem que a inibição da DPPIV em ratos com DRC atenua o remodelamento e a disfunção cardíaca, e que esses efeitos estão envolvidos ao menos em parte, com a redução nos níveis de angiotensina II. Esse é o primeiro trabalho a demonstrar a interação da DPPIV com o SRA intracardíaco em 
modelo de DRC, e abre portas para estudos envolvendo os mecanismos que levam a essa associação nas síndromes cardiorrenais.

Descritores: doença renal crônica; inibidores da dipeptidil peptidase IV; sitagliptina; sistema renina angiotensina; remodelamento cardíaco; ratos Wistar. 
Abstract 


\begin{abstract}
Beraldo Jl. Dipeptidyl peptidase IV inhibition reduces cardiac angiotensin II levels and 2 mitigates diastolic dysfunction in experimental chronic kidney disease [Dissertation]. São Paulo: "Faculdade de Medicina, Universidade de São Paulo"; 2017.

Cardiac dysfunction is one of the main outcomes of chronic kidney disease, with the axis system renin angiotensin (RAS) being a key mediator in this condition. Studies have shown that dipeptidyl peptidase IV (IDPPIV) inhibitors, a class of drugs used in the treatment of type II diabetes, are capable of exerting renoprotective and cardioprotective effects, however, the effects of IDDPIV on cardiac tissue against renal injury were not described. Thus, this study aimed to investigate whether inhibition of DPPIV attenuates cardiac dysfunction and remodeling in rats with $\mathrm{CKD}$ and whether these effects are associated with changes in RAS. For this purpose, Wistar rats $(N=37)$ aged 2-3 months were subjected to 5/6 nephrectomy for induction of CKD. After surgery, the rats were randomized into 2 groups: Nx (treated with vehicle) and Nx + IDPPIV (treated with sitagliptin - $200 \mathrm{mg} / \mathrm{kg} /$ day). Sham operated rats were used as controls. After eight weeks of treatment, we identified that the Nx group had marked renal dysfunction. On the other hand, in rats treated with sitagliptin, the decrease in RFG was significantly attenuated, as well as serum creatinine, albuminuria and caudal blood pressure in relation to the Nx group. Interestingly, both the activity and the protein and gene expression of the cardiac DPPIV were increased in Nx rats compared to the control rats. Additionally, histological analysis showed that the cardiomyocytes of Nx rats presented greater nuclear volume and cardiac interstitial fibrosis compared to sham. Conversely, in animals treated with sitagliptin the nuclear volume of cardiomyocytes and fibrosis were reduced in relation to Nx rats. Systolic function was not different among the three groups of rats. However, the isovolumic relaxation time (IVR) was higher in Nx than in sham, as suggestive of CKD-associated diastolic dysfunction and treatment with sitagliptin was able to attenuate IVRT. Cardiac angiotensin II levels were elevated in $\mathrm{Nx}$ rats relative to sham rats. Treatment with sitagliptin prevented their elevation. Taken together, data suggest that inhibition of DPPIV in rats with CKD attenuates remodeling and cardiac dysfunction, and that these effects are at least partially involved with the reduction in angiotensin II levels. This study is the first to demonstrate an interaction of DPPIV with the intracardiac RAS in a CKD model, and will help further studies focusing the mechanisms that lead this association in cardiorrenal syndromes.
\end{abstract}


Descriptors: chronic kidney disease; dipeptidyl-peptidase IV inhibitors; sitagliptin; angiotensin renin system; cardiac remodeling; Wistar rats. 
Introdução 


\section{INTRODUÇÃO}

\subsection{Epidemiologia da doença renal crônica}

A doença renal crônica (DRC), termo genérico que envolve o comprometimento estrutural e funcional dos rins, tem aumentado significativamente nas últimas décadas, tanto em países desenvolvidos como em desenvolvimento, tornando-se um problema de saúde pública mundial. Nos Estados Unidos, por exemplo, a prevalência de DRC foi maior entre 1999-2004 do que em 1988-1994 e, atualmente, aproximadamente 23 milhões de americanos são acometidos pela doença (1-3). Essa expansão nos casos de DRC pode ser atribuída a vários fatores, em especial, pela crescente prevalência do diabetes mellitus e hipertensão arterial, principais causas de DRC.

Mundialmente, estima-se que aproximadamente $8-16 \%$ da população possui DRC (3). No Brasil, a prevalência é notória, segundo os dados do censo feito em 2014, cerca de 100.000 pacientes encontra-se em terapia renal substitutiva, com crescimento anual de 5 a $10 \%$ (4). Esse crescimento reflete em maiores custos com diálise e transplante renal, que em particular, nos países desenvolvidos tiveram um aumento aproximado de $6-12 \%$ nas últimas duas décadas e continua a crescer (5). Tendo em vista a alarmante prevalência aliada a altos custos, a DRC tem sido alvo de preocupação nos últimos anos, recebendo cada vez mais atenção no que se refere ao desenvolvimento de ferramentas capazes de prevenir ou minimizar a progressão de seu curso. 


\subsection{Definição e classificação da DRC}

A DRC é definida como uma anormalidade estrutural ou funcional dos rins que se estabelece por um período igual ou maior que três meses, conduzindo a uma perda progressiva e irreversível das funções renais, tanto a nível glomerular, como tubular e endócrino. De curso lento e insidioso, ela é classificada com base em três parâmetros: causa, ritmo de filtração glomerular (RFG) e excreção urinária de proteínas. O RFG é expresso em $\mathrm{ml} / \mathrm{min} / 1,73 \mathrm{~m}^{2}$ e subdividido em seis diferentes estágios: G1: $\geq 90$; G2:60-89; G3a: 45-59; G3b: 30-44; G4: 15-29 e G5:0-15, sendo considerado um marcador de grande importância dada sua diminuição mesmo antes do início dos sintomas da doença. A análise da excreção urinária de albumina é feita após sua subclassificação em normo $(<30$ mg/24h), micro (30-300 mg/24h) e macroalbuminúria (> $300 \mathrm{mg} / 24 \mathrm{~h}$ ). A albuminúria é um marcador que auxilia na detecção de lesões no parênquima renal, sendo um facilitador no rastreamento da doença (6).

A identificação da excreção urinária de proteínas totais e, em especial, da albumina merece notoriedade, pois além de ser um marcador de lesão renal, é um fator de risco para doenças cardiovasculares e outras doenças na população em geral, principalmente em diabéticos e hipertensos. Sendo assim, a albuminúria é um relevante instrumento de diagnose que quando presente revela um mau prognóstico (7-9).

Os valores considerados aceitáveis, bem como os indicativos de dano renal estão exemplificados na Tabela 1. 
Tabela 1. Classificação da DRC e risco cardíaco associado com base no ritmo de filtração glomerular e excreção urinária de albumina.

\section{Classificação da DRC e risco cardíaco associado}

\section{Categorias do RFG Albumina/Creatinina e Risco Cardíaco}

\begin{tabular}{|c|c|}
\hline $\begin{array}{c}\geq 90 \\
\text { Normal ou alto }\end{array}$ & G1 \\
\hline $60-89$ & G2 \\
\hline Ligeira diminuição & G3a * \\
\hline \begin{tabular}{c} 
45-59 \\
Diminuição moderada \\
$30-44$ \\
Diminuição pouco severa \\
$15-29$ \\
\hline Diminuição grave \\
\hline$<15$ \\
Falência renal
\end{tabular} & G3b \\
\hline
\end{tabular}

Albumina/Creatinina $(\mathrm{mg} / \mathrm{mmol})$

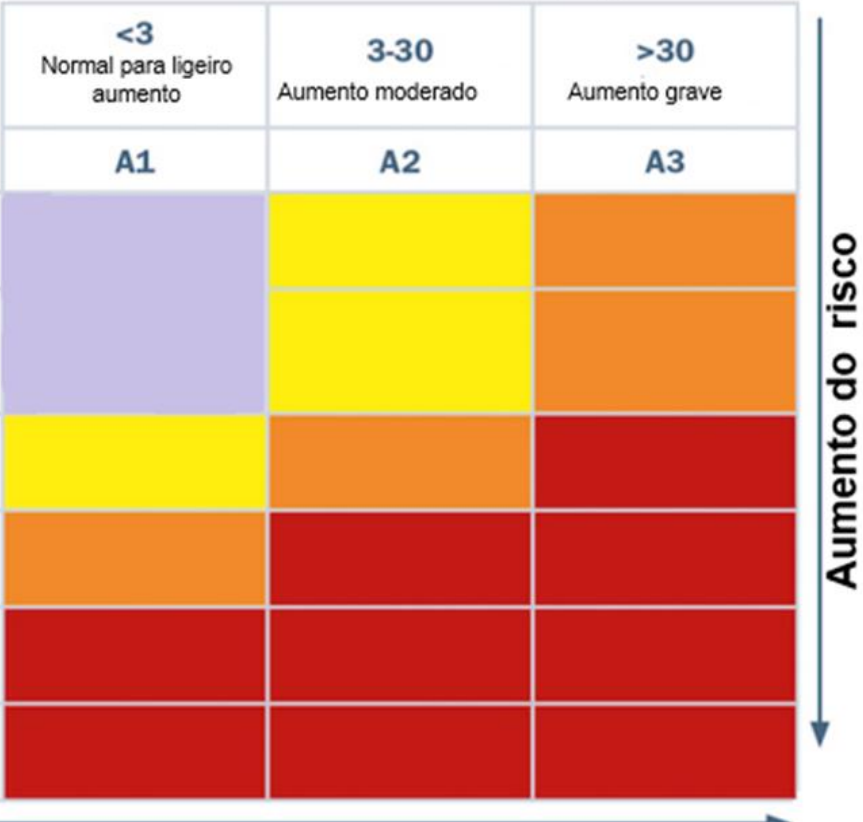

Aumento do risco

Verde: baixo risco, se não houver outros marcadores de DRC. Amarelo: risco moderado. Laranja: alto risco. Vermelho: risco muito elevado. Adaptado: Fraser, 2016 (10).

\subsection{Fisiopatologia da DRC}

A via inicial comum da DRC ocorre quando parte dos néfrons são destruídos, seja por ablação cirúrgica ou doenças, provocando hiperatividade dos néfrons remanescentes como tentativa de manter as funções renais dentro da normalidade. Apesar de imprescindível, em longo prazo essa "compensação" 
resulta em hipertrofia estrutural e funcional dos néfrons remanescentes, cujos desfechos podem levar a doença renal crônica terminal, havendo a necessidade de diálise ou transplante.

O processo adaptativo ocorre inicialmente com aumento do fluxo plasmático renal e pressão intraglomerular em cada néfron, em consequência da vasodilatação preferencial das arteríolas aferentes. Nesse momento, é observado um aumento demasiado do RFG (hiperfiltração), que causa dano à barreira de ultrafiltração glomerular, desencadeando proteinúria (11).

Além da proteinúria, ocorre produção aumentada de angiotensina II (Ang II), que em conjunto com o acúmulo anormal de proteínas no túbulo, provoca a estimulação de citocinas e quimiocinas inflamatórias, levando a infiltração de macrófagos e produção de MCP-1 (Monocyte chemoattractant protein-1), gerando uma retroalimentação que irá perpetuar a lesão renal. No túbulo renal, ocorre lesão da membrana basal e conversão de células epiteliais em mesenquimais, formando os fibroblastos intersticiais, produtores de excessivas fibras de colágeno, causando a fibrose. A fibrose tubulointersticial progressiva é a via final da DRC, causada por lesão prolongada aliada a desregulação no processo de reparação e excesso de matriz extracelular, que culmina na perda das funções renais $(12,13)$.

Muitos são os fatores que contribuem para a evolução da DRC, como por exemplo, o fator beta-1 de crescimento transformante (TGF- $\beta 1$ ), que estimula a produção de colágeno tanto em células glomerulares quanto em células túbulointersticiais e mesangiais, além de aumentar a captação de albumina, a produção de interleucina-18 em células do túbulo proximal e participar da geração de espécies reativas de oxigênio (EROs) via dinucleótido de nicotinamida e adenina 
fosfato (NADPH). Na DCR, a disponibilidade de EROs é aumentada pelo fato de sua produção ser maior que dos agentes antioxidantes que o degradam (14). A angiotensina II, além de contribuir para o processo de inflamação, estimula a hipertrofia e proliferação de células mesangiais através dos receptores AT1, aumenta a síntese de proteínas da matriz extracelular, via TGF- $\beta$ e ativa o fator nuclear kappa B (NF-kB) (15). Estes e outros elementos estão intimamente ligados à fisiopatologia da DRC.

Estudos sugerem que a presença contínua de albumina em quantidade anormal na luz tubular e, por conseguinte, o aumento da captação da mesma pelas células do túbulo proximal renal, ative vias inflamatórias perivasculares, resultando em fibrose túbulo-intersticial (9).

Diversas doenças podem causar DRC, podendo ser classificadas como doenças glomerulares, túbulo-intersticiais, vasculares, obstrutivas ou tumorais. Entre todas as causas, a nefropatia diabética, a nefropatia hipertensiva, as glomerulonefrites crônicas, as nefrites intersticiais crônicas e a doença renal policística são as etiologias mais frequentes. A nefropatia diabética (ND) é a causa primária de DRC, constituindo principal causa de terapia renal substitutiva no mundo. A ND, termo genérico que designa apenas lesão do parênquima renal ocasionado por diabetes, é caracterizada por declínio da função renal, proteinúria, anormalidades tubulares e glomerulares e hipertensão arterial. O tratamento da ND consiste em promover a remissão para a normoalbuminuria, evitar a evolução da microalbuminúria para a macroalbuminúria, desacelerar o declínio do RFG e prevenir a ocorrência de eventos cardiovasculares (16). De acordo com o United KingdomProspective Diabetes Study (UKPDS), estudo multicêntrico, randomizado, que acompanhou por cerca de 10 anos mais de 
7.000 pacientes submetidos a diversos tratamentos para controle do diabetes tipo 2, demonstrou que o controle da glicemia e da pressão arterial, reduz significativamente o risco de desenvolvimento de complicações microvasculares, incluindo a nefropatia (17).

Atualmente, o tratamento da ND reside fundamentalmente em três medidas clínicas: controle da glicemia, controle da hipertensão arterial sistêmica e o uso de drogas inibidoras do sistema renina-angiotensina aldosterona. Entretanto, a variabilidade interindividual na resposta anti-albuminúrica e na $\begin{array}{llll}\text { prevenção da } & \text { da } & \text { da } & \text { DRC }\end{array}$ é muito ampla. Assim, a taxa de progressão para a DRC terminal, mesmo nos pacientes tratados, segue alarmante. Tais aspectos justificam o empenho em se obter uma maior compreensão sobre os mecanismos de progressão da DRC, notadamente no que se refere a viabilizar o desenvolvimento de novas medidas terapêuticas e de prevenção.

Uma série de evidencias clínicas e experimentais documentaram a eficácia e a segurança da administração de inibidores da dipeptidil peptidase IV (gliptinas) para o controle da glicemia em pacientes com nefropatia diabética (1824). Num estudo conduzido em pacientes diabéticos que se encontravam em hemodiálise, o inibidor da DPPIV alogliptina, demonstrou efetividade diminuindo a glicemia pós-prandial, hemoglobina glicada e albumina glicada, além de ser bem tolerada pelos pacientes que receberam a droga durante 48 semanas (21). Corroborando a esse estudo, a linagliptina foi avaliada em 133 pacientes com deficiência renal grave associada ao DM2. Esse fármaco proporcionou melhora significativa nos níveis glicêmicos sem causar hipoglicemia, além de não apresentar danos renais relacionados ao fármaco no período de 1 ano (23). Os 
resultados positivos provenientes desses fármacos são inegáveis, contudo é preciso avaliá-los em longo prazo a fim de solidificar tais evidências.

\subsection{Dipeptidil Peptidase IV}

A enzima dipeptidil peptidase IV (DPPIV), também conhecida como CD26, é uma serino-protease que cliva a região $\mathrm{N}$-terminal de polipeptídios que contêm prolina ou alanina como segundo resíduo $(25,26)$. Esta enzima é expressa na superfície de células epiteliais (túbulo proximal renal, intestino e fígado), endoteliais, linfócitos e fibroblastos (26). Uma forma solúvel da DPPIV, sDPPIV, é também encontrada no plasma e em outros fluidos corporais. Seus substratos principais são as incretinas GLP-1 (peptídeo-1 semelhante ao glucagon) e GIP (polipeptídeoinsulinotrópico dependente de glicose). Ambas incretinas fornecem um sinal antecipatório do trato gastrintestinal para as ilhotas pancreáticas, moderando a elevação precoce da glicose plasmática que se segue à ingestão e à absorção de uma refeição contendo carboidratos. O achado de que a secreção de GIP fica preservada, enquanto a secreção de GLP-1 se deteriora é essencial para a justificativa da terapia de reposição de GLP-1 no tratamento do DM2 $(27,28)$. Os inibidores da DPPIV prolongam a sobrevida das incretinas endógenas e, desse modo, reforçam os mecanismos existentes no organismo para o controle fisiológico dos níveis sanguíneos de glicose. Concomitantemente, a produção de glucagon pelas células- $\alpha$ pancreáticas é suprimida, reduzindo dessa maneira a liberação de glicose hepática na corrente sanguínea (28-31). Portanto, as gliptinas fazem com que os efeitos 
glicorregulatórios do GLP-1 sejam prolongados, operando terapeuticamente no combate ao DM2.

Numerosos substratos com funções cardiorrenais são clivados no penúltimo aminoácido pela DPPIV, incluindo o péptido-1 semelhante ao glucagon (GLP-1), peptídeo natriurético cerebral (BNP) e fator 1a derivado de células do estroma (SDF-1a) (32-36). Diversos estudos demonstraram que a redução da atividade biológica destes substratos pela DPPIV pode estar associada a disfunção cardíaca e aumento na retenção de sódio e água pelos rins. A Figura 1 ilustra os principais substratos clivados pela DPPIV e os efeitos resultantes dessa clivagem.

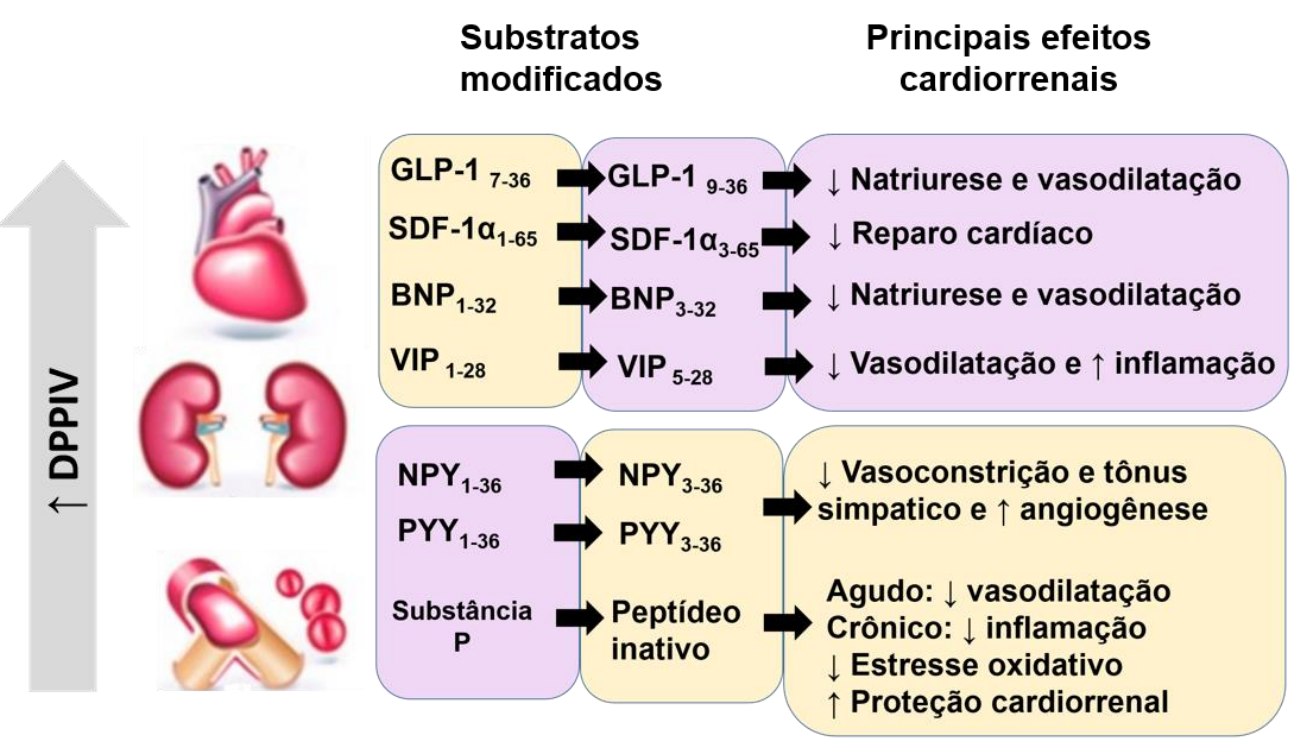

Figura 1. Peptídeos clivados pela DPPIV. O aumento da atividade da DPPIV cardíaca e circulante pode reduzir a atividade biológica de peptídeos com ações cardiovasculares, vaso e renoprotetoras, incluindo o GLP-1, BNP e o SDF -1a. A atividade da DPPIV também pode ser benéfica por clivar o NPY e o peptídeo PYY. Adaptado: Salles, T.A e colaboradores, 2015 (36). 


\subsection{Efeitos renais dos inibidores da dipeptidil peptidase IV}

A identificação da expressão de DPPIV em membrana apical de células do túbulo proximal foi o primeiro passo para posteriores descobertas com relação às ações desta enzima no rim. Girardi et al, revelaram que a DPPVI se associa a isoforma 3 do trocador $\mathrm{Na} /{ }^{+} \mathrm{H}^{+}(\mathrm{NHE})$ na região de borda em escova, em túbulo proximal, e que esse complexo (NHE3-DPPIV) é localizado em microvilosidades nas quais o NHE3 é ativo (37). Essa descoberta levantou a possibilidade de que a DPPIV poderia influenciar na atividade e/ou expressão do NHE3. O NHE3 é o trocador de $\mathrm{Na}^{+} / \mathrm{H}^{+}$mais abundante no túbulo proximal, reabsorvendo a maior parte do $\mathrm{NaCl}$ provindo dos glomérulos, assim, ele desempenha papel importante nos níveis de pressão arterial sistêmica.

Em ensaios utilizando células OKP do túbulo proximal, foi demonstrado que o inibidor da DPPIV exerceu efeito reduzindo significativamente a atividade do NHE3 (38). Adicionalmente, em modelo experimental, ratos tratados com inibidor da DPPIV apresentaram aumento na produção de urina, bem como na excreção de sódio, além disso, foi identificado que o NHE3 sofreu redistribuição, migrando da membrana apical para o domínio intermicrovilar (39). Em conjunto, estes achados demonstraram que a DPPIV modula a atividade do NHE3, bem como inibidores dessa enzima são capazes de atenuar a reabsorção de sódio.

Trabalhos clínicos avaliaram recentemente os efeitos renais da sitagliptina e constataram que inibidores da DPPIV não somente regulam a glicemia em pacientes diabéticos como também repercutem positivamente nos rins (40-43). Em síntese, os estudos mostraram que a sitagliptina desempenha um papel eficaz em inibir significativamente a albuminúria (microalbuminúria e 
macroalbuminúria) e inflamação vascular. Esses estudos sugerem que os efeitos renoprotetores provenientes dos inibidores da DPPIV podem se tornar fortes aliados no combate à progressão da DRC.

Efeitos renoprotetores dos inibidores da DPPIV também foram observados em modelo experimental de diabetes induzido por estreptozotocina (44). Neste estudo, os camundongos com diabetes tratados com o inibidor da DPPIV linagliptina, apresentaram uma melhora significativa da estrutura e função renal. Especificamente, a linagliptina exerceu ação anti-fibrótica, por inibir a transição epitélio-mesenquimal via bloqueio da atividade e expressão de TGF-2. Além disso, a linagliptina diminuiu significativamente a excreção urinária de albumina. Esses achados sugerem que a linagliptina pode reparar as lesões renais em pacientes diabéticos com insuficiência renal e seu potencial uso como ferramentas terapêuticas no combate a fibrose renal.

Em consistência com este estudo, Joo e colaboradores demonstraram que a sitagliptina não somente exerce ações renoprotetoras em pacientes ou modelos experimentais de nefropatia diabética, como, também age na DRC não associada à hiperglicemia (45). De fato, a administração de sitagliptina, durante 8 semanas, em ratos submetidos à nefrectomia $5 / 6$, reduziu a injúria nos rins remanescentes, diminuindo significativamente a glomeruloesclerose e a lesão túbulo-intersticial em comparação aos ratos com DRC não tratados.

Em conjunto, estes trabalhos salientam a eficácia e segurança da administração de inibidores da DPPIV em pacientes com DRC, bem como sugerem que estes agentes podem exercer ações renoprotetoras associadas ou não com as ações anti-hiperglicêmicas da classe das gliptinas. Porém, os mecanismos moleculares responsáveis pelos efeitos renoprotetores dos 
inibidores da DPPIV ainda não foram descritos. Sabe-se que a DPPIV circulante se encontra aumentada no DM1 e DM2, mas não há descrição se há aumento da atividade desta peptidase circulante ou renal na DRC e se o aumento dos níveis desta enzima correlaciona-se com a severidade da doença.

\subsection{DRC e os desfechos cardiovasculares}

Depois de instalada, a DRC representa um alto risco para desfechos cardiovasculares e desde as primeiras descrições, inúmeros estudos epidemiológicos têm confirmado essa condição. Nos EUA, por exemplo, a prevalência de doenças cardiovasculares em pacientes com DRC atinge 63\%, em contraste com apenas $5,8 \%$ em pessoas sem DRC, e essa prevalência está diretamente relacionada com a gravidade da DRC (2). No paciente renal crônico com doença renal em estágio terminal, o risco de mortalidade cardiovascular é cerca de 10 a 20 vezes maior do que em indivíduos controle pareados por idade e gênero sem DRC $(46,47)$. A interação patofisiológica envolvendo coração e rins é denominada síndrome cardiorrenal e atualmente classificada em 5 subtipos. Observa-se que tanto a IC como a DRC são capazes de acelerar comorbidades, através da indução da inflamação, ativação do sistema imunológico, anemia, desordens minerais, ósseas e etc. Entretanto, apesar da DRC ser considerada um fator de risco independente para mortalidade e eventos cardiovasculares, os mecanismos fisiopatológicos que desencadeiam tais desfechos não estão totalmente esclarecidos. Dentre as alterações observadas, está a disfunção diastólica no ventrículo esquerdo e a hipertrofia ventricular 
esquerda. Essas anormalidades podem ser explicadas, em parte, por fatores hemodinâmicos como o aumento da pré-carga (sobrecarga de volume) e póscarga (sobrecarga de pressão) e por fatores não hemodinâmicos relacionados à DRC, como a ativação inapropriada do SRA, estresse oxidativo, inflamação, aumento de colágeno, dentre outros.

Além dos fatores citados acima, a identificação da excreção urinária de proteínas totais e, em especial da albumina é importante, pois além de ser um marcador de lesão renal, é um fator de risco para doenças cardiovasculares. 0 mecanismo pelo qual a albuminúria reflete em alterações cardiovasculares ainda é hipotético, porém há evidências que o mesmo esteja associado a alterações fisiopatológicas como disfunção endotelial, inflamação crônica de baixo grau ou aumento do vazamento transvascular de macromoléculas (7-9). De modo geral, o aumento da proporção de albumina/creatinina urinária e a pressão arterial estão independentemente associados com o aumento do risco de morbidade e mortalidade cardiovascular, permanecendo como alvos de estudo para o desenvolvimento de novas terapias.

Evidências clínicas e experimentais mostram que o sistema reninaangiotensina (RAS) tem um papel chave na doença cardiovascular associada à hipertensão e outras comorbidades metabólicas. Esse sistema é um dos principais reguladores da pressão arterial e homeostase de sódio, mas, quando ativado de forma inapropriada é capaz de causar hipertrofia e fibrose cardíaca. Dentre os principais mecanismos que associam o SRA à hipertrofia no coração estão o aumento da pressão sanguínea, ações diretas da angiotensina II circulante e local sobre os cardiomiócitos, mediadas pelo receptor AT1, além das ações exercidas pela aldosterona $(48,49)$. A Figura 2 ilustra a cascata do SRA, 
bem como os principais fatores que contribuem para os desfechos cardíacos (hipertrofia e fibrose).

Foi demonstrado que a inibição da DPPIV em ratos com DRC reduz a hipertrofia e fibrose cardíaca (50) e melhora a função renal em modelos experimentais de insuficiência cardíaca (32, 51, 52). Curiosamente, pesquisadores relataram que a angiotensina II estimula a atividade de DPPIV renal tanto in vitro como in vivo através do receptor de angiotensina II tipo 1 (AT1) (53), e que a inibição de DPPIV é capaz de reduzir os níveis de angiotensina II circulante em ratos espontaneamente hipertensos (54). Estes estudos, portanto, elevam possibilidade de uma associação entre a DPPIV e ativação do SRA em doenças cardiorrenais.

No contexto de hipertrofia cardíaca, a atividade da isoforma 1 do trocador $\mathrm{Na}^{+} / \mathrm{H}^{+}(\mathrm{NHE} 1)$ se encontra elevada (49). O NHE1 é um trocador que dentre suas ações, faz a regulação do pH intracelular, eliminando o excesso de ácido das células metabolicamente ativas, por meio da extrusão de $\mathrm{H}^{+}$em troca de $\mathrm{Na}^{+}$. No remodelamento, a alta atividade do $\mathrm{NHE} 1$ faz com que haja redução do $\mathrm{Na}^{+}$ transmembrana, com consequente aumento do $\mathrm{Ca}^{2+}$ intracelular, pelo permutador $\mathrm{Na} / \mathrm{Ca}$, ativando cascatas de sinalização. Estudos demonstram que a inibição de NHE1 pelo seu inibidor, cariporeno, é capaz de reduzir a hipertrofia cardíaca (55). 
A

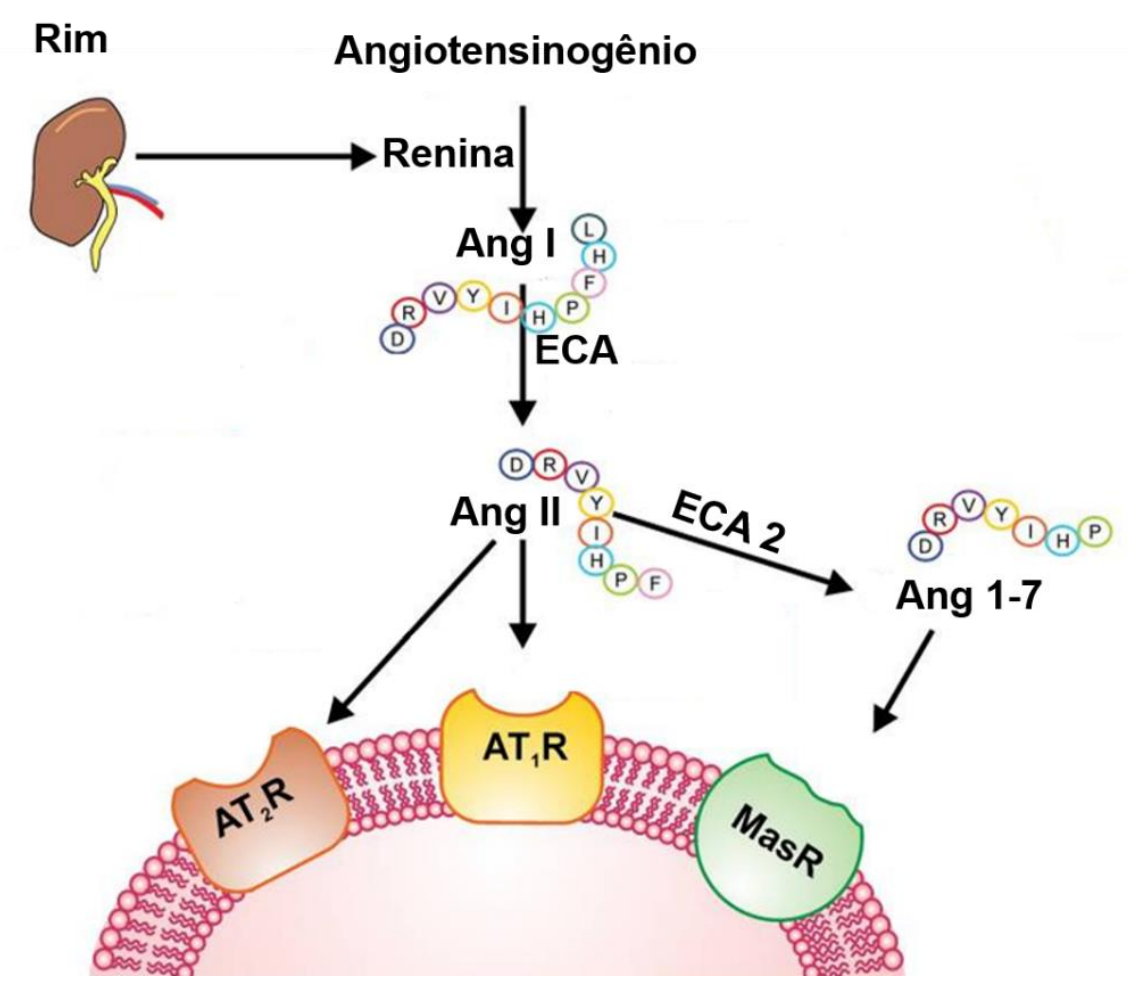

B

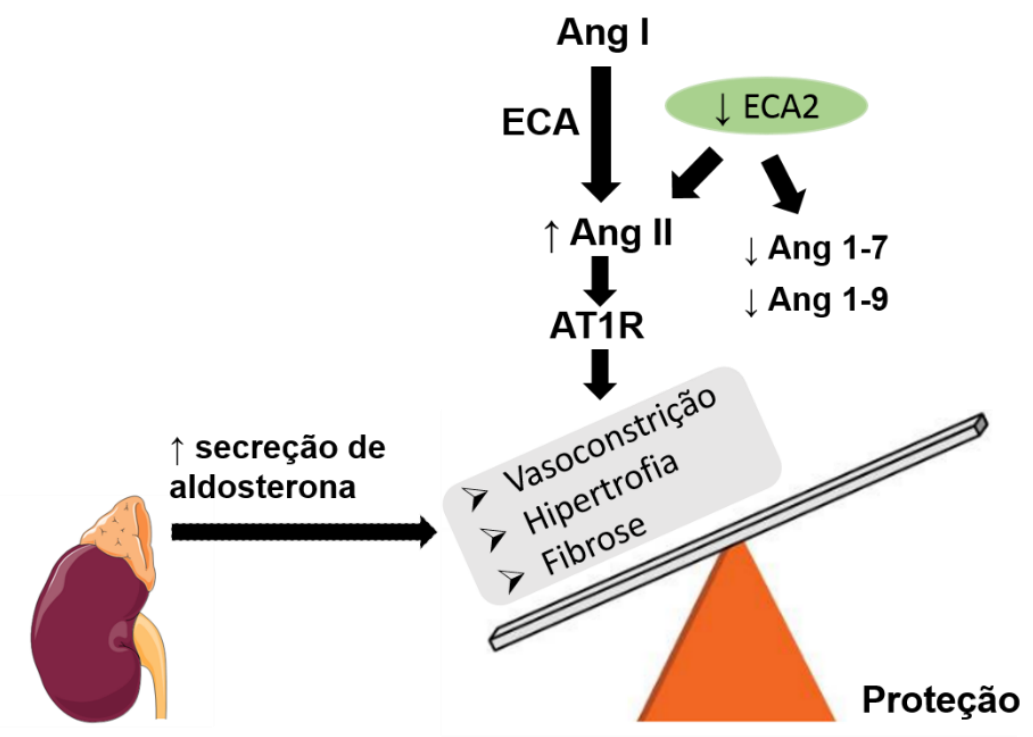

Figura 2. Esquematização do sistema renina angiotensina aldosterona. (A) $O$ angiotensinogênio é clivado pela renina, formando Ang I. A Ang I por sua vez, é clivada por ECA formando Ang II, que pode ser clivado por ECA II, formando Ang 1-7. A Ang II atua nos receptores AT1 e AT2. Ang 1-7 atua nos receptores Mas e contrabalança as ações da Ang II/AT1R. (B) A diminuição de ECA2 desloca o equilíbrio no RAS para o eixo Ang II/AT1R, resultando em vasoconstrição, hipertrofia e ficrose cardíaca. A 
secreção aumentada de aldosterona corrobora para os efeitos hipertróficos cardíacos. Adaptado: Patel , V.B. e colaboradores, 2016 (56).

Como tentativa de entender os mecanismos fisiopatológicos envolvidos na DRC, bem como testar diferentes abordagens terapêuticas, modelos experimentais de DRC tem sido cada vez mais utilizados e aprimorados para tais propósitos. Na década de oitenta, Barry M. Brenner desenvolveu um modelo de DRC chamado nefrectomia 5/6, um modelo de DRC não associado à hiperglicemia. A técnica foi refinada e atualmente é uma das mais fidedignas à DRC em humanos. Dentre as principais alterações renais observadas após o procedimento, estão à progressiva hipertrofia glomerular, redução do ritmo de filtração glomerular e proteinúria, concomitante ao aumento da creatinina sérica e desenvolvimento de hipertensão arterial. A hipertensão arterial tem papel chave na progressão da DRC nesse modelo, de modo que o grau de glomeruloesclerose é diretamente proporcional à elevação dos níveis pressóricos $(57,58)$. Alterações em parâmetros cardiovasculares também estão presentes $(59,60)$. Além da hipertensão arterial, foi identificado que o modelo leva ao aumento da frequência cardíaca, diminuição da resposta parassimpática, hipertrofia do ventrículo esquerdo, além de alterações funcionais. Estudos ecocardiográficos demonstram que a velocidade da onda $A$ se encontra aumentada nesse modelo, com redução na razão $E / A$, caracterizando alteração na função diastólica. Além disso, foi observado aumento na espessura da parede ventricular que progride de forma conjunta à progressão da DRC. Em suma, esses achados sugerem que o modelo de nefrectomia 5/6 pode servir como uma boa ferramenta para estudos envolvendo a DRC e suas complicações cardiovasculares. 
Dado que os efeitos dos inibidores da DPPIV sobre o coração de ratos com DRC não estão bem elucidados, bem como há indícios de uma associação da DPPIV com o SRA, o presente estudo teve como objetivo testar a hipótese de que a inibição da DPPIV atenua o remodelamento e a disfunção cardíaca em ratos nefrectomia 5/6, além disso, investigar se esses efeitos, se presentes se associam a alterações nos componentes do SRA cardíaco. Adicionalmente, investigamos se a inibição da DPPIV é capaz de prevenir o estresse oxidativo cardíaco, a inflamação e a ativação do trocador de $\mathrm{Na}+/ \mathrm{H}+\mathrm{NHE} 1$, processos bem estabelecidos e que estão envolvidos na hipertrofia cardíaca. 
2. Objetivos 


\section{OBJETIVOS}

Investigar se a inibição da DPPIV atenua a disfunção cardíaca em ratos com nefrectomia 5/6, um modelo experimental de DRC não associado à hiperglicemia;

Avaliar se os efeitos cardioprotetores da inibição de DPPIV estão associados a alterações nos componentes do SRA intracardíaco. 
3. Materiais e métodos 


\section{MATERIAIS E MÉTODOS}

\subsection{Modelo experimental}

Todos os procedimentos executados foram submetidos e aprovados pelo Comitê de Ética em Pesquisa e Experimentação Animal da Faculdade de Medicina da USP (Protocolo de Pesquisa N003/16). Foram utilizados 37 ratos Wistar com idade entre 2-3 meses de vida (200-230g), comprados no Biotério Central da Faculdade de Medicina de São Paulo (FMUSP) e mantidos no biotério do Instituto do Coração, Hospital das Clínicas, Faculdade de Medicina da Universidade de São Paulo (HC-FMUSP). Os ratos foram alojados em gaiolas sob condições controladas de umidade $(60 \%)$, temperatura $\left(22^{\circ} \mathrm{C}\right)$ e ciclo claroescuro de 12 horas, com livre acesso à água e ração.

\subsection{Indução da Doença Renal Crônica}

Como o intuito de induzir a doença renal crônica, os ratos foram submetidos à remoção de tecido renal equivalente a 5/6 da massa total (nefrectomia em 5/6), segundo protocolo padronizado por Shimizu e colaboradores (61).

Para tal, os ratos foram anestesiados com ketamina $(50 \mathrm{mg} / \mathrm{Kg})$ e cloridrato de xilazina $(10 \mathrm{mg} / \mathrm{Kg})$, via intraperitoneal. A seguir, foi realizada a laparotomia para que os pedículos renais ficassem expostos, sendo então efetuada a nefrectomia direita, seguida da ligação de duas ramificações da 
artéria renal esquerda, com fio mononylon 6-0. O procedimento encontra-se exemplificado na Figura 3.
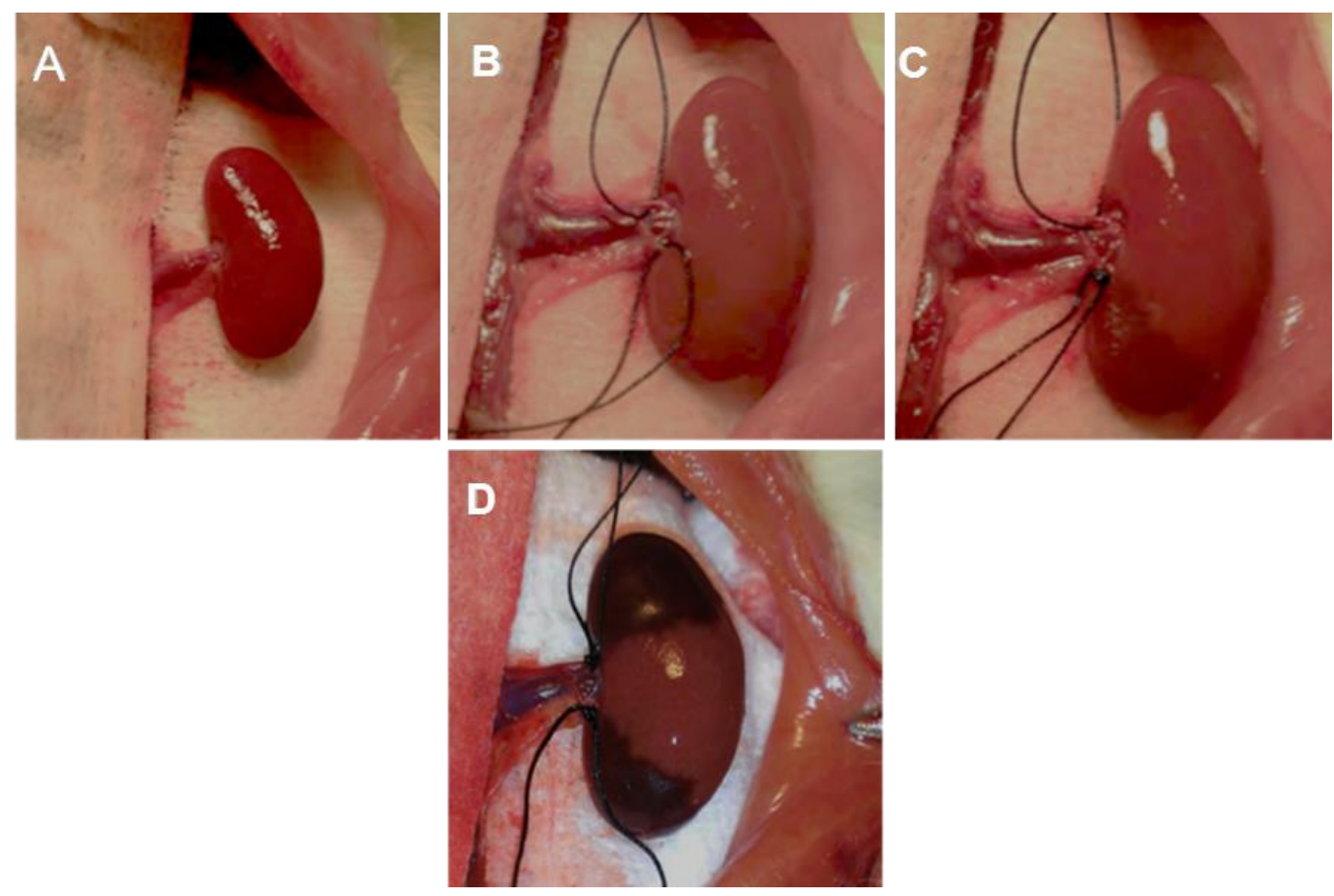

Figura 3. Cirurgia de nefrectomia $5 / 6$ em ratos Wistar para indução da DRC. Após anestesiado, o animal foi fixado na mesa cirúrgica e realizada a incisão abdominal para que os rins ficassem expostos. Após identificado o rim direito, este foi descapsulado e amarrado na base da artéria renal. Com auxílio de uma tesoura foi realizada a ressecção total do rim direito. Posteriormente o rim esquerdo foi isolado para melhor visualização (A) e então duas ramificações da artéria renal esquerda foram amarradas com fio mononylon 6-0 (B e C). Infarto de 2/3 no rim esquerdo após a ligação de duas ramificações da artéria renal (D). Reprodução modificada de lliesco et al (62). 
Após a cirurgia (24 horas), os ratos submetidos à nefrectomia 5/6 foram aleatoriamente divididos em 2 grupos. Foram empregados também ratos submetidos à cirurgia fictícia, como controles. Portanto, o trabalho foi constituído de três grupos experimentais:

1) Sham (N=8): ratos que sofreram os mesmos estresses cirúrgicos dos ratos nefrectomizados, porém, não foram submetidos à nefrectomia 5/6 ou qualquer outra lesão semelhante.

2) $N x(N=16)$ : ratos submetidos à nefrectomia $5 / 6$, tratados com veículo (água) durante 8 semanas.

3) $\mathrm{Nx}+$ IDPPIV $(\mathrm{N}=13)$ : ratos submetidos à nefrectomia $5 / 6$, tratados com 0 inibidor da DPPIV sitagliptina, via oral, durante 8 semanas (200mg/Kg/dia).

\subsection{Preparo da sitagliptina}

Para o preparo da solução contendo o inibidor da DPPIV, 6 comprimidos contendo $100 \mathrm{mg}$ de monofosfato de sitagliptina foram adicionados em $15 \mathrm{ml}$ de água. $\mathrm{O}$ falcon foi colocado em repouso sob refrigeração por 1 hora, para completa dissolução. Posteriormente, o frasco foi homogeneizado em vórtex e centrifugado a $6.000 \mathrm{rpm}$ por 10 minutos. O sobrenadante foi coletado e utilizado para o tratamento dos ratos. 


\subsection{Desenho experimental}

Primeiramente foram realizadas as cirurgias, e após 24 horas foi iniciado o tratamento com o inibidor da DPPIV no grupo Nx+IDPPIV, ou veículo no grupo $\mathrm{Nx}$ (semana zero). O tratamento com sitagliptina foi realizado duas vezes ao dia (12/12h), na dose de $200 \mathrm{mg} / \mathrm{Kg} / \mathrm{dia}$. No final do tratamento, semana oito, os ratos foram alojados em gaiolas metabólicas para análise da função renal. Também foi feita a coleta de sangue para análise de diversos parâmetros fisiológicos (glicose, creatinina, ureia, sódio, potássio, cálcio, hemoglobina, atividade da DPPIV e BNP), medidas dos níveis pressóricos e ecocardiografia para avaliação da função cardíaca. Posteriormente os ratos foram eutanasiados, e então realizada a coleta de sangue arterial e tecidos para futuras análises biométricas, histológicas e moleculares. Antes do sacrifício (2h), os ratos Nx+IDPPIV receberam o inibidor da DPPIV. O desenho experimental do trabalho encontrase ilustrado na Figura 4. 


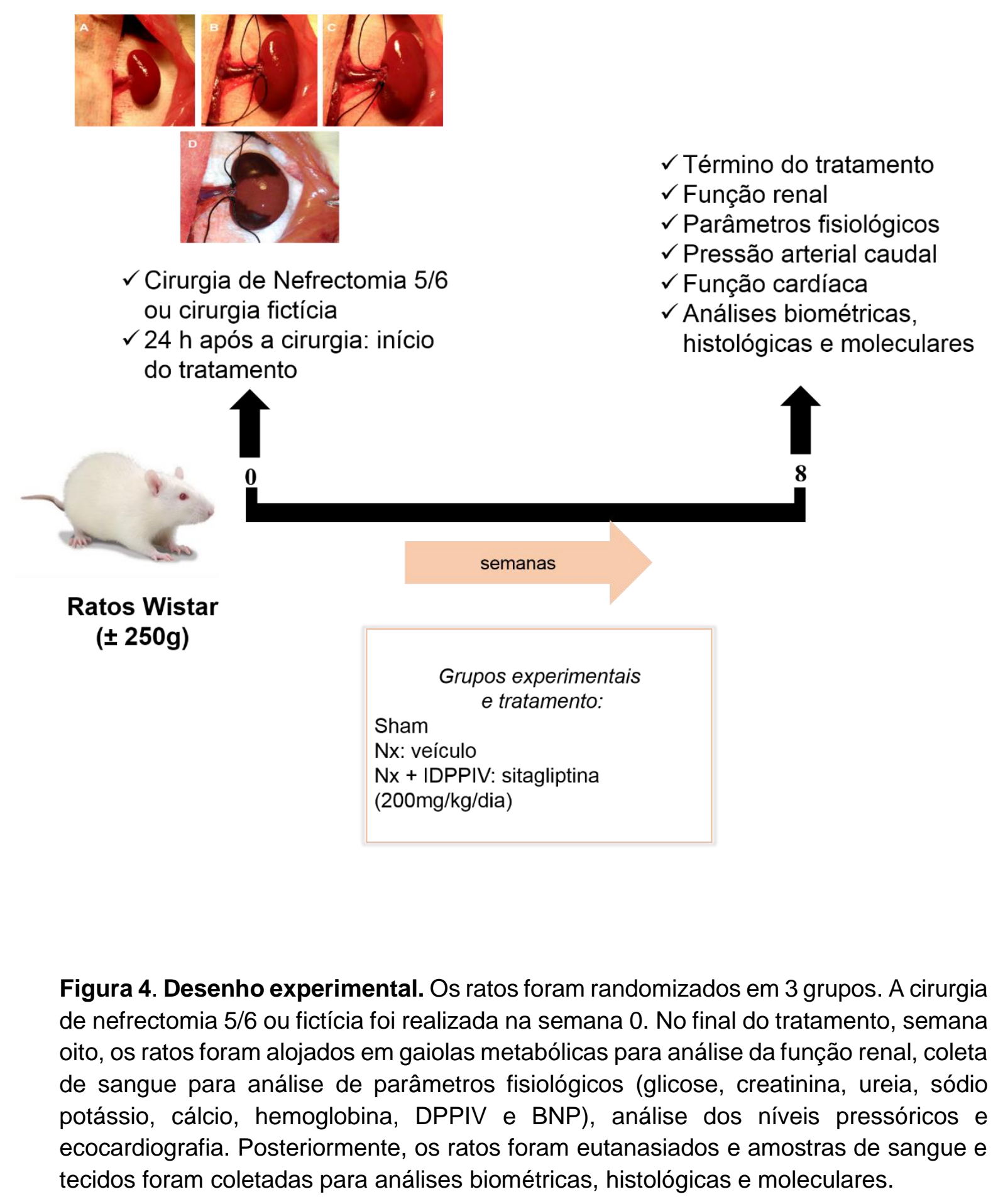

\subsection{Análise da sobrevida}

Para o cálculo da sobrevida, considerou-se como tempo zero, 72 horas após a cirurgia de nefrectomia 5/6 ou cirurgia fictícia (animais nefrectomizados e 
animais controles). Foram excluídos do cálculo os animais que morreram em até 72 horas após o procedimento cirúrgico, bem como os animais que morreram por erro em técnicas ao longo do estudo (8 semanas). A análise de sobrevida foi feita pela curva de Kaplan-Meier.

\subsection{Determinação das concentrações plasmáticas de creatinina, ureia, glicose, sódio, potássio, cálcio e hemoglobina}

Após oito semanas de tratamento com sitagliptina na dose de $200 \mathrm{mg} / \mathrm{kg} / \mathrm{dia}$ ou veículo, foram realizadas análises séricas envolvendo creatinina, ureia, sódio, potássio, cálcio, hemoglobina e glicose. A creatinina no soro foi dosada através do aparelho BeckmanCoulterSynchron CX7 Analyzer (BeckmanCoulter, Fullerton, CA). A ureia foi medida por meio do kit da LabTest Diagnóstica (Lagoa Santa, MG), segundo as instruções do fabricante. As concentrações plasmáticas de $\mathrm{Na}^{+} \mathrm{K}^{+}, \mathrm{Ca}^{+}$e hemoglobina foram mensuradas através do analisador de gases sanguíneos e eletrólitos ABL800 FLEX (Radiometer). Por fim, para medir a concentração de glicose, foi utilizado o glicosímetroAccu-chek (Roche diagnostiGmbH, Mannheim, Alemanha). Antes de iniciar a coleta para a dosagem de glicose os ratos permaneceram em jejum por um período de oito horas. 


\subsection{Avaliação da Função Renal}

A função renal dos três grupos experimentais foi analisada oito semanas após realização da cirurgia para indução de insuficiência renal $(\mathrm{Nx})$ ou apenas laparotomia (Sham). Para tal, os ratos foram alojados em gaiolas metabólicas individuais para coleta de urina de 24 horas. Durante este período, o consumo de água e ração dos ratos foi monitorado diariamente. $\mathrm{O}$ procedimento foi realizado em duplicata. O primeiro dia para adaptação dos ratos às gaiolas e os dois dias seguintes para coleta de urina de 24 horas. As seguintes variáveis foram examinadas:

- Consumo de sódio: Foi obtido multiplicando o consumo de ração pela concentração de sódio na mesma.

- Carga excretada de sódio: Foi calculada com base na fórmula: $U_{\mathrm{Na}+} \mathrm{X}$ $\bigcup_{\mathrm{F} /} / 1000$, onde $\bigcup_{\mathrm{Na}+}$ corresponde ao sódio urinário e $\bigcup_{\mathrm{Fl}}$, ao fluxo urinário.

- Balanço de sódio: Foi obtido, subtraindo a carga excretada de sódio do consumo de sódio.

- Balanço de água: Foi estimado subtraindo o fluxo urinário do consumo de água.

- Fluxo urinário: obtido dividindo-se o volume urinário pelo tempo de coleta. O valor foi corrigido pelo peso do rato, sendo assim, expresso em $\mathrm{ml} / \mathrm{kg} / \mathrm{dia}$.

- Ritmo de Filtração Glomerular (RFG): O ritmo de filtração glomerular foi estimado através da depuração endógena de creatinina, calculado pela fórmula ( $\mathrm{UCrX} \mathrm{V} / \mathrm{PCr}$ ), sendo $\mathrm{UCr}$ a concentração de creatinina na urina, V o fluxo urinário e PCra concentração plasmática de creatinina. A 
creatinina urinária foi determinada por meio do kit comercial Labtest (Lagoa Santa, MG, Brasil). As análises foram feitas em duplicata, seguindo as instruções do fabricante.

- Excreção urinária de proteínas totais: Foi analisada através do Kit Sensiprot. O princípio do ensaio é baseado na reação do vermelho pirogalol com o molibdato de sódio, formando um complexo, que na presença de proteína há o aparecimento de cor azul. O ensaio foi feito em duplicata e de acordo com as instruções do fornecedor. Os resultados foram padronizados pelo fluxo urinário e pelo peso corporal dos ratos, expressos em mg/kg/24h.

- Razão proteínas totais/creatinina: Os valores de proteínas totais foram normalizados pela creatinina urinária para minimizar diferenças no RFG e perdas urinárias.

\subsection{Aferição da pressão arterial caudal}

A pressão arterial caudal dos ratos foi medida oito semanas após o tratamento com sitagliptina ou veículo. A análise seguiu as seguintes etapas: Inicialmente foi realizada a calibração do aparelho (BP-2000 BloodPressureAnalysis System; Visitech Systems, Inc.) e então, os ratos foram colocados em um meio de contensão e inseridos numa plataforma aquecida. A região proximal da cauda ficou encaixada em um manguito de borracha acoplado a um transdutor de pulso (sensor) que capta os sinais a serem enviados e registrados em computador para a realização das medidas de pressão arterial 
sistólica. Antes das análises, os animais passaram por um processo de adaptação ao aparelho e ambiente por três dias consecutivos. O experimento iniciou-se apenas após os sinais de pulso e frequência cardíaca estarem estabilizados. Para determinação dos níveis pressóricos foi considerada no mínimo a média de dez medidas.

\subsection{Determinação da atividade da DPPIV circulante e cardíaca}

A atividade da DPPIV no soro e tecido cardíaco foi medida por colorimetria, resultante da hidrólise do composto tosilato de glicil-prolil-pnitroanilida. O método consiste na adição de $15 \mu \mathrm{L}$ de soro ou tecido homogeneizado em $185 \mu \mathrm{L}$ de tampão Tris HCL (10 mM pH 7.6) contendo 4 mM do substrato da DPPIV glicil-prolil-p-nitroanilida (Bachem). Leva-se ao banho maria $37^{\circ} \mathrm{C}$ por 1 hora e, $\mathrm{m}$ seguida, adiciona-se $500 \mu \mathrm{L}$ de tampão acetato (1 $\mathrm{mmol} / \mathrm{L}$ pH 4.2) para parar a reação. A liberação enzimática da p-nitroanilina foi determinada em espectrofotômetro com absorbância em 405 nm.

\subsection{Determinação da concentração plasmática de BNP}

Primeiramente, as amostras de soro foram aliquotadas em tubos de microcentrífuga e armazenadas a $-80^{\circ} \mathrm{C}$. $\mathrm{O}$ método utilizado para determinar as concentrações circulantes de BNP total foi o ensaio imunoenzimático ELISA, 
utilizando para essa finalidade o kit da Abcam (Massachusetts, US). Todos os procedimentos foram realizados seguindo as instruções do fabricante.

\subsection{Avaliação da função cardíaca por ecodopplercardiograma}

As análises ecocardiográficas foram realizadas para avaliar a função cardíaca dos ratos submetidos à nefrectomia $5 / 6$, bem como dos ratos controles.

As medidas ecocardiográficas seguiram as recomendações do Comitê de Padronização da Sociedade Americana de Ecocardiografia, com adaptação para o modelo de roedor e foram analisadas por duplo observador cego para a condição ou grupo ao qual pertence 0 animal examinado. $O$ exame ecocardiográfico foi realizado com os ratos anestesiados com Ketamina $(60 \mathrm{mg} / \mathrm{kg})$ e xilazina $(10 \mathrm{mg} / \mathrm{kg})$ via intraperitoneal, utilizando o sistema de ultrassom SONOS 5500 (Philips Medical Systems, EUA) que permite a obtenção de imagens cardíacas em tempo real nos modos mono e bidimensional, além da velocidade de fluxo por efeito Doppler espectral com transdutor de $14 \mathrm{MHz}$. A partir da visualização do ventrículo esquerdo (corte transversal) ao nível dos músculos papilares, foi realizado o modo $\mathrm{M}$.

\subsection{Eutanásia}

Após o término dos estudos cardíacos, ou seja, depois de oito semanas, os ratos foram anestesiados com Ketamina e Xilazina $(50 \mathrm{mg} / \mathrm{Kg})$ e o sangue 
arterial foi retirado por punção na aorta abdominal. Após esse procedimento os ratos foram mortos por decaptação e os rins e o coração foram removidos para posteriores análises.

\subsection{Análise Biométrica e morfométrica}

Após a remoção do coração, descartou-se os átrios e os vasos da base do órgão e os ventrículos direito e esquerdo foram separados e pesados em balança analítica. O septo interventricular foi considerado como parte do ventrículo esquerdo. Para estimar a hipertrofia cardíaca, foi calculada a razão ventrículo esquerdo/peso corpóreo, ventrículo direito/peso corpóreo e coração total/peso corpóreo. Posteriormente o ventrículo direito foi descartado.

Depois de realizada a pesagem do ventrículo esquerdo, este foi seccionado transversalmente em 2 partes. A porção superior foi armazenada a 80 para análises moleculares e a porção inferior, correspondente ao ápice foi fixada em formalina tamponada (10\%) por $24 \mathrm{~h}$ para análises histológicas. $\mathrm{Na}$ análise histológica o tecido cardíaco foi processado por técnicas histológicas habituais, embebido em parafina e seccionados em cortes com cinco micrômetros de espessura. As lâminas foram coradas com hematoxilina-eosina (para determinar o volume nuclear da célula) e picrosírius red (para determinar

o colágeno intersticial). Para aquisição das imagens utilizou-se o sistema computadorizado Leica Imaging Systems, Bannockburn, IL, EUA.

Como uma estimativa de hipertrofia dos miócitos, o volume nuclear médio foi determinado em 50-70 cardiomiócitos cortados longitudinalmente. As 
imagens foram adquiridas em 5 campos randomizados com ampliação de 400x por animal. O volume nuclear foi estimado medindo o diâmetro nuclear mais curto (d) e o diâmetro nuclear mais longo (D) de acordo com a seguinte equação:

$$
\text { Volume Nuclear }=\pi \times \mathrm{D} \times \mathrm{d} 2 / 6
$$

A fibrose intersticial no miocárdio foi avaliada como a área ocupada por fibras de colágeno. As áreas coradas de vermelho foram quantificadas como a percentagem média da área total de cada um dos cinco campos aleatórios com ampliação de $200 \times$ por animal.

\subsection{Preparação do homogenato de tecido cardíaco}

O ventrículo esquerdo e septo foram homogeneizados através do homogeneizador Polymix PX-SR 50E (Kinematica, AG, Suiça) em um tampão PBS gelado (140 mM de cloreto de sódio; 2,8 mM de fosfato de sódio monobásico 7,2 mM de fosfato de sódio dibásico, $\mathrm{pH} 7,4$ ), inibidores de protease (1 mM de leupeptina e $230 \mathrm{mM}$ de pirofosfato de sódio), com adição do inibidor de fosfatase "Cocktail 2" (diluição 1:300). Posteriormente, foram feitas alíquotas do homogenato e este foi acondicionado em $-80^{\circ} \mathrm{C}$. 


\subsection{Determinação da concentração de proteínas}

A determinação da concentração de proteínas em tecido cardíaco e renal foi determinada pelo método de Lowry. O método consiste na adição de hidróxido de sódio, de carbonato de cálcio, de sulfato de cobre e de tartarato de sódio a uma mistura contendo proteínas. Adiciona-se ainda Folin-fenol Ciocalteau no qual há um constituinte ativo que sofre redução quando reage com proteínas na presença do cobre em solução alcalina produzindo um complexo de coloração azul com absorbância máxima em 750 nm.

\subsection{Análise da atividade da enzima conversora de angiotensina (ECA)}

A análise da atividade da ECA foi feita través de um ensaio fluorimétrico. O homogenato de coração foi centrifugado (3000 rpm, 5 minutos a $\left.4{ }^{\circ} \mathrm{C}\right)$ e o sobrenadante foi utilizado para a análise. Primeiramente, $10 \mu \mathrm{L}$ do sobrenadante foi adicionado a $490 \mu \mathrm{L}$ de tampão de ensaio borato contendo $5 \mathrm{mM}$ de Hip-His-Leu e incubados durante 30 minutos a $37^{\circ} \mathrm{C}$. Esta reação foi interrompida com a adição de $1200 \mu \mathrm{L} \mathrm{NaOH}$ a 0,34 N, em seguida, $100 \mu \mathrm{L}$ oftaldialdeído (20 mg / ml em metanol) foi adicionado,se ligando ao produto da reação de His-Leu, e permitindoaleitura fluorimetrica. Após 10 minutos, $200 \mu \mathrm{L} 3$ $\mathrm{N}$ de $\mathrm{HCl}$ foi adicionado para acidificar a solução e, em seguida, realizou-se a centrifugação a 3000 rpm durante 10 minutos. Os sobrenadantes foram lidos em ELISA Reader (BioTekSynergy TM 2; Biotek, VT, EUA), utilizando comprimentos 
de onda de $365 \mathrm{~nm}$ de excitação e $495 \mathrm{~nm}$ de emissão. A atividade da ECA foi expressa em nmol His-Leu/min/ug de proteína.

\subsection{Análise da atividade da enzima conversora de angiotensina 2 (ECA2)}

A atividade enzimática da ECA2 renal foi determinada utilizando-se substrato fluorescente sintético (FPS VI), Mca-YVADAPK (Dnp) OH (catálogo n - ES007; R \& D Systems, Minneapolis, MN, EUA). Os homogenato de coração foi centrifugado a $20.000 \mathrm{~g}$ por 40 minutos. $\mathrm{O}$ sobrenadante foi utilizado para 0 ensaio enzimático. Para isso, utilizou-se uma solução de captopril (10 $\mu \mathrm{M}$ de captopril em tampão de ensaio) para inibição da ECA. Inicialmente, foram adicionados $1 \mu \mathrm{l}$ de solução de captopril e $2 \mu \mathrm{l}$ de $\mathrm{NaCl} 5 \mathrm{M}$. Em seguida, foi adicionado $70 \mu \mathrm{g}$ de proteínas do tecido renal e um volume de tampão de ensaio suficiente para completar $90 \mu \mathrm{l}$ em cada poço, e por fim, incubação por 10 minutos. O substrato fluorogênico $(10 \mu \mathrm{l}$ do substrato $50 \mu \mathrm{M})$ foi adicionado imediatamente antes da leitura da placa simultaneamente nos poços com auxílio de pipeta multicanal. A fluorescência foi emitida por clivagem do peptídeo FPS VI mensurada utilizando um leitor de microplacas (BioTekSynergy тм 2; BioTek, Winooski, VT, EUA) a cada minuto durante 60 min imediatamente após a adição de substrato peptídico fluorogênico a $37^{\circ} \mathrm{C}$ em $320 \mathrm{~nm}$ de excitação e $405 \mathrm{~nm}$ de emissão. A fluorescência total foi corrigida pela a quantidade de proteínas totais. Os dados foram apresentados em unidades de fluorescência por minuto normalizado pela proteína total. 


\subsection{Eletroforese em gel de poliacrilamida (SDS - PAGE)}

As proteínas foram solubilizadas em 50 L de tampão de amostra SDS (SDS a 2\%, 10\% de glicerol, 0,1\% de azul de bromofenol, $50 \mathrm{mM}$ de TrisHCL, pH 6,8), em seguida as amostras foram aplicadas no gel imerso em tampão de eletroforese (Tris-base $25 \mathrm{mM} \mathrm{Ph} \quad 7,4$; glicina $192 \mathrm{mM}$ ) e submetidas a SDS - PAGE utilizando 7,5 ou $10 \%$ de gel de poliacrilamida. Um padrão de massa molecular (Precision Plus Protein ${ }^{\mathrm{TM}}$ Kaleidoscope, Bio-Rad) foi adicionado ao gel para estimar a massa das proteínas. A corrida foi interrompida

de acordo com o tamanho das proteínas de interesse, tomando como base o padrão de massa molecular.

\subsection{9 "immunoblotting"}

As proteínas contidas no gel foram transferidas para membranas de difluoreto de polivinilideno (PVDF Immobilon-P; Millipore, Bedford, MA). Antes disso as membranas foram tratadas com metanol $100 \%$ por 2 minutos e equilibrada em tampão de transferência (25 mM Tris-base, 192 mM glicina, metanol 20\%) por pelo menos 5 minutos. Utilizamos um sistema tipo sanduíche (GE Heathcare, TE62 - Piscataway, NJ) submerso em tampão de transferência, onde aplicamos uma voltagem de $350 \mathrm{~mA}$ overnight a $4^{\circ} \mathrm{C}$. Após a transferência, as membranas foram coradas com Ponceau (Ponceau S - Sigma - 0,1\%; ácido acético 10\%). Em seguida, as membranas de PVDF contendo as proteínas transferidas são incubadas em primeiro lugar em solução de bloqueio (150 
mMNaCl; 2,8 mM fosfato de sódio monobásico; 7,2 mM fosfato de sódio dibásico; leite em pó desnatado $5 \%$, Tween20 $0,1 \%$ ou albumina de soro bovino (BSA) $150 \mathrm{mMNaCl}$; $50 \mathrm{mM}$ Tris-base; BSA 5\%, Tween20 0,1\%) durante 1 hora para bloquear ligações inespecíficas de anticorpos, seguido de incubação overnight a $4^{\circ} \mathrm{C}$ com anticorpo primário conforme Tabela 2. As membranas de PVDF foram, em seguida, lavadas durante 10 minutos cinco vezes em solução de bloqueio e incubadas durante 1 hora com um anticorpo secundário conjugado com HRP apropriado [goatanti-mouse ou goatanti-rabbit da Life Technologies Corporation (Carlsbad, CA)] diluído 1:2000 em solução de bloqueio. Após lavagem (5X) em solução de bloqueio e (2X) em PBS ou TBS um reagente para detecção de quimioluminescência aumentada $(E C L)$ foi usado para visualização de anticorpos ligados. As bandas foram visualizadas por meio de um fotodocumentador (GE Healthcare) e as imagens digitalizadas pelo software ImageQuant LAS 4000 (GE Healthcare). Para quantificação das bandas por densitometria utilizamos o software Image $\mathrm{J}$ (Scion). A lista de anticorpos primários e secundários utilizados no estudo está ilustrada na Tabela 2. 
Tabela 2. Lista de anticorpos primários e secundários utilizados nos experimentos de "immunoblotting".

\begin{tabular}{|c|c|c|c|}
\hline Anticorpo & Empresa & Diluição & $\begin{array}{c}\text { Solução de } \\
\text { bloqueio }\end{array}$ \\
\hline $\begin{array}{c}\text { DPPIV } \\
\text { (Clone 5H8) }\end{array}$ & Santa Cruz & $1: 1000$ & Leite \\
\hline AGT & Santa Cruz & $1: 1000$ & Leite \\
\hline ECA & Santa Cruz & $1: 1000$ & Leite \\
\hline ECA2 & Abcam & $1: 1000$ & Leite \\
\hline AT1 & Santa Cruz & $1: 1000$ & Leite \\
\hline AT2 & Santa Cruz & $1: 1000$ & Leite \\
\hline $\begin{array}{c}\text { NHE1 } \\
\text { (Clone 4F9) }\end{array}$ & Santa Cruz & 1:1000 & Leite \\
\hline GAPDH & Abcam & $1: 5000$ & Leite \\
\hline $\begin{array}{l}\text { HRP - Cabra anti- } \\
\text { camundongo igM }\end{array}$ & $\begin{array}{l}\text { Jackson Immuno } \\
\text { Research }\end{array}$ & $1: 2000$ & Leite \\
\hline HRP - Cabra anti-coelho igG & $\begin{array}{l}\text { Jackson Immuno } \\
\text { Research }\end{array}$ & $1: 2000$ & Leite \\
\hline HRP - Coelho anti-cabra igG & $\begin{array}{c}\text { Jackson Immuno } \\
\text { Research }\end{array}$ & $1: 2000$ & Leite \\
\hline
\end{tabular}




\subsection{Reação em cadeia de polimerase em tempo real}

\subsubsection{Extração de RNA total}

Para extrair e preparar o RNA total de amostras do coração dos ratos estudados, as seguintes etapas foram realizadas:

- O tecido cardíaco armazenado em freezers $-80^{\circ} \mathrm{C}$, foi transferido para um falcon de $50 \mathrm{ml}$ e homogeneizados com $1 \mathrm{ml}$ de TRIzol (Gibco/BRL, Invitrogen, Carlsbad, CA), no gelo por 30 segundos.

- Posteriormente, as amostras foram colocadas em tubos de 1,5 ml (Eppendorf) e $200 \mathrm{ml}$ de clorofórmio foi adicionado. Depois de homogeneizado, estes tubos foram centrifugados a 10.000 rpm por 15 minutos a $4^{\circ} \mathrm{C}$ para que o RNA total fosse separado do DNA e proteínas. A fase aquosa superior que continha o RNA total foi retirada e transferida para um outro tubo de $1,5 \mathrm{ml}$.

- Na precipitação do RNA foi colocado a cada tubo $500 \mathrm{ml}$ de isopropanol que, depois, foram invertidos suavemente, para serem centrifugados a $10.000 \mathrm{rpm}$ por 45 minutos a $4^{\circ} \mathrm{C}$. Depois de centrifugado, o sobrenadante foi desprezado e as amostras lavadas com $1 \mathrm{ml}$ de etanol $75 \%$ gelado diluído em água isenta de RNAse, sendo novamente centrifugadas a 10.000 rpm por 10 minutos a $4^{\circ} \mathrm{C}$. O sobrenadante foi novamente desprezado e os tubos invertidos e colocados para secar a $4^{\circ} \mathrm{C}$.

- Posteriormente, o RNA precipitado foi lavado com etanol 70\% para eliminar resíduos de fenol e sal, e solubilizado em 150 I de água tratada com DEPC, sua concentração foi determinada a partir da medida de 
absorbância a 260 nm em espectrofotômetro (ND-1000 spestrophotometer - NanoDrop Technologies, Inc.). As soluções de RNA foram aliquotadas e armazenadas a $-80^{\circ} \mathrm{C}$ até o uso.

A integridade das amostras de RNA foi verificada através da eletroforese em gel de agarose a 0,8\%. Apenas as preparações íntegras e sem indício de degradação, como falta de integridade das bandas 28S RNAr e diminuição da razão de fluorescência das bandas ribossomais 28S RNAr/18S RNAr (razão para o RNA intacto igual aproximadamente a 2), foram utilizadas na etapa subsequente.

\subsubsection{Transcrição do DNA complementar}

Para a síntese do DNA complementar (Cdna) foram utilizados5 $\mu \mathrm{g}$ de RNA total. Amostras de RNA foram incubadas com 1,5 $\mu$ de água isenta de RNAses; 4,0 $\mu \mathrm{l}$ 5X FirstStrand Buffer (concentração final de 1X); 1,0 $\mu$ l de OligodT (concentração final de 0,025 nM); 0,5 $\mu \mathrm{l}$ de RNAsin (concentração final de $10 \mathrm{U} / \mu \mathrm{L})$ para cada amostra. Incubou-se estas amostras a $50^{\circ} \mathrm{C}$ por 2 horas e, em seguida, as mesmas foram aquecidas a $95^{\circ} \mathrm{C}$ por 5 minutos. Ao final da reação obteve-se um estoque de Cdna na concentração de $250 \mathrm{ng} / \mu \mathrm{L}$. As amostras foram armazenadas $\mathrm{a}-20^{\circ} \mathrm{C}$ até o uso. 


\subsubsection{Reação em cadeia de polimerase em tempo real (Qrt-PCR)}

A reação de Qrt-pcr foi realizada com auxílio do aparelho ABI Prism 7500 FastSequenceDetection System (AppliedBiosystem, Foster City, CA). A amplificação consistiu em: $95^{\circ} \mathrm{C}$ por 10 minutos para a ativação da AmpliTaq DNA Polymerase, seguido por 40 ciclos de $95^{\circ} \mathrm{C}$ por 15 minutos (desnaturação) e $60^{\circ} \mathrm{C}$ por 60 segundos (associação do primer e extensão). A coleta do sinal fluorescente foi realizada ao final de cada ciclo. Para excluir a possibilidade de contaminação, foi realizado um controle negativo para cada gene que consistiu em uma reação com ausência de Cdna.

Os primers oligonucleotídeos utilizados para detectar DPPIV, BNP, TGF-beta e os controles internos GAPDH, beta actina, ciclofilina e $28 \mathrm{~S}$ estão mostrados na Tabela 2. A ciclofilina foi utilizada como melhor normalizador. O método comparativo "cyclethreshold" (CT) foi utilizada para as análises de dados. Todas as reações foram processadas em triplicata. 
Tabela 3. Oligonucleotídeos utilizados para PCR em tempo real.

\begin{tabular}{|c|c|}
\hline Gene & Sequência \\
\hline \multirow[t]{2}{*}{ DPPIV } & $S-A T G G T G A A G G T C G G T G T G$ \\
\hline & A S - G A A C T T G C C G T G GG T A G A G \\
\hline \multirow{2}{*}{$\mathrm{ACTb}$} & S - C T G T G A C A T C C G T A A G A C C \\
\hline & A S - GCCACCAATCCACACA GA \\
\hline \multirow{2}{*}{ Cyclo } & $S-A A T G C T G G A C C A A A C A C A A A$ \\
\hline & A S - C C T T C T TT C A C C T T C CC A AA \\
\hline \multirow{2}{*}{ DPPIV } & $S-C C A A C T C C A G A G G A C A A C C T$ \\
\hline & A S - TCT TCGTCCGTGTACCACAT \\
\hline \multirow{2}{*}{ BNP } & S - G A T T C T G C T C C T G C T TTT C C \\
\hline & A S - T C T TTT G T A G GG C C T T G G T C \\
\hline \multirow{2}{*}{ MCP-1 } & S - T G C C C A C T C A C C T GCTGCT \\
\hline & A S - T G G G G T C A G C A C A G A T C T C T C T C T \\
\hline \multirow{2}{*}{ TNF- $\alpha$} & S- A T C G G T C C C A A C A A G G A G G \\
\hline & A S - GATAAGGTACA GC C C A T C T G C \\
\hline \multirow{2}{*}{ IL-6 } & S - C T G G T C T T C T G G A G T T C C G T \\
\hline & A S - G C C A C T C C T T C T G T G A C T C T \\
\hline \multirow{2}{*}{$\mathrm{IL}-1 \beta$} & $S-C C T G T G T G A T G A A A G A C G G C$ \\
\hline & A S - TATGTCCCGACCATTGCTGT \\
\hline \multirow{2}{*}{ IL-10 } & S - T G G G A G A G A A G C T G A A G A C C \\
\hline & A S - A G A T G C C G G G T G G T T C A A T \\
\hline \multirow{2}{*}{ AGT } & S - T G G ATAAAGAAC C C G C C T C \\
\hline & A S - T G G A T A A A G A A C C C G C C T C \\
\hline \multirow{2}{*}{ ACE } & $S-G A C C A A A A G C T G C G A A G G A T$ \\
\hline & A S - T T G T T G G G G A A G C A G A C C T T \\
\hline \multirow{2}{*}{ ACE2 } & S - T G T G G G G TA G G T T T T G G A C A \\
\hline & A S - G G A A G GC CA A C A G A A A C G A A \\
\hline \multirow{2}{*}{ AT1 } & S-TCTGCCACATTCCCTGAGTTA \\
\hline & A S - C T T G G G G C A G T C A T C T T G G A \\
\hline \multirow{2}{*}{ AT2 } & S - T T T G C C A T C C T C C T G G G A T T \\
\hline & A S - GC C T T G G A G C C A A G T A A T G G \\
\hline
\end{tabular}

GAPDH, gliceraldeído-3-fofato desidrogenase; ACTb, beta actina; Cyclo, Ciclofilina; 28S; DPPIV, Dipeptidil peptidase IV, BNP, Peptídeo natriurético cerebral; MCP-1, Monocytechemoattractant protein-1; TNF- $\alpha$ Tumournecrosisfactor alpha; IL-6, Interleucina 6; IL-1 3 , Interleucina-1 $\beta$; IL-10, Interleucina 10; AGT, Angiotensinogênio; ECA, enzima conversora de angiotensina; Isoforma 2 da enzima conversora de angiotensina; AT1, Receptor tipo 1 da angiotensina II; AT2, receptor tipo 2 da angiotensina II; S, Sense; AS,Antisense. 


\subsection{Determinação dos níveis de nitrotirosina}

Os níveis de nitrotirosina (3-nitrotirosina), foram medidos no homogenato de coração, utilizando a técnica de ELISA. Os procedimentos realizados foram embasados em instruções do fabricante (Hycult, Biotech, Plymouth Meeting, PA).

\subsection{Análises Estatísticas}

Os resultados foram expressos em média \pm erro padrão da média, sendo n o número da amostra. A comparação entre os grupos experimentais foi realizada através da análise de variância ANOVA uma via, seguido pelo teste de Newman-Keuls. O nível de significância foi estabelecido para valores de $p<0,05$

e todas as análises estatísticas foram feitas utilizando-se do Graphy Prism 5.0 (GraphyPad Softwares Inc.). 
4. Resultados 


\section{RESULTADOS}

Como pode ser observado na Figura 5, a sobrevida nos ratos nefrectomizados tratados com o inibidor da DPPIV foi maior em relação aos ratos não tratados. No geral, a taxa de sobrevida foi de aproximadamente $56 \%$ no grupo de ratos nefrectomizados que receberam veículo e $85 \%$ no grupo que recebeu sitagliptina, sendo que a maioria das mortes ocorreu 30 dias após o procedimento cirúrgico.

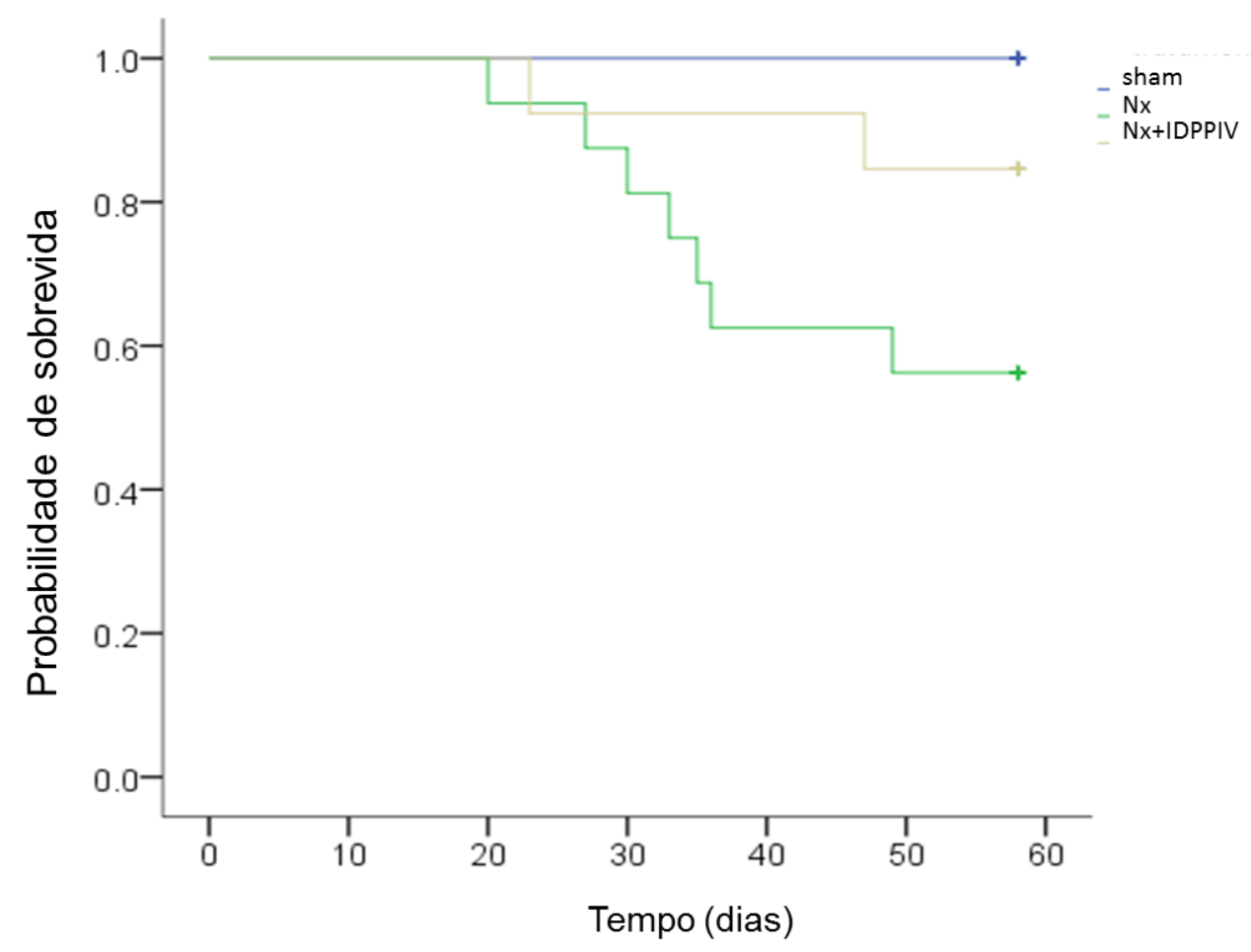

Figura 5. Curva da sobrevida global dos animais sham, Nx e Nx+IDPPIV. 


\subsection{Parâmetros biométricos, metabólicos e atividade da DPPIV plasmática em ratos sham, $\mathrm{Nx}$ e $\mathrm{Nx}+$ IDPPIV}

Nota-se na Tabela 4, que as análises envolvendo níveis plasmáticos de sódio, potássio e cálcio não mostraram diferenças significativas entre os grupos, bem como a concentração de hemoglobina. Esses resultados demonstram que o modelo não apresentou anemia e desequilíbrios eletrolíticos durante o período estudado. Os dados biométricos também não revelaram diferenças significativas nos pesos corpóreos ao final do tratamento, tampouco no ganho de peso ao longo do estudo.

Com relação à glicemia, não foi observada distinção entre os diferentes grupos experimentais, sugerindo que mesmo administrando um antidiabético (inibidor da DPPIV) em modelo de DRC não associada a hiperglicemia, não ocorre hipoglicemia.

Para avaliar se o tratamento com sitagliptina estava de fato inibindo a enzima DPPIV no modelo experimental, bem como avaliar se ratos $\mathrm{Nx}$ apresentavam diferenças na atividade sérica da enzima em relação aos ratos controles, analisamos a atividade da DPPIV no soro. Como ilustrado na Tabela 4, os ratos Nx não apresentaram diferença significativa na atividade da DPPIV sérica, em comparação aos ratos sham. Por sua vez, a administração de sitagliptina diminuiu significativamente a atividade da DPPIV em comparação com os grupos Nx e sham, demonstrando inibição satisfatória da DPPIV no plasma dos ratos tratados. 
Tabela 4. Biometria, atividade da DPPIV no plasma e parâmetros metabólicos em ratos sham, $\mathrm{Nx}$ e $\mathrm{Nx}+$ IDPPIV

\begin{tabular}{cccc}
\hline Descrição & sham & $\mathrm{Nx}$ & $\mathrm{Nx}+$ IDPPIV \\
\hline Biometria & & & \\
Peso corporal inicial (g) & $203 \pm 9$ & $217 \pm 2$ & $229 \pm 9$ \\
Peso corporal final (g) & $334 \pm 0$ & $304 \pm 9$ & $334 \pm 9$ \\
Ganho de peso (\%) & $65 \pm 3$ & $43 \pm 8$ & $47 \pm 8$ \\
Glicemia & & & \\
(mg/dL) & $77 \pm 1$ & $72 \pm 3$ & $79 \pm 3$ \\
Eletrólitos $_{\text {Na }}$ (mmol/L) & $141 \pm 1$ & $138 \pm 2$ & $138 \pm 3$ \\
$\mathrm{~K}^{+}$(mmol/L) & $4,0 \pm 0,4$ & $4,0 \pm 0,4$ & $3,6 \pm 0,2$ \\
$\mathrm{Ca}^{+}$(mmol/L) & $1,31 \pm 0,10$ & $1,30 \pm 0,03$ & $1,30 \pm 0,02$ \\
Hemoglobina $_{\text {(g/dL) }}$ & $17 \pm 1$ & $15 \pm 0$ & $16 \pm 0$ \\
Atividade da DPPIV plasmática & & & $0,199 \pm 0,01^{* * \# \#}$ \\
\hline (D.O) & $0,413 \pm 0,03$ & $0,418 \pm 0,045$ & \\
\hline
\end{tabular}

Os valores estão expressos como média \pm EPM. Os eletrólitos, glicose e hemoglobina foram analisados no plasma. O Ritmo de filtração glomerular (RFG) foi calculado por meio do clearence de creatinina. A atividade da DPPIV no plasma foi mensurada por colorimetria. D.O (Densidade óptica). ${ }^{* *} \mathrm{P}<0,01$ vs. sham. ${ }^{* *} \mathrm{P}<0,001$ vs. sham. ${ }^{\# \# P}$ $<0,01$, " $P<0,05$ vs. Nx.

\subsection{Efeitos da sitagliptina sobre a função renal e níveis pressóricos em ratos com DRC}

Após oito semanas de tratamento com sitagliptina ou veículo, análises de função renal envolvendo creatinina e ureia plasmáticas, RFG, fluxo urinário, excreção urinária de proteínas dentre outras, foram executadas para validar o modelo de DRC (Nx), bem como para analisar os efeitos da inibição da DPPIV sobre esses parâmetros. 
Como esperando, os ratos $\mathrm{Nx}$ apresentam aumento nos níveis séricos de creatinina e ureia, acentuada queda no RFG, e proteinúria (Figura 6). A excreção de proteínas normalizada pela creatinina (Figura 6E) acompanhou o dado de proteínas totais (Figura 6D) e, quando analisada especificamente a excreção de albumina, nota-se na Figura 6F que o grupo Nx apresentou albuminúria em relação aos ratos controles. Em contrapartida, nos ratos com doença renal crônica tratados com o inibidor da DPPIV ( $N x$ e $N x+$ IDPPIV), a disfunção renal foi significativamente atenuada (Figura 6).

O consumo de água (Figura 7A) e fluxo urinário (Figura 7B), como esperado, aumentou nos ratos com DRC, entretanto, o balanço de água foi mantido (Figura 7C).

Nas avaliações do consumo e carga excretada de sódio, não houve diferenças entre os grupos (Figura 8) e o balanço de sódio foi mantido. Pode-se sugerir que o balanço de sódio foi preservado nos ratos nefrectomizados ( $\mathrm{Nx}$ e $\mathrm{Nx}$ +IDPPIV) às custas de um aumento nos níveis pressóricos (Figura 8D). Por sua vez, a administração do inibidor da DPPIV em ratos nefrectomizados reduziu significativamente a pressão arterial caudal, em relação aos animais não tratados, mostrando um efeito anti-hipertensivo. 
A

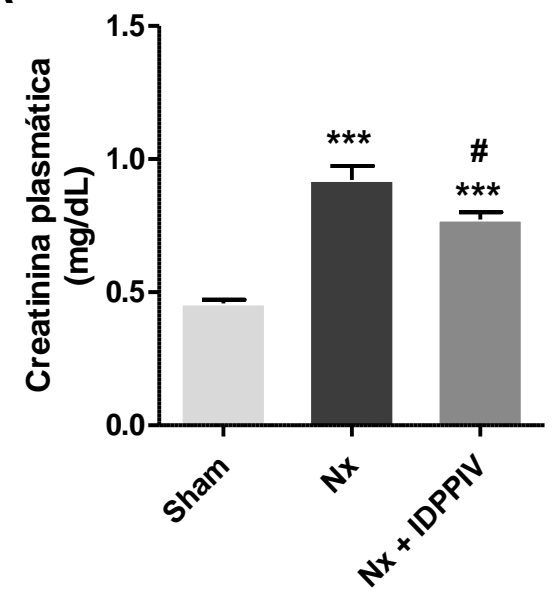

C

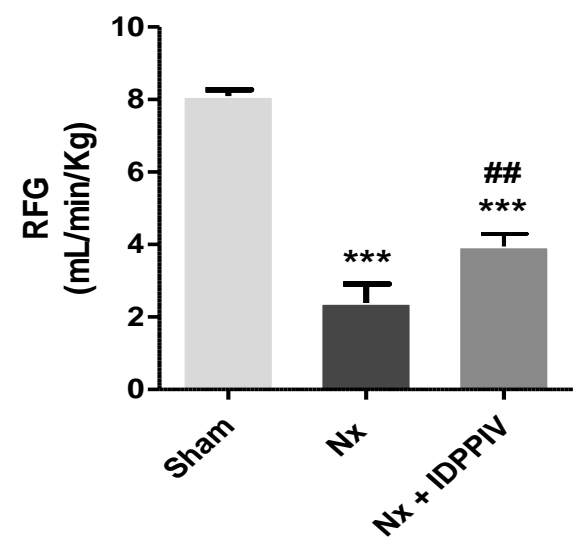

E

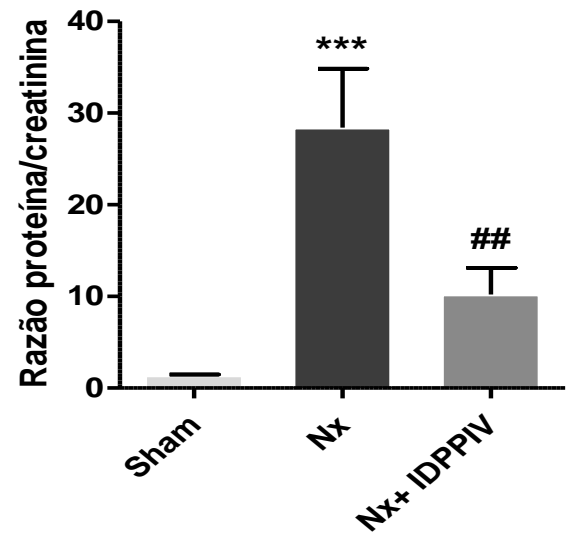

B

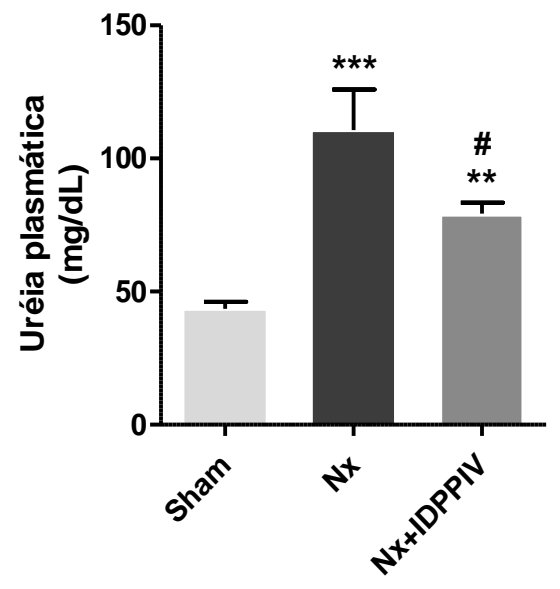

D
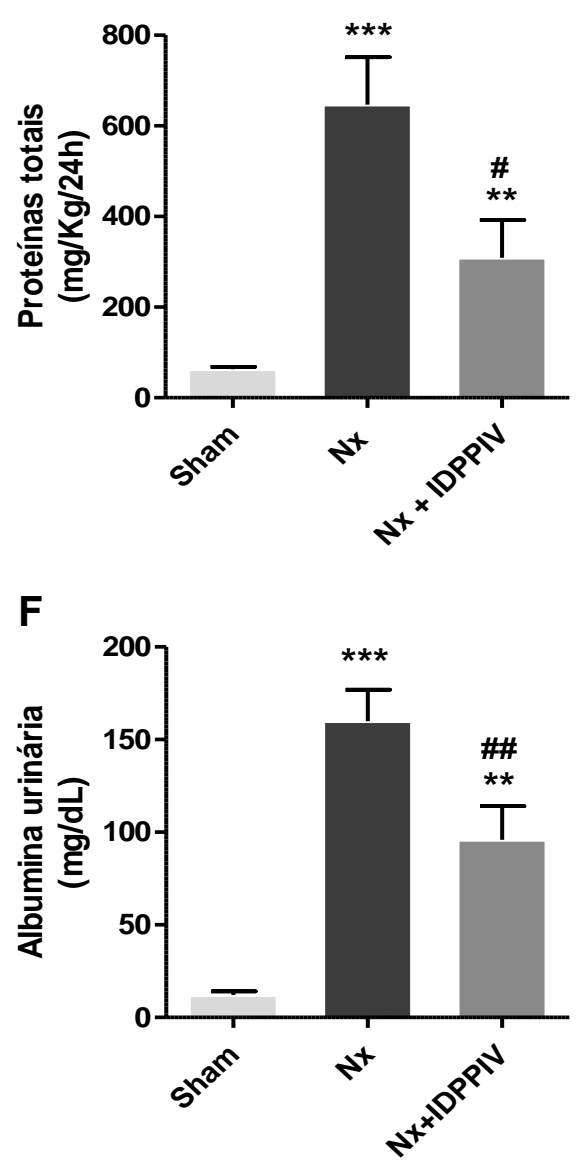

Figura 6. Avaliação da função renal em ratos sham, $\mathrm{Nx}$ e Nx+IDPPIV. A creatinina e ureia plasmáticas foram medidas por colorimetria (A) e (B). Para a análise do Ritmo de filtração glomerular (RFG), foi empregado o clearence de creatinina, calculado pela fórmula (Ucr $x \mathrm{~V} / \mathrm{Pcr}$ ), em que Ucr é a concentração de creatinina urinária, $\mathrm{V}$ o fluxo urinário e Pcr a concentração de creatinina sérica (C). A Excreção urinária de proteínas foi quantificada por meio do kit comercial Labtest (D). A Razão proteína/creatinina foi mensurada por meio do clearence de creatinina e excreção de proteínas (E). Os níveis de albumina urinária foram analisados por ELISA (F). Valores expressos com média \pm EP. $n=8$ ratos/grupo, ${ }^{\star \star} P<0,01 e^{* \star \star} P<0,001$ vs. sham. ${ }^{\#} P<0,01,{ }^{\# \#} P<0,01$ vs. Nx. 
A

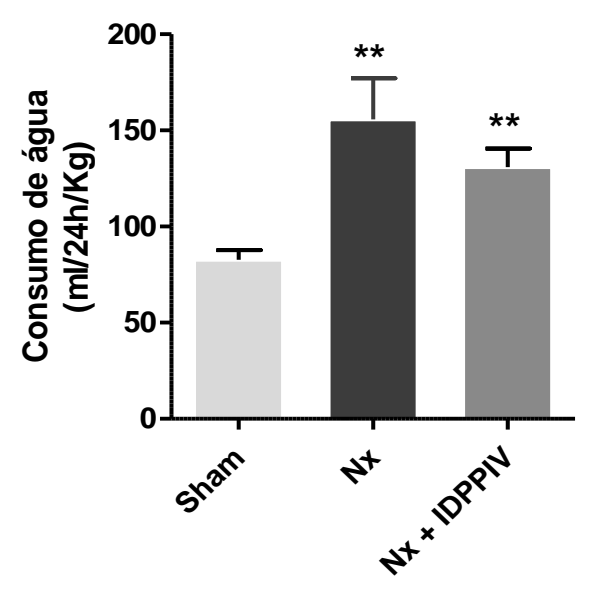

B

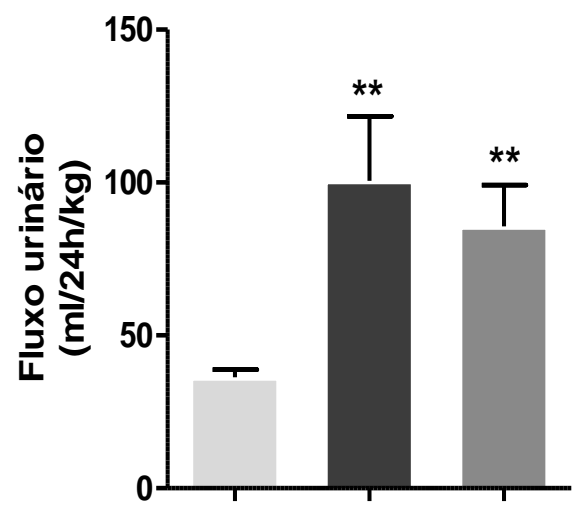

C

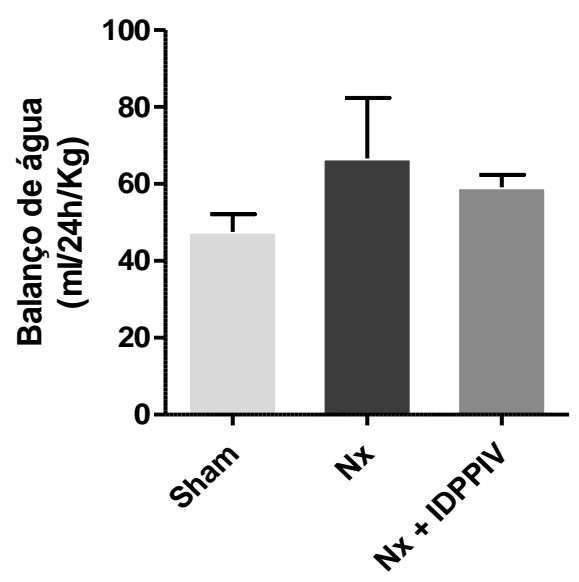

Figura 7. Consumo de água e fluxo urinário em ratos sham, $\mathrm{Nx}$ e Nx + IDPPIV. 0 Consumo de água e o fluxo urinário foram calculados por meio da gaiola metabólica (A) e (B). O balanço de água foi estimado subtraindo o fluxo urinário do consumo de água (C). Valores expressos com média \pm EP. $n=8$ ratos/grupo, ${ }^{* *} \mathrm{P}<0,01 \mathrm{vs}$. Nx. 
A

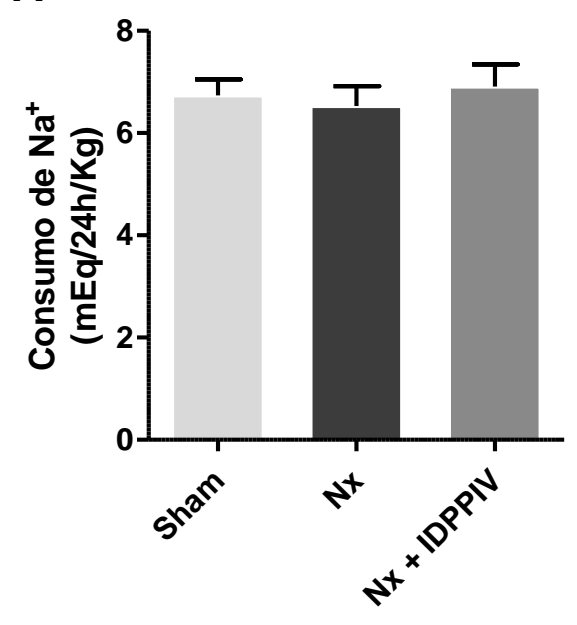

C

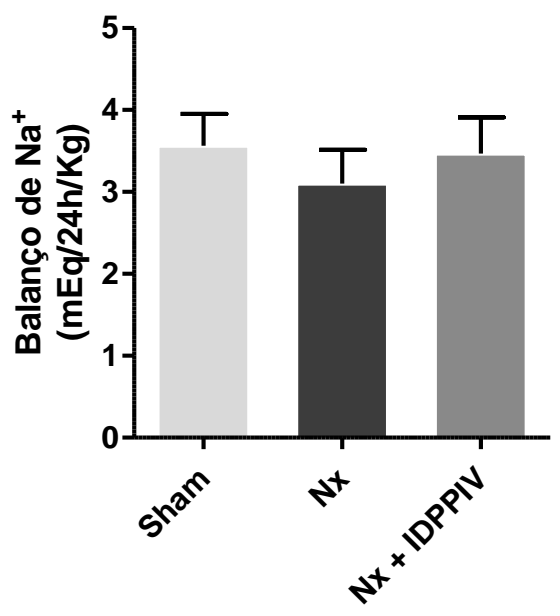

B

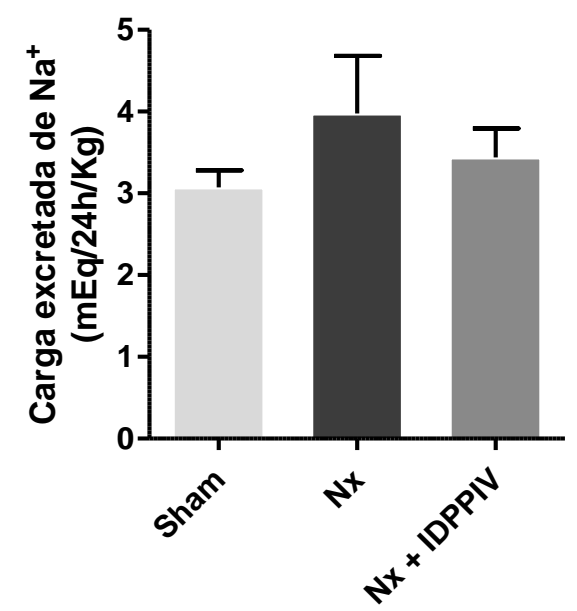

D

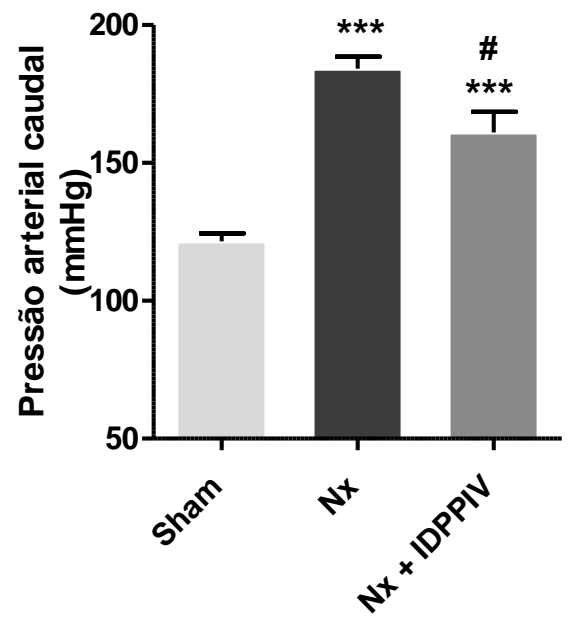

Figura 8. Consumo, excreção e balanço de sódio e níveis pressóricos em ratos sham, Nx e Nx+IDPPIV. O consumo de sódio foi calculado multiplicando o consumo de ração pela concentração de sódio na mesma (A). A carga excretada de sódio (B) foi calculada com base na fórmula $U_{\mathrm{Na}_{+}} \times U_{\mathrm{F}} / 1000$, onde $U_{\mathrm{Na}+}$ corresponde ao sódio urinário e $\bigcup_{\mathrm{Fl}}$, ao fluxo urinário. $\mathrm{O}$ balanço de sódio foi estimado subtraindo a carga excretada do consumo de sódio (C). As análises pressóricas foram obtidas através do método indireto de pletismografia de cauda (D). Valores expressos com média \pm EP. $n=8$ ratos/grupo, ${ }^{\star * *} P<0,001$ vs. sham. ${ }^{\#} P<0,01$ vs. $N x$. 


\subsection{Efeitos da sitagliptina sobre a atividade e expressão da DPPIV cardíaca de ratos com DRC}

Análises da atividade e abundância da DPPIV em tecido cardíaco foram realizadas e estão apresentadas na Figura 9. De acordo com a Figura 9A, a atividade da DPPIV cardíaca mostrou-se significativamente elevada em ratos com DRC tratados com veículo e o tratamento com sitagliptina inibiu de forma significativa sua atividade.

Como pode ser observado na Figura 9B, a expressão proteica de DPPIV variou de modo semelhante ao observado na atividade, ou seja, aumentou significativamente em ratos nefrectomizados tratados com veículo, em relação aos ratos controles. O mesmo foi observado quando analisamos a expressão gênica (Figura 9C). Também é possível notar que a intervenção com sitagliptina reduziu tanto a expressão proteica quanto a expressão gênica em ratos com $\mathrm{DRC}$, quando comparados aos ratos $\mathrm{Nx}$. 
A

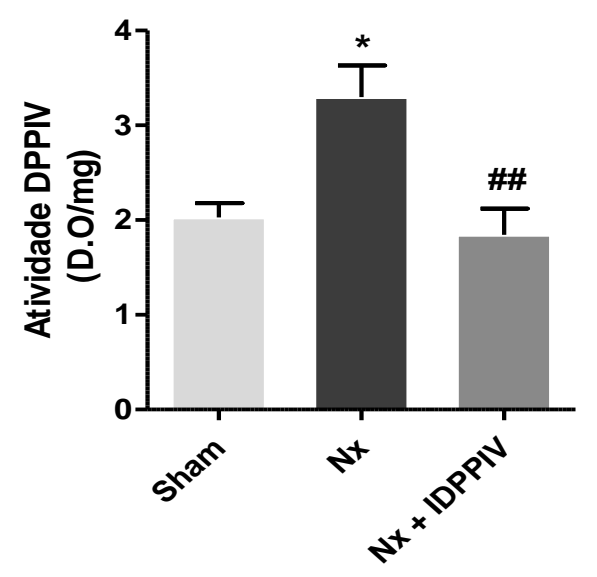

B
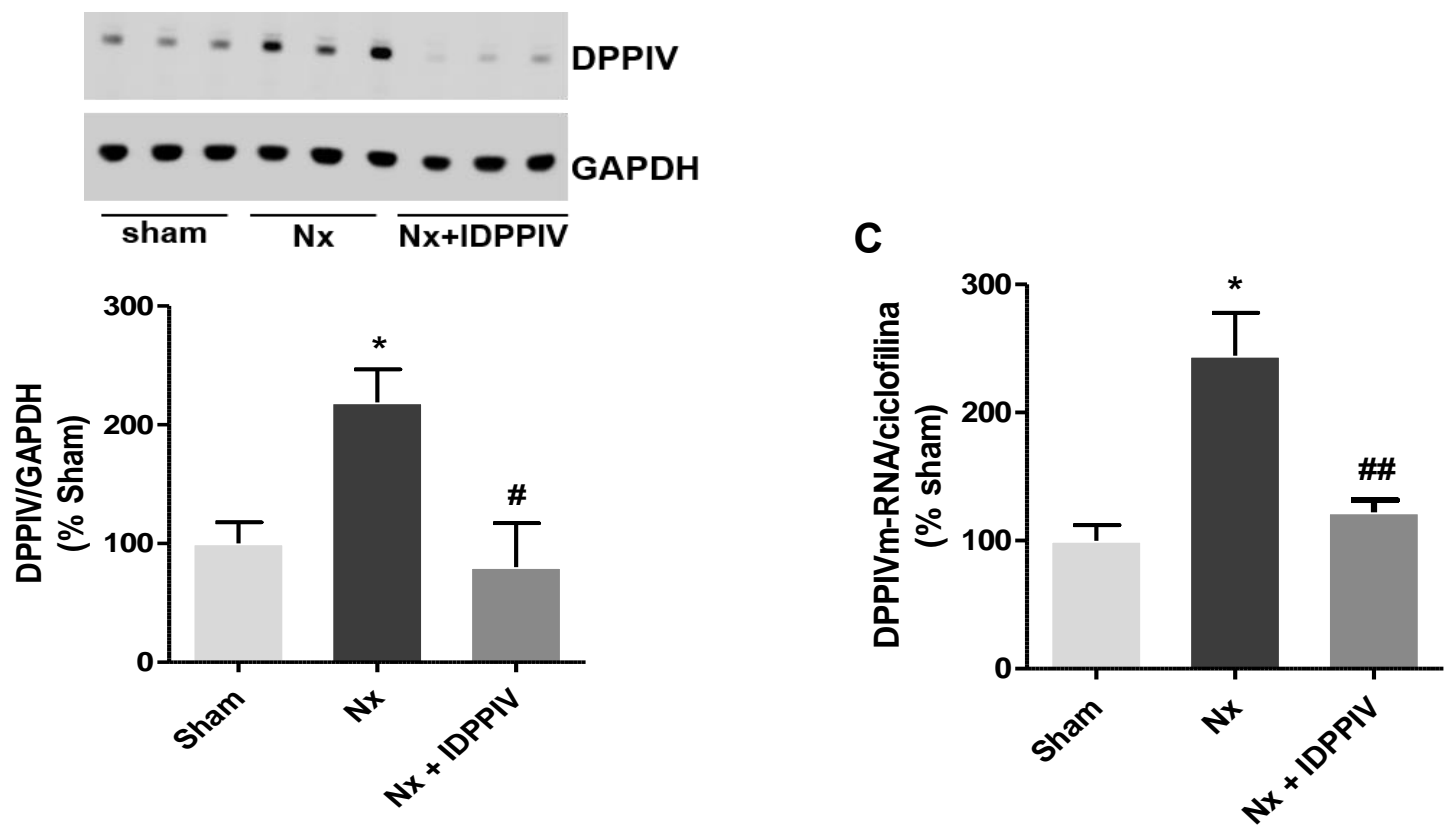

Figura 9. Determinação da atividade e abundância da DPPIV cardíaca em ratos sham, Nx e Nx+IDPPIV. A atividade da DPPIV no coração foi avaliada por colorimetria (A). A expressão proteica foi avaliada por immunoblotting (B). Quantidades equivalente a 100 ug foram submetidas à eletroforese em gel de poliacrilamida (SDS-PAGE), transferido para membrana de PVDF e incubado com o anticorpo secundário anti-DPPIV (1:1000). O GAPDH foi utilizado como controle interno. Os níveis de RNA mensageiro para DPPIV no coração foram determinados por PCR em tempo real (Real-time-PCR), a ciclofilina foi empregada como controle interno (C). Os valores estão expressos em média $\pm E P$. ${ }^{*} P<0,05$, vs. Sham. ${ }^{\#} P<0,05$ e ${ }^{\# \#} P<0,01$ vs. Nx. 


\subsection{Parâmetros biométricos e BNP cardíaco e circulante em ratos sham, $\mathrm{Nx}$ e Nx +IDPPIV}

Parâmetros biométricos, bem como o BNP cardíaco e circulante foram analisados e estão ilustrados na figura 10. Ratos nefrectomizados ( $\mathrm{Nx}$ e $\mathrm{Nx}+$ IDPPI), apresentaram maior peso do coração em proporção ao peso corporal (Figura 10A), bem como aumento na razão ventrículo direito/peso corpóreo (Figura 10C) e, diferentemente, na proporção ventrículo esquerdo/peso corpóreo, somente nos animais $\mathrm{Nx}$ foi identificado aumento em relação aos controles (Figura 10B). No grupo Nx+IDPPIV por sua vez, é possível perceber que as proporções coração total/peso corpóreo, ventrículo direito/peso corpóreo e ventrículo esquerdo/peso corpóreo estavam menores em relação ao grupo Nx (Figura 10).

$\mathrm{Na}$ análise da expressão gênica de BNP (Figura 10D), tanto os ratos nefrectomizados tratados com veículo, quanto os tratados com sitagliptina apresentaram aumento significativo em comparação aos ratos sham. Em contrapartida, no grupo Nx+IDPPIV, observa-se que a expressão foi menor em relação aos ratos Nx. Já na avaliação dos níveis de BNP sérico, somente o grupo Nx apresentou aumento em relação aos ratos controles (Figura 10E). 
A

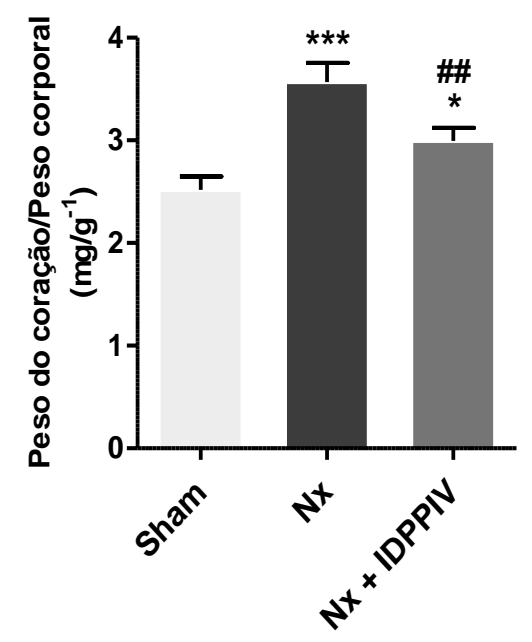

C

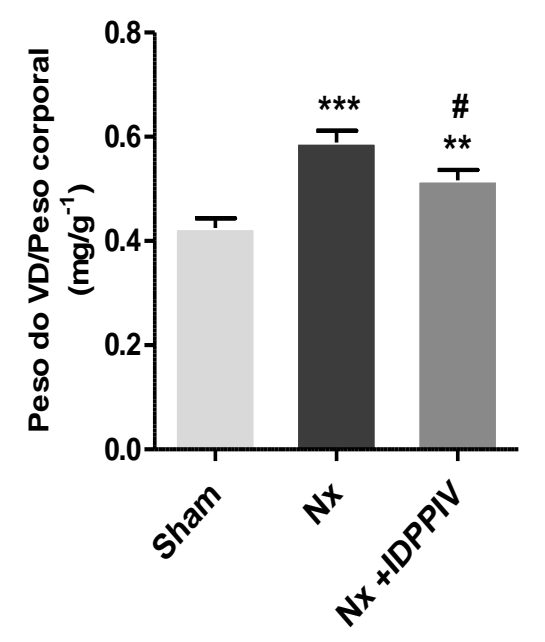

B

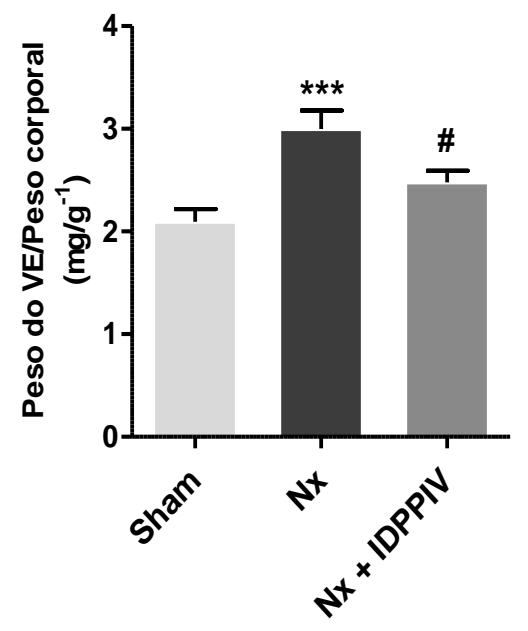

D

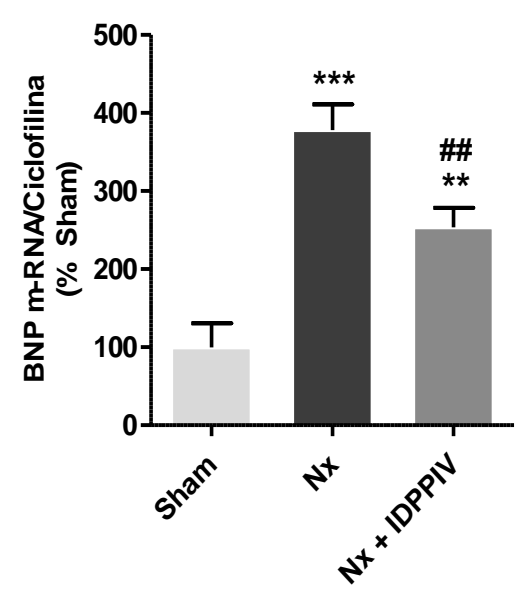

E

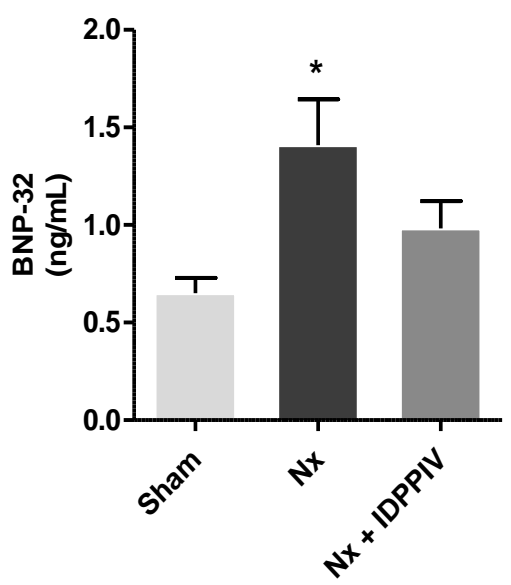

Figura 10. Parâmetros biométricos e BNP circulante e cardíaco em ratos sham, Nx e Nx+IDPPIV. As medidas biométricas foram calculadas envolvendo a razão: peso do coração/peso corpóreo (A), peso do ventrículo esquerdo/peso corpóreo (B), e peso do ventrículo direito/peso corpóreo (C). Os níveis de RNA mensageiro para BNP foram analisados pela técnica de PCR em tempo real (Real-time PCR) (D). Ciclofilina foi 
utilizada como controle interno. A dosagem de BNP circulante foi realizada através do sangue coletado na punção da aorta abdominal, utilizando um kit de ELISA. (E). Os valores estão expressos em média $\pm E P$. ${ }^{* * *} P<0,001$ e ${ }^{* *} P<0,01$ e ${ }^{*} P<0,05$ vs. sham. ${ }^{\#} \mathrm{P}<0,01 \mathrm{e}{ }^{\# \#} \mathrm{P}<0,01$ vs. Nx .

\subsection{Efeitos da sitagliptina sobre o remodelamento cardíaco}

A quantificação de deposição de colágeno é conhecida como uma análise para avaliar fibrose intersticial e, como observado na Figura 11, a deposição de colágeno foi significativamente superior nos ratos $\mathrm{Nx}$, quando comparado aos ratos sham. Já no grupo Nx+IDPPIV, é possível perceber que a deposição de colágeno foi significativamente menor em relação aos ratos nefrectomizados tratados com veículo.

Complementar à quantificação de deposição de colágeno, a medida do volume nuclear de cardiomiócitos é uma análise comumente realizada para avaliar a hipertrófica cardíaca. Nota-se na Figura 12 que os ratos nefrectomizados ( $\mathrm{Nx}$ e $\mathrm{Nx}+$ IDPPIV) apresentaram volumes nucleares significativamente maiores, quando comparados aos ratos sham. Por outro lado, os ratos que receberam sitagliptina apresentaram volume nuclear médio reduzido, em comparação aos ratos que receberam veículo. Coletivamente, os dados obtidos das análises biométricas, aliados às análises estruturais, sugerem que a inibição da DPPIV exerceu efeitos atenuantes sobre a hipertrofia e fibrose cardíaca. 

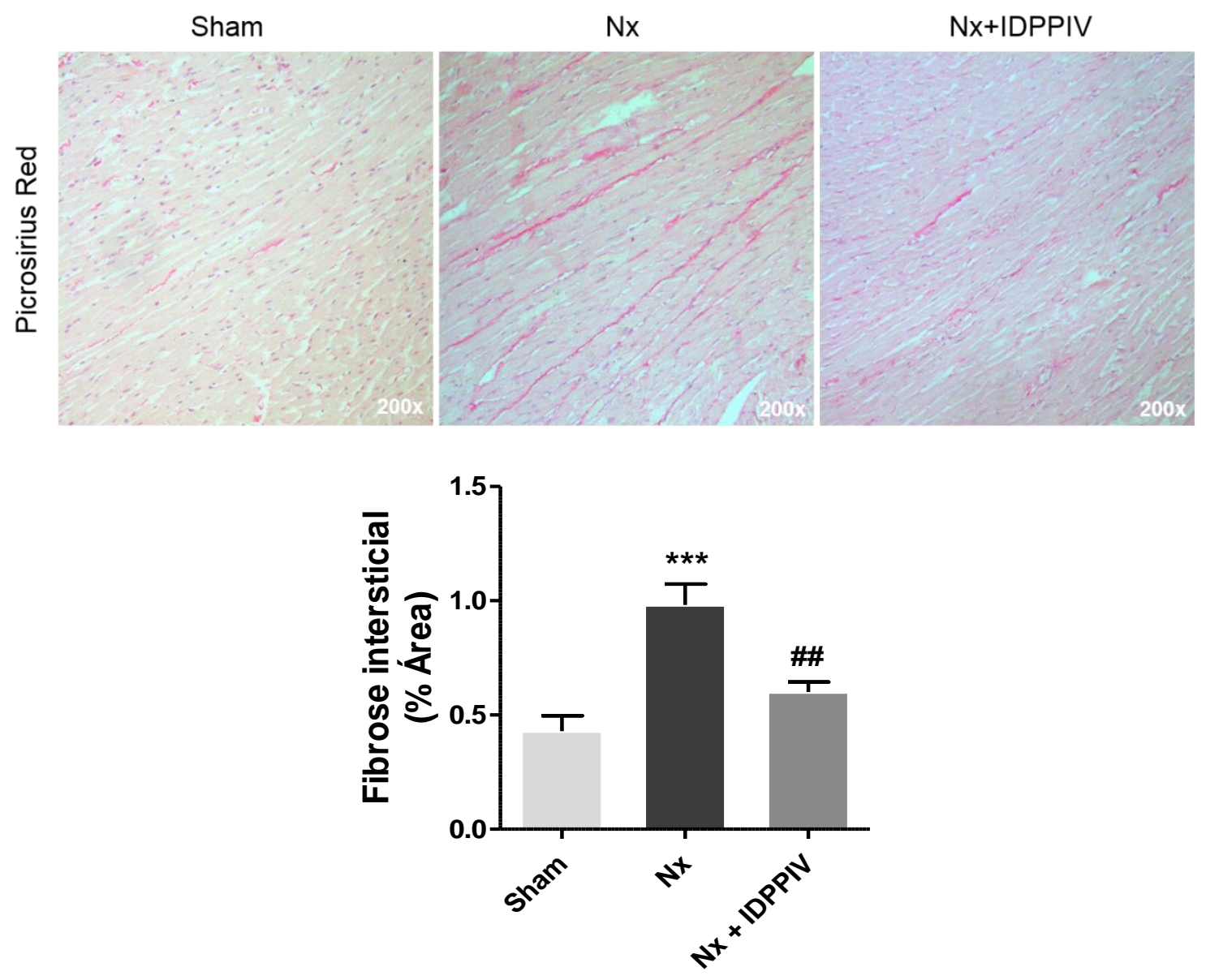

Figura 11. Efeitos da sitagliptina sobre a fibrose intersticial. A fibrose intersticial cardíaca foi analisada através da quantificação da deposição de colágeno intersticial em secções do coração coradas com PicrosiriusRed. Para a quantificação, a imagem foi amplificada com aumento de 200x a partir da imagem original. Os valores estão expressos em média $\pm E P$. ${ }^{* * *} P<0,001$ vs. sham $e^{\# \#} P<0,01$ vs. $N x$. 

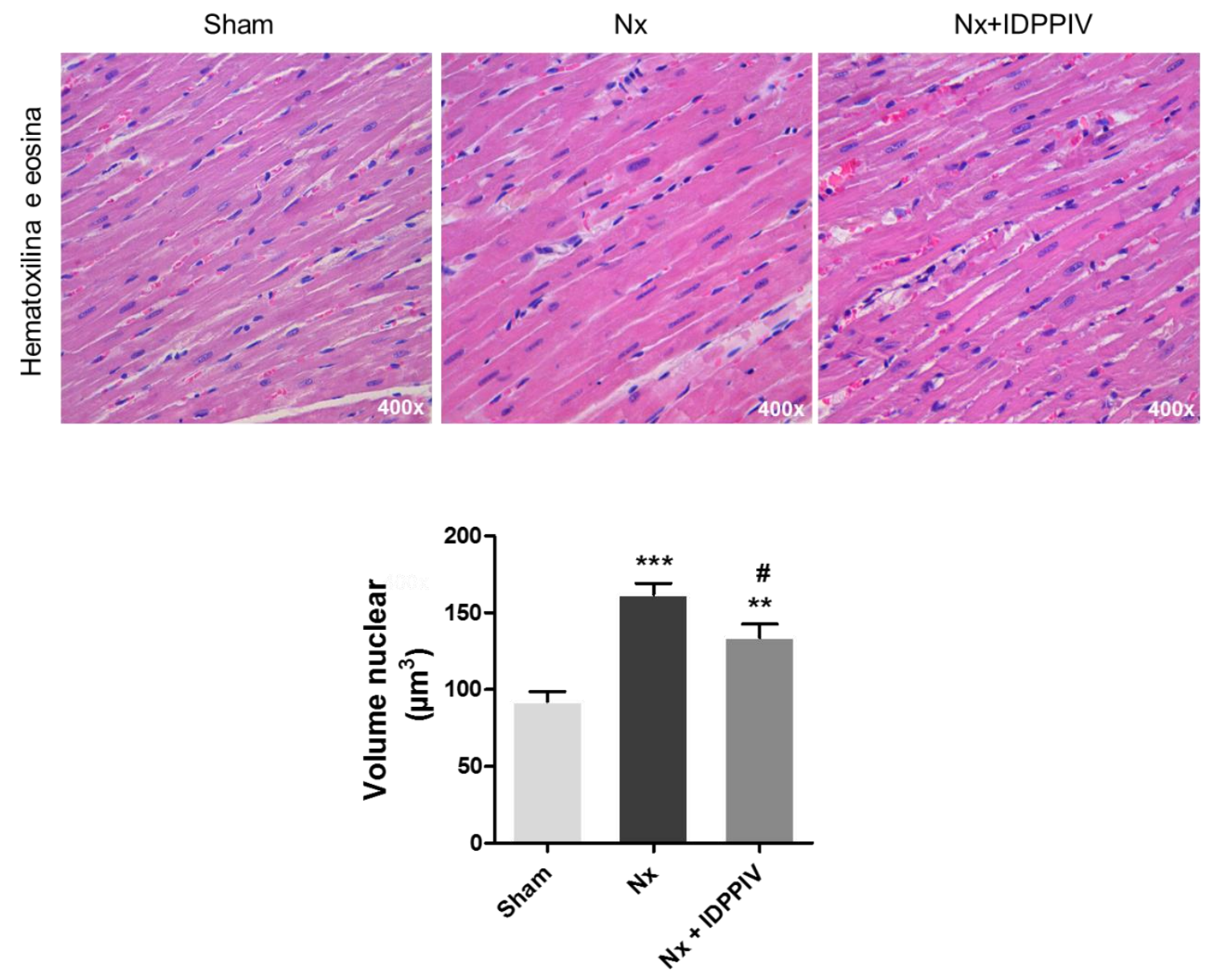

Figura 12. Efeitos da sitagliptina sobre a hipertrofia cardíaca. A hipertrofia cardíaca foi analisada através da medida do volume nuclear dos cardiomiócitos. O tecido cardíaco foi corado com hematoxilina e eosina e as imagens analisadas com aumento de 400x a partir da imagem original. Os valores estão expressos em média $\pm E P$. ${ }^{* *} P<0,01,{ }^{* *} P<0,001$ vs. sham. ${ }^{\#} P<0,05$ vs. Nx. 


\subsection{Expressão do NHE1 em ratos sham, Nx e Nx + IDPPIV}

A expressão do NHE1 em homogenato de coração foi quantificada e encontra-se ilustrada Figura 13. Observa-se que os animais nefrectomizados tratados com sitagliptina apresentaram a expressão de NHE1 significativamente reduzida, em comparação aos animais nefrectomizados tratados com veículo, sugerindo que a inibição da DPPIV influenciou no remodelamento, em parte, através da inibição do NHE1.
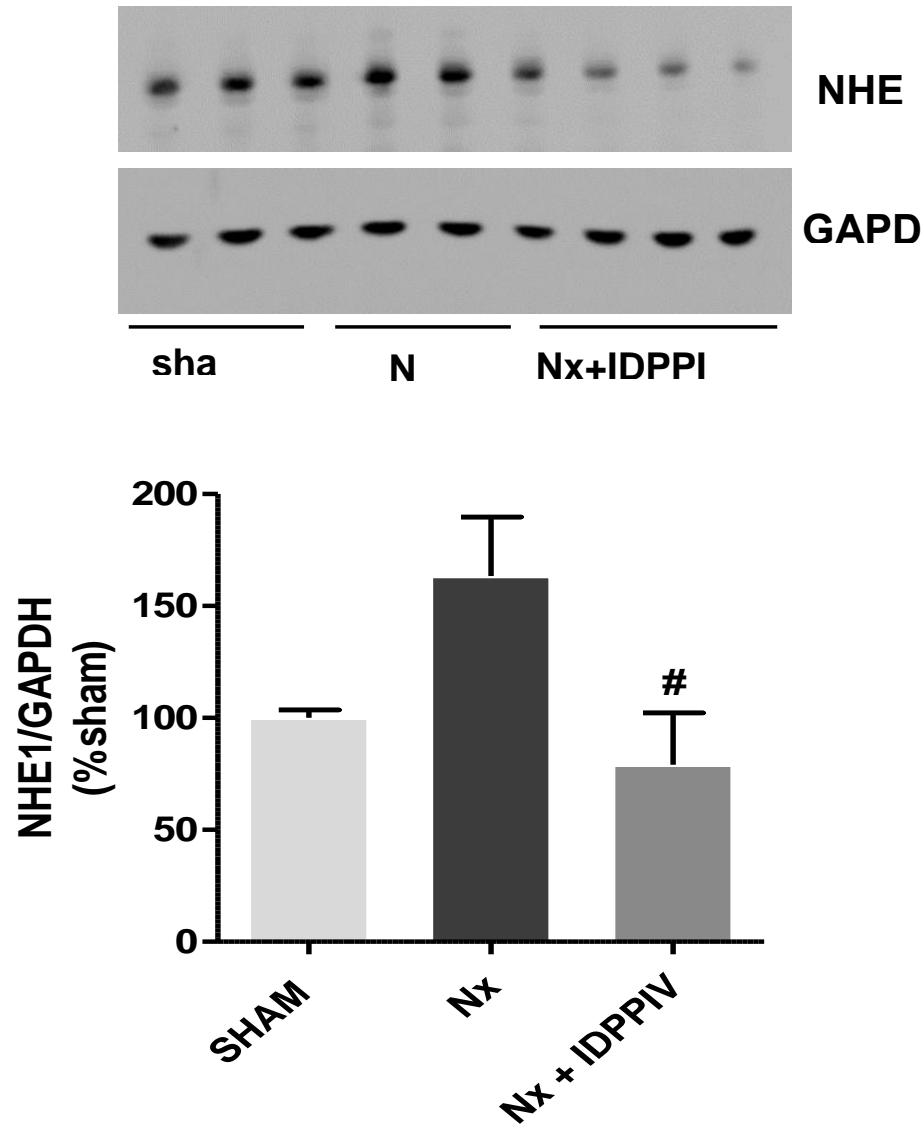

Figura 13. Expressão proteica de NHE1 em ratos sham, Nx e Nx+IDPPIV. Amostras equivalentes $(100 \mathrm{ug})$ de proteínas de homogenato de coração foram submetidas à eletroforese em gel de poliacrilamida (SDS-PAGE), transferidas para membrana PVDF e analisadas por "immunoblotting". O GAPDH foi utilizado como controle interno. Valores expressos como média $\pm \mathrm{EP}$. ${ }^{\#} \mathrm{P}<0,05$ vs. Nx. 


\subsection{Avaliação da função cardíaca em ratos sham, Nx e Nx+IDPPIV}

Através de estudos ecocardiográficos, avaliamos a função cardíaca nos três grupos experimentais após oito semanas de tratamento com sitagliptina (200 $\mathrm{mg} / \mathrm{kg} / \mathrm{dia}$ ) ou veículo.

Como medidas sistólicas avaliamos a fração de ejeção do ventrículo esquerdo (FEVE) e a fração de encurtamento do ventrículo esquerdo (FenVE). Nota-se na Figura 14A que os diferentes grupos experimentais não apresentaram diferença significativa com relação a Fração de ejeção. Igualmente, como mostra a Figura 14B, não foi observada diferença significativa entre os grupos experimentais com relação à Fração de encurtamento do ventrículo esquerdo.

A função diastólica foi determinada através do TRIV (tempo de relaxamento isovolumétrico). Observa-se na Figura 14C, que ratos nefrectomizados tratados com veículo e sitagliptina apresentaram o TRIV significativamente maior, quando comparados aos ratos Sham. Por sua vez, no grupo Nx+IDPPIV, o TRIV mostrou-se significativamente menor, sugerindo que a inibição da DPPIV possa ter desempenhado papel na disfunção diastólica. 

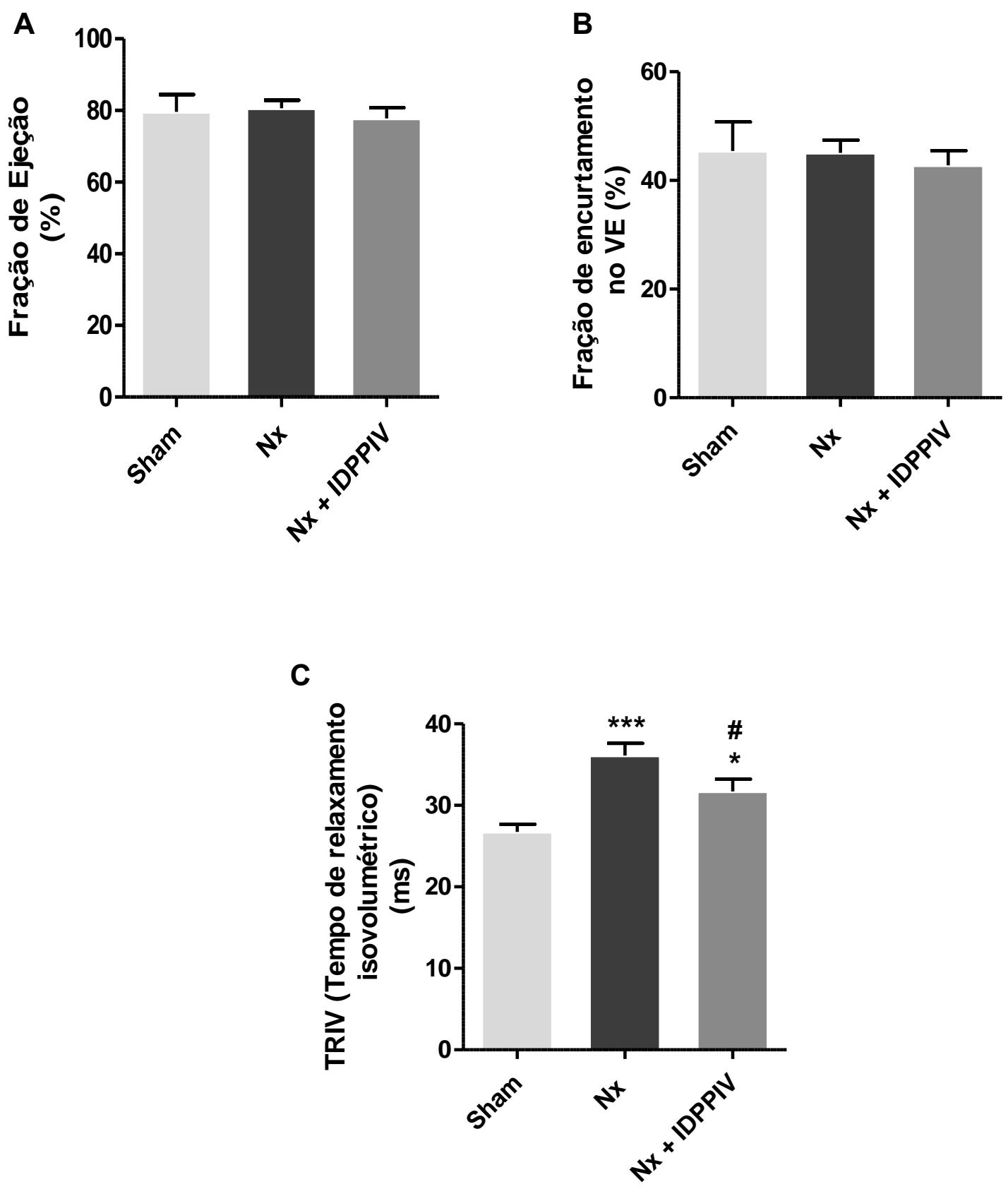

Figura 14. Análise da função cardíaca em ratos sham, Nx e Nx+IDPPIV. As análises ecocardiográficas foram realizadas 8 semanas após o tratamento com sitagliptina (200mg/kg/dia) ou veículo. (A) Fração de ejeção do ventrículo esquerdo (FEVE), (B) Fração de encurtamento do ventrículo esquerdo (FEnVE), (C) Tempo de relaxamento isovolumétrico (TRIV). Os valores estão expressos como média $\pm E P$. ${ }^{* *} P<0,001 \mathrm{e}$ ${ }^{*} \mathrm{P}<0,5$ vs. sham. ${ }^{\#} \mathrm{P}<0,5$ vs. $\mathrm{Nx}$. 


\subsection{Atividade e expressão dos componentes do sistema renina angiotensina (SRA) em ratos sham, $\mathrm{Nx}$ e $\mathrm{Nx}+$ IDPPIV}

Como o estudo teve como objetivo avaliar os componentes do SRA, realizamos análises de expressão gênica do angiotensinogênio, ECA, ECA2, AT1 e AT2; expressão proteica de ECA e ECA2 e também dos níveis de Angiotensina II e Angiotensina 1-7 no homogenato de coração.

Nota-se na Figura 15A, que a expressão gênica do angiotensinogênio (AGT) não variou entre os grupos, bem como a expressão gênica e proteica de ECA (Figuras 15B e 16A). Curiosamente, a expressão proteica e gênica de ECA2 foi significativamente menor no grupo Nx em relação aos controles. Por sua vez, a intervenção com sitagliptina reverteu essa condição, elevando a expressão de ECA2 (Figuras 15C e 16B). Apesar de não identificarmos diferença na expressão de ECA, quando calculada a razão ECA/ECA2, esta foi maior em ratos $\mathrm{Nx}$, e menor no grupo Nx+IDPPIV (Figura 16C).

No presente trabalho, ao mensurarmos a atividade de ECA, não foi vista diferença entre os grupos (Figura 16D), bem como na análise da atividade de ECA2 (Figura 16E). Entretanto, esse perfil enzimático resultou em redução da razão ECA/ECA2 em ratos tratados com sitagliptina em relação aos ratos $\mathrm{Nx}$ (Figura 16F).

Por fim, na avaliação dos níveis de angiotensina II (Figuira 17A) e angiotensina 1-7 (Figuras 17B), os resultados foram interessantes. Ratos Nx apresentaram aumento significativo de angiotensina II, que foi significativamente reduzido no grupo que recebeu sitagliptina (Nx+IDPPIV). Na análise dos níveis de angiotensina 1-7, não houve diferença entre os grupos. Contudo, quando 
calculada a razão Angll/Ang 1-7, esta foi menor no grupo Nx+IDPPIV em relação aos animais $\mathrm{Nx}$ (Figura 17C).

A

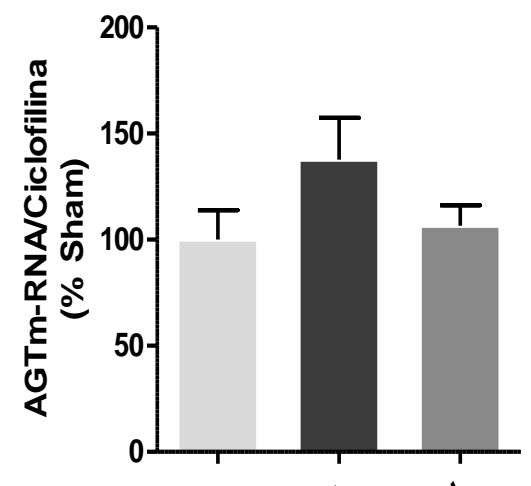

B

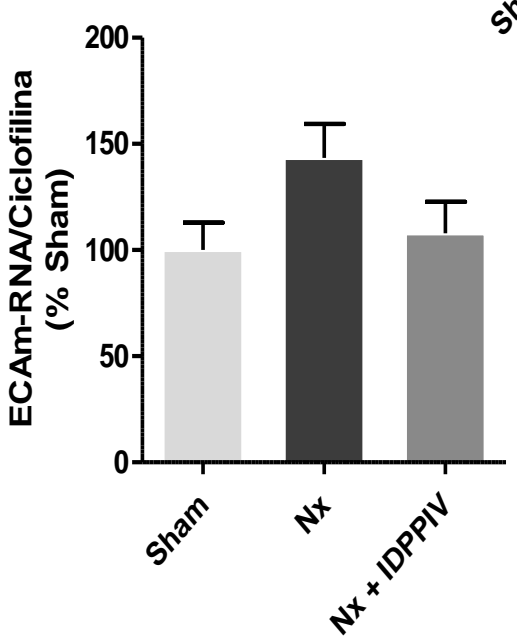

D

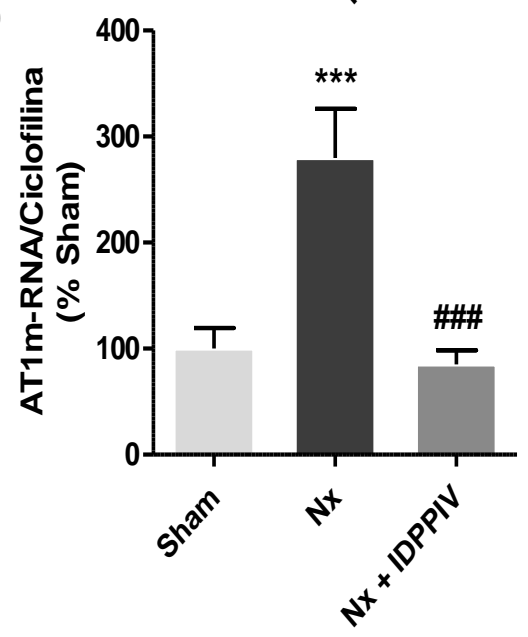

C

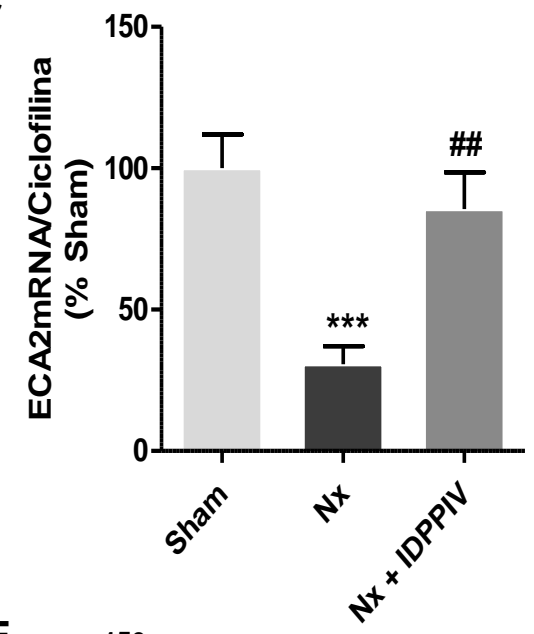

E

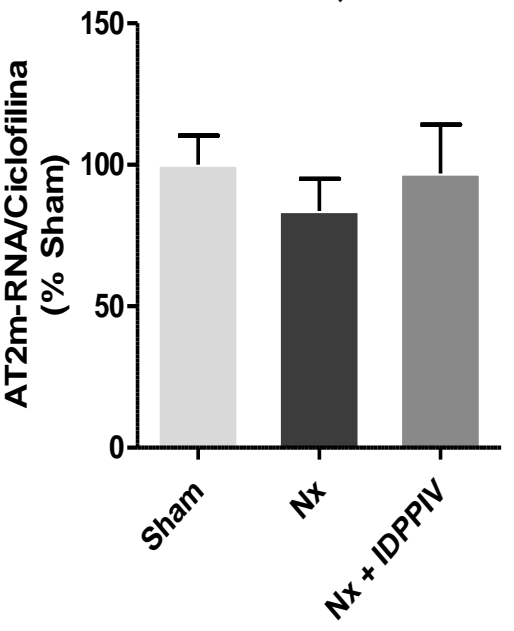

Figura 15. Expressão gênica dos componentes do sistema renina angiotensina (SRA) intracardíaco. Os níveis de RNA mensageiro para AGT (A), ECA (B), ECA2 (C), AT1 (D) AT2 (E) foram determinados por PCR em tempo real (Real-time-PCR), e a ciclofilina foi empregada como controle interno. Valores expressos como média \pm EP. ${ }^{* * *} \mathrm{P}<0,001$ vs. sham. ${ }^{\# \#} \mathrm{P}<0,001$ e ${ }^{\#} \mathrm{P}<0,01$ vs. $\mathrm{Nx}$ 


\section{Expressão proteica:}

A
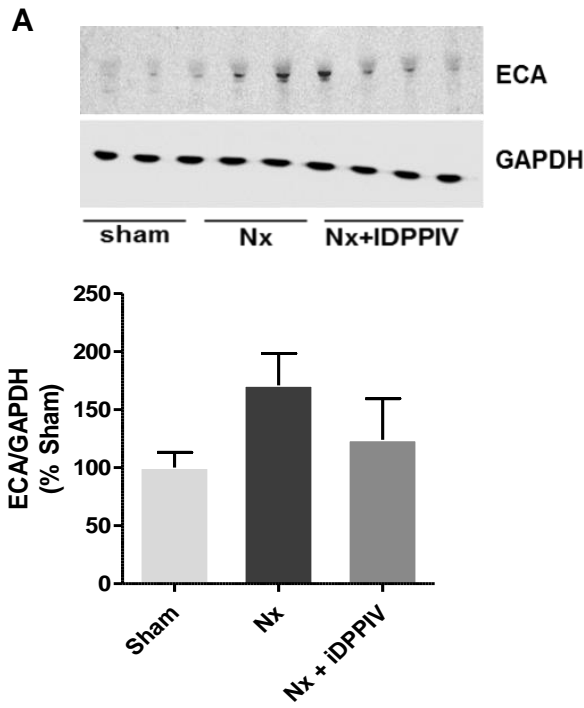

Atividade:

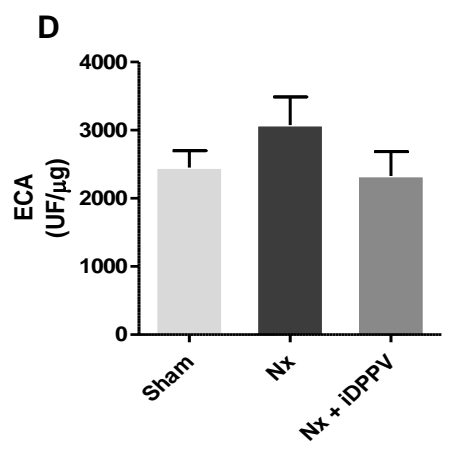

B
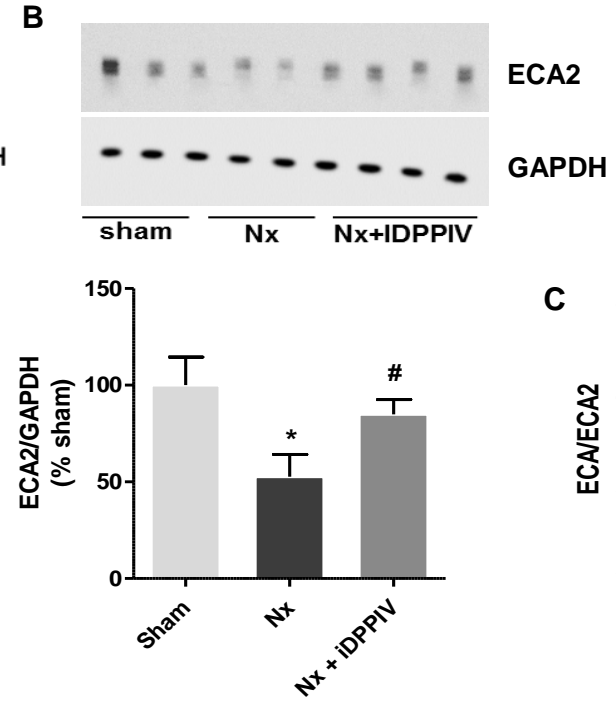

C

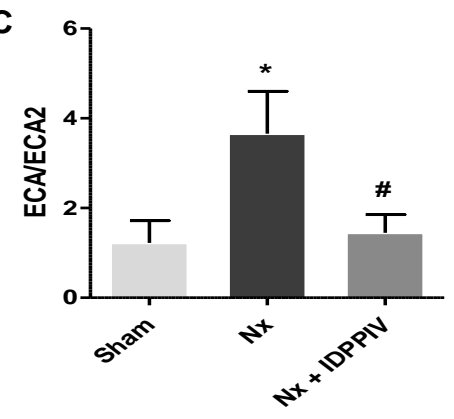

$\mathbf{F}$

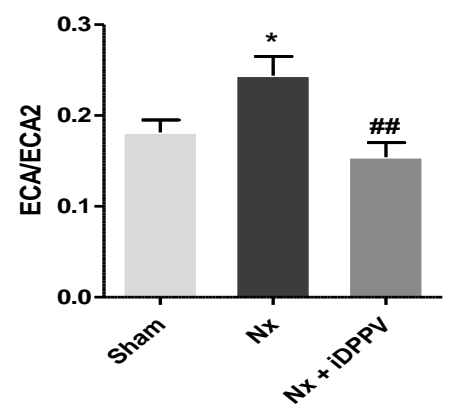

Figura 16. Expressão proteica e atividade de ECA e ECA2, ECA (A), ECA2 (B), ECA/ECA2 (C). Amostras equivalentes (ECA: 100ug e ECA2: 20ug) de proteínas de homogenato de coração foram submetidas à eletroforese em gel de poliacrilamida (SDS-PAGE), transferidas para membrana PVDF e analisadas por "immunoblotting". $O$ GAPDH foi utilizado como controle interno. A atividade enzimática de ECA (D) e ECA2 (E) foram determinadas por ensaio fluorimétrico. Razão ECA/ECA2 (F). Valores expressos como média $\pm E P$. ${ }^{*} P<0,05$ vs. sham. ${ }^{\# P} P<0,01$ e ${ }^{\# P}<0,05$ vs. Nx. 
A

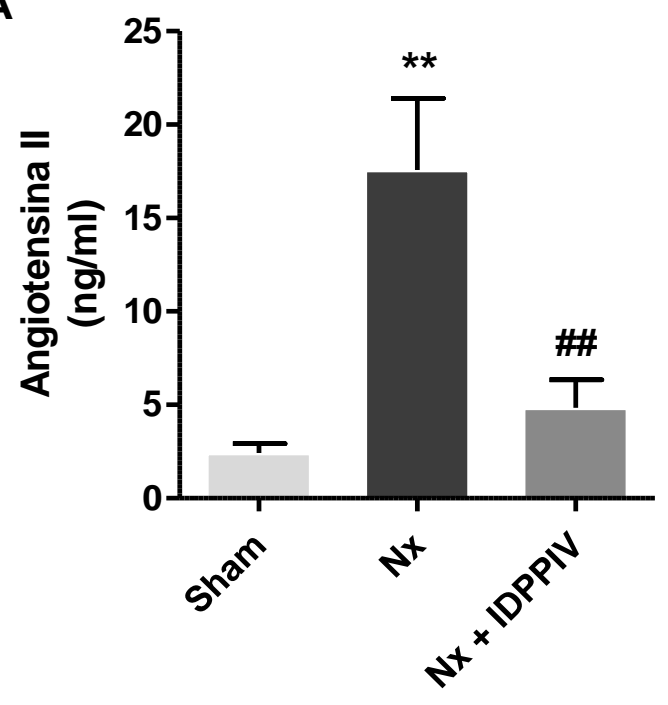

B

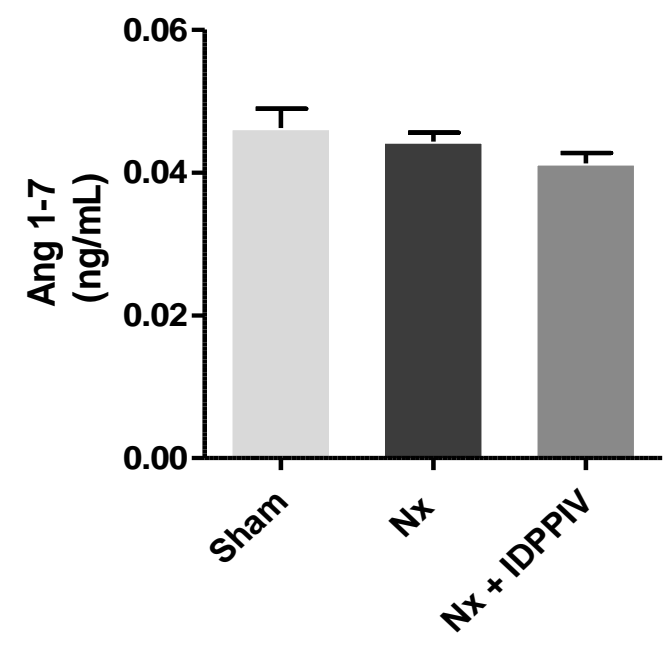

C

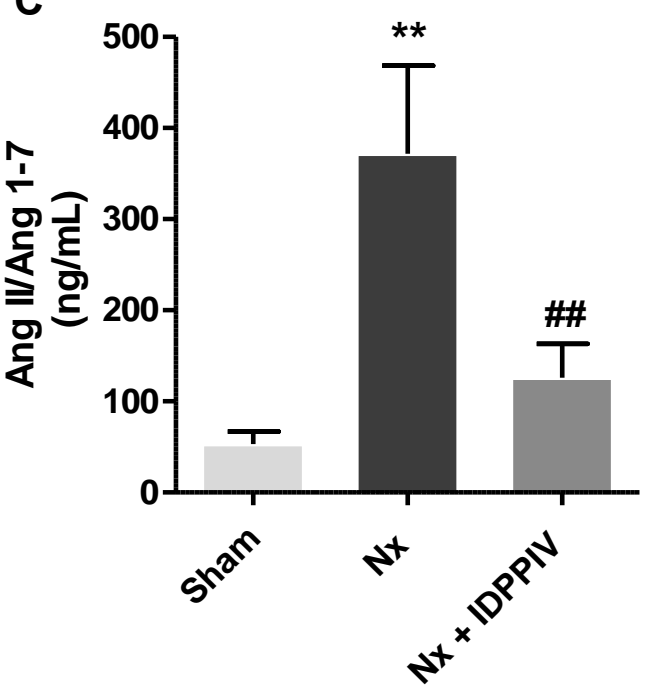

Figura 17. Níveis de angiotensina II e angiotensina 1-7 em ratos sham, Nx e Nx+IDPPIV. A determinação quantitativa de Angiotensina II (A) e Angiotensina 1-7 (B) em homogenato de coração foi obtida por ELISA. Razão angiotensina II e angiotensina 1-7(C). Valores expressos como média $\pm E P$. ${ }^{* \star} P<0,01$ vs. sham. ${ }^{\# \#} P<0,01$ vs. $N x$. 
4.9 Expressão gênica dos mediadores inflamatórios cardíacos e infiltração de macrófagos em ratos sham, Nx e Nx+IDPPIV

As análises de expressão gênica de mediadores inflamatórios no coração não revelaram diferenças significativas entre os diferentes grupos, exceto MCP1 e IL-1 $\beta$ (Figura 18). O tratamento com sitagliptina atenuou significativamente tanto MCP-1 (Figura18A) quanto IL-1 $\beta$ (Figura18E) em ratos com DRC. Além disso, os ratos $\mathrm{Nx}$ apresentaram aumento significativo de MCP-1 em relação ao grupo sham. 
A

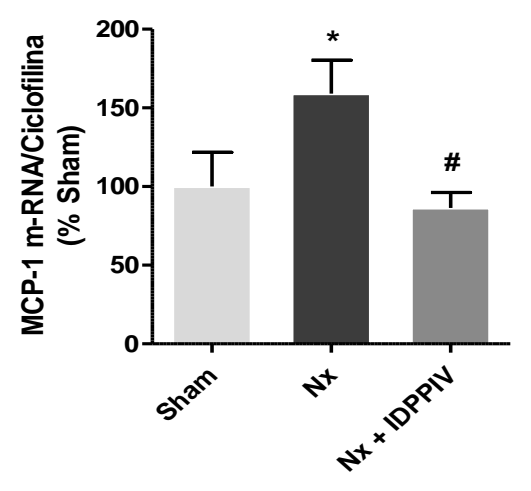

C

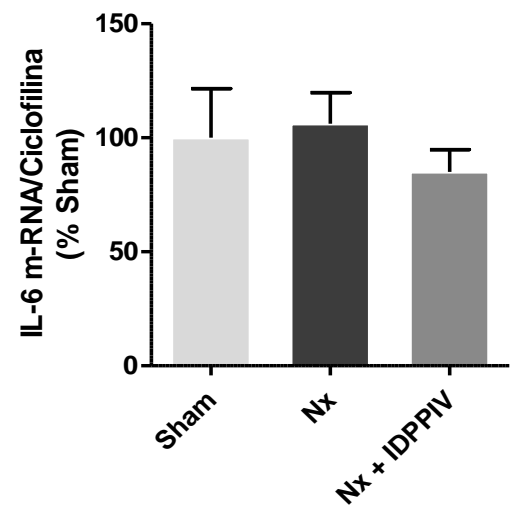

B

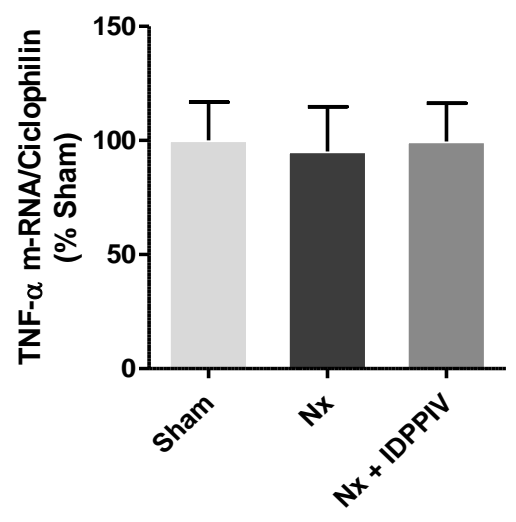

D

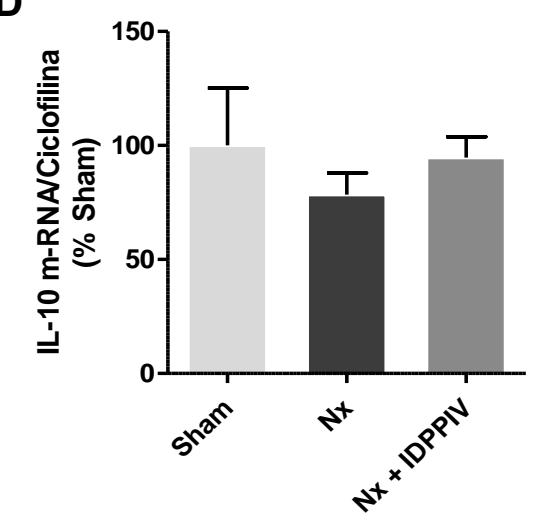

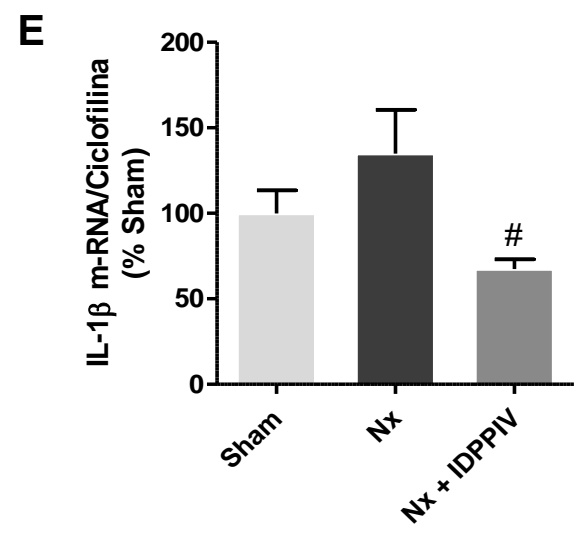

Figura 18. Avaliação dos marcadores inflamatórios e anti-inflamatórios em homogenato de coração de ratos com DRC tratados com sitagliptina ou veículo. Os níveis de RNA mensageiro para MCP-1 (A), TNF-alfa (B), IL-6 (C), IL-10 (D) e IL-1及 (E) no coração foram determinados por PCR em tempo real (Real-time-PCR); a ciclofilina foi empregada como controle interno. Valores expressos como média \pm EP. ${ }^{*} \mathrm{P}<0,5$ vs. sham. ${ }^{\#} \mathrm{P}<0,05$ vs. $\mathrm{Nx}$. 


\subsection{Avaliação do estresse oxidativo em ratos sham, Nx e Nx + IDPPIV}

É sabido que a angiotensina II, dentre seus inúmeros efeitos, estimula a produção de espécies reativas de oxigênio, mediada pela NADPH oxidase, conferindo aumento do estresse oxidativo e consequentemente contribuindo para o remodelamento cardíaco. Assim, analisamos os níveis de nitrotirosina cardíaca para avaliar o estresse oxidativo nos diferentes grupos. Nota-se na Figura 19 que os ratos nefrectomizados tratados com veículo apresentaram aumento significativo nos níveis de nitrotirosina, em comparação aos ratos controles. Em contrapartida, os ratos com DRC que receberam sitagliptina apresentaram diminuição, em relação aos ratos $\mathrm{Nx}$.

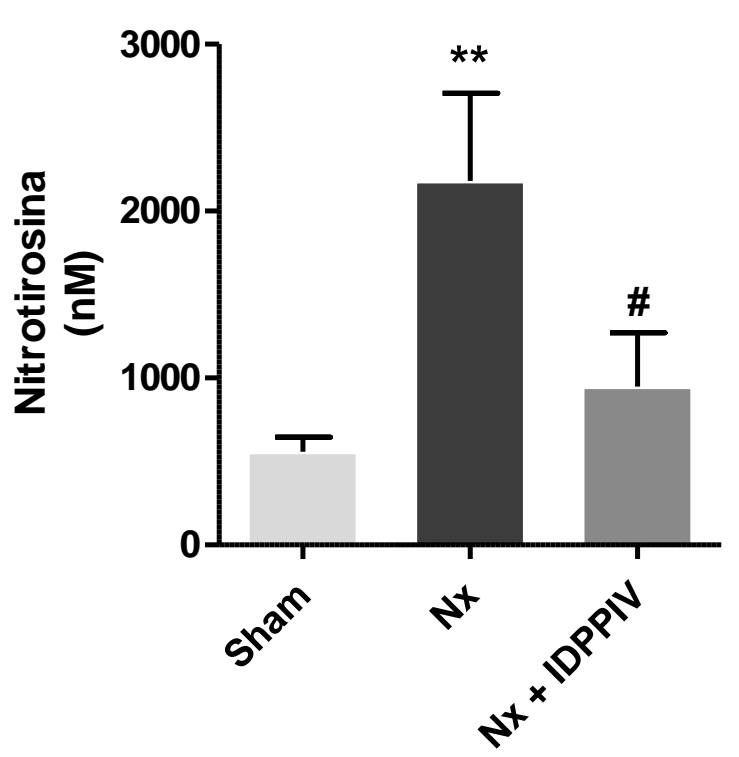

Figura 19. Avaliação dos níveis de nitrotirosina em homogenato de coração de ratos sham, Nx e Nx+IDPPIV. A determinação quantitativa dos níveis de nitrotirosina foi obtido por ELISA. Valores expressos como média $\pm E P$. ${ }^{* *} P<0,01 v$ s. sham. ${ }^{\#} P<0,05$ vs. Nx. 


\section{DISCUSSÃO}

As complicações cardiovasculares são altamente prevalentes em pacientes portadores de DRC (63). O rim está diretamente associado ao funcionamento cardíaco e vice-versa, de modo que compartilham vias relacionadas a alterações metabólicas, ativação neuro-hormonal e regulação de cascatas inflamatórias $(64,65)$. Estes elementos, quando alterados, predispõem o remodelamento cardíaco e, posteriormente, a disfunção cardíaca.

No presente estudo, foi demonstrado o envolvimento da DPPIV na progressão da síndrome cardiorrenal. Nossos dados demonstram que a administração do inibidor de DPPIV em ratos submetidos a nefrectomia 5/6 atenua a hipertrofia cardíaca, fibrose intersticial e a disfunção diastólica, sugerindo que os inibidores da DPPIV são capazes de atenuar a progressão da doença cardiovascular, presente na DRC. Além disso, sugere que a cardioproteção conferida pela inibição de DPPIV em ratos com DRC está associada à redução dos níveis cardíacos da angiotensina II, que foram acompanhados por efeitos locais anti-hipertróficos, anti-inflamatórios e antioxidantes.

Diversos mecanismos podem estar atrelados ao benefício cardiovascular observado neste estudo e, a melhora da função renal promovida pela sitagliptina, possivelmente exerceu papel considerável, tendo em vista que o agravamento da função renal é um importante fator desencadeante na progressão do remodelamento cardíaco e insuficiência cardíaca. 
Os efeitos renoprotetores dos inibidores da DPPIV têm sido relatados em diversos estudos. Um trabalho clínico randomizado realizado em pacientes com diabetes tipo II apresentando albuminúria e que faziam uso de inibidores da enzima conversora de angiotensina II (IECA), mostrou que a linagliptina reduziu a excreção de albumina em $32 \%$, contrastando em $6 \%$ naqueles que receberam placebo (66). Além disso, outros trabalhos têm demonstrado que os inibidores da DPPIV não somente exercem ações renoprotetoras em pacientes ou modelos experimentais de nefropatia diabética, como também age na DRC não associada à hiperglicemia (45).

As vias pelas quais a inibição da DPPIV causa renoproteção têm sido vastamente investigadas. Recentemente, um estudo experimental conduzido em ratos diabéticos mostrou que a inibição da DPPIV se correlacionou com a redução na excreção urinária de nefrina, prevenindo lesões nos podócitos (67). Kanasaki et al., após identificarem que a linagliptina melhorou significativamente a fibrose renal de ratos diabéticos, verificaram que a inibição de EndMT (transição endotelial-mesenquimal) e a consequente inibição da ativação dos fibroblastos poderiam estar associados a reversão da fibrose (44). Nesse estudo, foi mostrado que a inibição da DPPIV reduz características importantes de mortalidade cardiovascular em modelo de nefrectomia 5/6 que não exibe glicemia alterada, incluindo aumento da taxa de filtração glomerular e redução da albuminúria e da pressão arterial. Assim, a redução no comprometimento cardíaco induzido pela sitagliptina pode ser explicada, ao menos em parte, devido a melhora na função renal. 
Além de exercer efeitos sobre os rins, a DPPIV cliva vários substratos com funções importantes no coração, incluindo o neuropeptídio $Y$, peptídeo natriurético cerebral, SDF-1 e GLP-1. Curiosamente, foi observado aumento notável tanto da atividade quanto da expressão de DPPIV cardíaca em ratos com DRC, que foram completamente inibidas por meio da sitagliptina. Esses achados sugerem que a inibição da DPPIV local também pode ter desempenhado um papel nos efeitos cardioprotetores observados. De fato, Lorenzo e colegas demonstraram que a inibição da DPPIV reduziu a fibrose miocárdica por meio da estabilização plasmática de GLP-1 e o controle de insulina, de maneira similar à metformina. (68). Adicionalmente, foi visto que o GLP-1 é capaz de modular a resposta pró-fibrótica em cardiomiócitos cultivados com palmitato e glicose. Além do GLP-1, o GLP-1 (9-36), também com propriedades anti-fibróticas, pode ser obtido a partir da clivagem do GLP-1 pela DPPIV. Interessantemente, observaram que o GLP-1, mas não o GLP-1 (9-36), foi capaz de aumentar a expressão do receptor de ativação do proliferador de peroxissoma $\delta$ (PPARס), um promotor anti-fibrótico. Assim, é possível sugerir que o GLP-1, um dos substratos da DPPIV pode agir diretamente sobre os cardiomiócitos, exercendo cardioproteção. Outro trabalho realizado em ratos diabéticos e normoglicêmicos que tiveram infarto do miocárdio mostrou que a deleção genética ou farmacológica da DPPIV aumentou a sobrevida dos animais (69), demonstrando que a inibição da DPPIV não somente é cardioprotetora em modelo diabético, como também em modelo independente da hiperglicemia. Em um modelo de inflamação induzida por sepse, Lin e colegas reforçaram o efeito direto dos inibidores da DPPIV em cardiomioblastos expostos ao LPS (lipopolissacarídeo), em que foi observado downregulation de forma dose-dependente nos níveis de 
mRNA para interleucina-6 (IL-6), ciclo-oxigenase-2 (COX-2) e óxido nítricosintase induzida (iNOS) (70). Tendo em vista os efeitos da inibição da DPPIV mostrados em inúmeros estudos, a realização desse trabalho teve como objetivo elucidar o impacto direto e indireto da cardioproteção exercida pela inibição de DPPIV, para discutir detalhadamente vias pró-fibróticas específicas, desde a atividade cruzada de Angiotensin II e a atividade cardíaca de NHE1, até a inflamação e downregulation do estresse oxidativo.

Para identificar mecanismos plausíveis relacionados a melhora da disfunção diastólica promovida pela sitagliptina, avaliamos a expressão gênica dos componentes do SRA cardíacos, atividade cardíaca de ACE e ACE2, bem como os níveis de Angiontesina II e Angiotensina 1-7 em homogeneizado de tecido cardíaco. No grupo que recebeu sitagliptina, foi observada uma redução acentuada da razão ECA/ECA2 e níveis de Angll, com relação aumentada de Angll/Ang 1-7 e maior expressão de ECA2, em comparação ao grupo que recebeu veículo. Tendo em vista esses achados, é factível que a ECA2 possa ter desempenhado papel importante, clivando a Ang II em Ang 1-7. Entretanto, os níveis de Ang 1-7 não aumentaram no grupo Nx+IDPPIV em relação ao grupo Nx. Isso pode ser explicado pelo fato de haver uma menor quantidade de Ang II em ratos $\mathrm{Nx}$ +IDPPIV, mostrando diferença apenas quando calculada a razão Angll/Ang 1-7.

A redução de Angll e aumento na relação Angll/Ang1-7 permanecem como características importantes no tratamento clínico da insuficiência cardíaca. As mudanças recíprocas no equilíbrio ECA/ECA2 são reconhecidas como mecanismos cardioprotetores essenciais para o desenvolvimento de hipertrofia 
ventricular esquerda não patológica em resposta ao exercício aeróbio (71-73). A ativação de componentes específicos do SRA leva a um ciclo vicioso de ativação e sinergia, que termina com o declínio da função cardíaca e renal. Interessantemente, foi verificada associação da DPPIV com o SRA. O tratamento com Ang II em células do túbulo proximal de ratos C57B1/6 fez com que a atividade da DPPIV aumentasse (53). Ademais, Zhang et al., demonstraram em um modelo de fibrose cardíaca induzida por angiotensina II, que a linagliptina, um inibidor da DPPIV, foi capaz de reduzir a expressão de AT1 e regular a expressão de AT2 e ECA2, juntamente com efeitos regulatórios sobre o colágeno 1 e fibrose cardíaca (74). A interação da DPPIV com o SRA cardíaco foi claramente evidenciada neste estudo, contudo, novas abordagens são necessárias para entender as vias associadas a essa ligação.

$\mathrm{O} \mathrm{pH}$ intracelular desempenha papel fundamental na regulação de vários aspectos relacionados a fisiologia celular. Os prótons podem atuar como um segundo mensageiro de maneira semelhante à cascata de sinalização de $\mathrm{Ca}^{2+}$. Além disso, o pH pode controlar a taxa de proliferação e transformação celular (75). No coração, a isoforma do trocador $\mathrm{Na}^{+} / \mathrm{H}^{+}$predominante é o $\mathrm{NHE} 1$, um dos principais reguladores do $\mathrm{pH}$ intracelular fisiológico e, sua atividade é ao menos parcialmente dependente de Angll $(76,77)$. O NHE1 demonstrou regular o ciclo celular, proliferação, migração, adesão e conferir resistência à apoptose (78, 79). Além disso, evidências experimentais e clínicas demonstraram implicações fisiopatológicas em relação ao aumento da atividade de NHE-1 na hipertrofia e fibrose de origem não-isquêmica. $\mathrm{O}$ aumento da atividade do NHE1 exerce efeitos deletérios na função do miocárdio, provavelmente por aumentar a carga de $\mathrm{Na}^{+}$intracelular, resultando em elevação do $\mathrm{Ca}^{2+}$ intracelular $(55,80)$. 
No presente estudo, demonstramos uma redução significativa na expressão do NHE1 cardíaco em ratos tratados com sitagliptina em comparação aos animais tratados com veículo. Curiosamente, Murohara et al.; demonstraram que a tenegliptina atenuou os níveis pressóricos e o remodelamento cardíaco em um modelo experimental de hipertensão, pela supressão direta de NHE1 e indireta de angiotensina II (54). Além disso, Gonzalez-Gronow e colegas evidenciaram que o plasminogênio do tipo II pode regular o pH intracelular através de uma associação com o NHE3 ligado à DPPIV nas células tumorais da próstata (75). Em conjunto, os dados anteriores e os mostrados nesse estudo, sustentam os efeitos diretos e indiretos da inibição de DPPIV, podendo apontar a atenuação do NHE1 como um fator que contribuiu para os benefícios relacionados ao remodelamento cardíaco.

Além de exercer efeitos sobre o SRA, os benefícios da inibição da DPPIV no coração parecem ser em parte, devido aos seus efeitos anti-inflamatórios. Um estudo prévio do nosso laboratório mostrou que a sitagliptina pode atenuar significativamente a inflamação e melhorar a perfusão cardíaca em um modelo experimental de insuficiência cardíaca. Além disso, mostramos que a inibição da DPPIV foi associada à menor infiltração de macrófagos no coração após lesão e à diminuição da expressão de marcadores inflamatórios como a fosforilação de p38, TNF-a, IL-1 e CCL2 (81). Na condição de uma insuficiência renal e cardíaca, a inflamação crônica permanece ativa, com níveis elevados de proteína C-reativa e várias citocinas pró-inflamatórias, como IL-1b, IL-6, TNF- $\alpha$. Além disso, mostramos nesse estudo redução pronunciada de MCP-1 e IL-1ß por meio do tratamento com sitagliptina, embora não evidenciamos uma 
diferença imune-moduladora, através da análise de desempenho de IL-6, IL-10 e TNF- $\alpha$.

Inúmeros trabalhos in vitro e em modelos experimentais demonstram que a atividade simpática, ativação do SRA e inflamação sustentadas levam ao aumento do estresse oxidativo e comprometimento cardíaco. Nesse trabalho, avaliamos os níveis de nitritirosina-3, que é um marcador do estresse oxidativo, e observamos uma redução significativa em animais que receberam o inibidor da DPPIV.

O aumento do estresse oxidativo e comprometimento cardíaco podem ser resultado de estímulos crônicos do SRA e citocinas inflamatórias. Uma vez gerada, as espécies reativas de oxigênio podem induzir efeitos deletérios ao coração, como a hipertrofia cardíaca, alterações na contratilidade de cardiomiócitos, transporte de íons e manuseio de cálcio. Nistala e colegas mostraram em lesão renal induzida por obesidade, que a inibição da DPPIV resultou em menores níveis de ácido úrico e nitrotirosina-3 (82). No presente trabalho, avaliamos os níveis de 3-nitrotirosina e observamos uma atenuação notável após 8 semanas administrando sitagliptina. Além disso, Koibuchi e cols. relataram um efeito cardioprotetor da linagliptina por meio da redução significativa de subunidades do NADPH oxidase, p67phox cardíaco e p22phox vascular (83) .

Os pacientes que apresentam diabetes tipo II e disfunção diastólica, apresentam piores desfechos em comparação aos pacientes com insuficiência sistólica (84). No entanto, a terapia visando redução da glicose por meio de agentes antidiabéticos nem sempre diminui o risco de insuficiência cardíaca, 
além disso, alguns agentes apresentam efeitos clínicos desfavoráveis na insuficiência cardíaca (85). No presente trabalho, julgamos importante avaliar o impacto da sitagliptina na função cardíaca e fornecemos evidências de que a sitagliptina atenua a disfunção diastólica em ratos com DRC. Por meio da ecocardiografia em repouso, identificamos melhora significativa do tempo de relaxamento isovolumétrico (IVRT). De acordo com esses achados, Hocher e colegas também mostraram que a linagliptina reduziu a abundância de biomarcadores fibróticos cardíacos e renais em modelo de DRC (50). Estudos clínicos, como a análise de subgrupos de pacientes do estudo PROLOGUE, relataram que a adição de sitagliptina ao tratamento convencional do diabetes pode atenuar significativamente o aumento de parâmetros funcionais diastólicos, independentemente de características clínicas, como pressão arterial e controle glicêmico (86).

Apesar de trabalhos demonstrarem efeitos benéficos dos inibidores da DPPIV sobre os rins e o coração, um estudo clínico (SAVOR-TIMI) conduzido em pacientes com diabetes tipo II que apresentavam riscos cardiovasculares, mostrou que a administração de saxagliptina aumentou em $27 \%$ o risco de hospitalização por insuficiência cardíaca (87). Esse resultado foi preocupante, e demonstra a necessidade de novos estudos clínicos para investigar se isso ocorre nos demais medicamentos pertencentes à classe dos inibidores da DPPIV, bem como identificar possíveis vias pelas quais esse efeito é decorrente. É importante considerar que outros estudos clínicos não encontraram associação dos inibidores da DPPIV com aumento de hospitalização. O estudo (TECOS) investigou os efeitos da sitagliptina sobre os desfechos cardiovasculares em pacientes com diabetes tipo II e não encontraram 
correlação com piores desfechos, além disso, esses efeitos também foram investigados utilizando outro inibidor da DPPV, a alogliptina, e semelhantemente, não foi encontrado ligação com o aumento na hospitalização $(88,89)$. Recentemente foi comparado um inibidor da DPPIV com a sulfonilureia em relação ao risco de insuficiência cardíaca em pacientes com diabetes tipo II, e constataram que o inibidor da DPPIV não teve correlação com aumentou do risco em comparação com o outro fármaco (90). Em vista do estudo SAVOR-TIMI, que encontrou resultados divergentes dos demais estudos clínicos, cabe salientar que o período de tempo de estudo para avaliar o impacto cardioprotetor dos inibidores da DPPIV, média ponderada de 2-3 anos, pode não ser suficiente para reverter processos pró-ateroscleróticos em pacientes com diabetes a mais de 10 anos, além disso, esses pacientes recebem estatinas, anti-hipertensivos, que podem influenciar nas análises.

Considerando os efeitos cardioprotetores dos inibidores da DPPIV em modelo experimental de DRC apresentados nesse trabalho, aliados aos estudos clínicos com relação a sua segurança em pacientes com risco cardiovascular, nota-se a necessidade de estudos a longo prazo, bem como ensaios clínicos para esclarecer tais aspectos. 
6. Conclusões 


\section{CONCLUSÕES}

Os dados apresentados no presente estudo demonstram que a inibição da DPPIV em ratos com nefrectomia $5 / 6$ atenua a injúria renal e reduz 0 remodelamento e a disfunção cardíaca (Figura 20). Além disso, mostra que esses efeitos podem estar atrelados à redução nos níveis de angiotensina II cardíacos, um dos principais efetores de hipertrofia cardíaca.

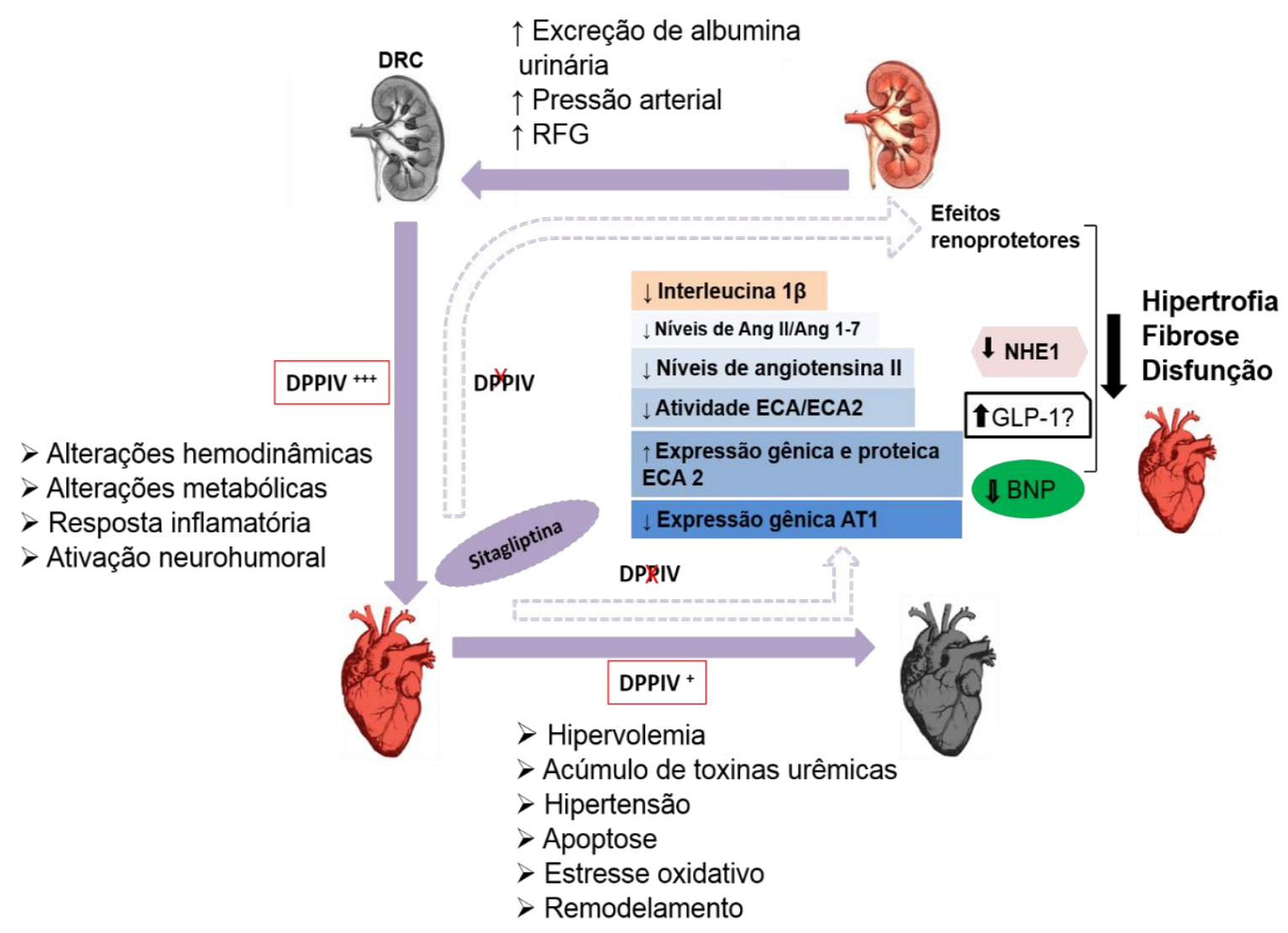

Figura 20. Efeitos da inibição da DPPIV em ratos com DRC. A deterioração da função renal, presente na $\mathrm{DRC}$, ativa vias neuro-humorais, inflamatórias, além de alterações metabólicas e hemodinâmicas que podem gerar influência sobre o tecido cardíaco. 0 acúmulo de toxinas urêmicas, hipertensão, apoptose, estresse oxidativo e remodelamento, são alguns dos fatores responsáveis pelos desfechos cardíacos potencialmente presentes na DRC: hipertrofia, fibrose e disfunção cardíaca. A inibição da DPPIV pela sitagliptina exerce efeitos renoprotetores e cardioprotetores, diminuindo o estresse oxidativo, citocinas inflamatórias e angiotensina II, resultando em efeitos atenuantes sobre a hipertrofia, fibrose e disfunção cardíaca. 


\section{Referências bibliográficas}




\subsection{REFERÊNCIAS BIBLIOGRÁFICAS}

1. Coresh J, Selvin E, Stevens LA, Manzi J, Kusek JW, Eggers P, et al. Prevalence of chronic kidney disease in the United States. JAMA. 2007;298(17):2038-47.

2. National Chronic Kidney Disease Fact Sheet [Internet]. 2014.

3. Jha V, Garcia-Garcia G, Iseki K, Li Z, Naicker S, Plattner B, et al. Chronic kidney disease: global dimension and perspectives. Lancet. 2013;382(9888):260-72.

4. Censo Brasileiro de Diálise 2014 (http://www.sbn.org.br/censo-brasileiro) [Internet].

5. Couser WG, Remuzzi G, Mendis S, Tonelli M. The contribution of chronic kidney disease to the global burden of major noncommunicable diseases. Kidney Int. 2011;80(12):1258-70.

6. KDIGO 2012 Clinical Practice Guideline for the Evaluation and Management of Chronic Kidney Disease. 2013. p. 1-150.

7. Basi S, Lewis JB. Microalbuminuria as a target to improve cardiovascular and renal outcomes. Am J Kidney Dis. 2006;47(6):927-46.

8. Currie G, Delles C. Proteinuria and its relation to cardiovascular disease. Int J Nephrol Renovasc Dis. 2013;7:13-24.

9. Roscioni SS, Lambers Heerspink HJ, de Zeeuw D. Microalbuminuria: target for renoprotective therapy PRO. Kidney Int. 2014;86(1):40-9.

10. Fraser SD, Blakeman T. Chronic kidney disease: identification and management in primary care. Pragmat Obs Res. 2016;7:21-32.

11. Maarten W. Taal, Chertow GM, Marsden PA, Karl Skorecki, Alan S. L. Yu, Brenner aBM. Brenner and Rector's The Kidney, 9th Edition,2012.

12. Zeisberg M, Neilson EG. Mechanisms of tubulointerstitial fibrosis. J Am Soc Nephrol. 2010;21(11):1819-34.

13. Hodgkins KS, Schnaper HW. Tubulointerstitial injury and the progression of chronic kidney disease. Pediatr Nephrol. 2012;27(6):901-9.

14. Lee $\mathrm{HB}, \mathrm{Yu} M \mathrm{MR}$, Yang $\mathrm{Y}$, Jiang $\mathrm{Z}, \mathrm{Ha} \mathrm{H}$. Reactive oxygen species-regulated signaling pathways in diabetic nephropathy. J Am Soc Nephrol. 2003;14(8 Suppl 3):S241-5.

15. Pan $\mathrm{Q}$, Yang $\mathrm{XH}$, Cheng YX. Angiotensin II stimulates MCP-1 production in rat glomerular endothelial cells via NAD(P)H oxidase-dependent nuclear factor-kappa B signaling. Braz J Med Biol Res. 2009;42(6):531-6.

16. Gross JL, de Azevedo MJ, Silveiro SP, Canani LH, Caramori ML, Zelmanovitz T. Diabetic nephropathy: diagnosis, prevention, and treatment. Diabetes Care. 2005;28(1):164-76.

17. King $P$, Peacock I, Donnelly R. The UK prospective diabetes study (UKPDS): clinical and therapeutic implications for type 2 diabetes. Br J Clin Pharmacol. 1999;48(5):643-8.

18. Arjona Ferreira JC, Corry D, Mogensen CE, Sloan L, Xu L, Golm GT, et al. Efficacy and safety of sitagliptin in patients with type 2 diabetes and ESRD receiving dialysis: a 54-week randomized trial. Am J Kidney Dis. 2013;61(4):579-87.

19. Arjona Ferreira JC, Marre M, Barzilai N, Guo H, Golm GT, Sisk CM, et al. Efficacy and safety of sitagliptin versus glipizide in patients with type 2 diabetes and moderate-to-severe chronic renal insufficiency. Diabetes Care. 2013;36(5):1067-73.

20. Friedrich C, Emser A, Woerle HJ, Graefe-Mody U. Renal impairment has no clinically relevant effect on the long-term exposure of linagliptin in patients with type 2 diabetes. Am J Ther. 2013;20(6):618-21.

21. Fujii $Y$, Abe $M$, Higuchi $T$, Mizuno $M$, Suzuki $H$, Matsumoto $S$, et al. The dipeptidyl peptidase-4 inhibitor alogliptin improves glycemic control in type 2 diabetic patients undergoing hemodialysis. Expert Opin Pharmacother. 2013;14(3):259-67. 
22. Kothny W, Shao Q, Groop PH, Lukashevich V. One-year safety, tolerability and efficacy of vildagliptin in patients with type 2 diabetes and moderate or severe renal impairment. Diabetes Obes Metab. 2012;14(11):1032-9.

23. McGill JB, Sloan L, Newman J, Patel S, Sauce C, von Eynatten M, et al. Long-term efficacy and safety of linagliptin in patients with type 2 diabetes and severe renal impairment: a 1-year, randomized, double-blind, placebo-controlled study. Diabetes Care. 2013;36(2):237-44.

24. Muskiet MH, Smits MM, Morsink LM, Diamant M. The gut-renal axis: do incretin-based agents confer renoprotection in diabetes? Nat Rev Nephrol. 2014;10(2):88-103.

25. Hopsu-Havu VK, Glenner GG. A new dipeptide naphthylamidase hydrolyzing glycylprolyl-beta-naphthylamide. Histochemie. 1966;7(3):197-201.

26. Lambeir AM, Durinx C, Scharpé S, De Meester I. Dipeptidyl-peptidase IV from bench to bedside: an update on structural properties, functions, and clinical aspects of the enzyme DPP IV. Crit Rev Clin Lab Sci. 2003;40(3):209-94.

27. Vilsbø\|l T, Holst JJ. Incretins, insulin secretion and Type 2 diabetes mellitus. Diabetologia. 2004;47(3):357-66.

28. Vilsbøll T, Krarup T, Deacon CF, Madsbad S, Holst JJ. Reduced postprandial concentrations of intact biologically active glucagon-like peptide 1 in type 2 diabetic patients. Diabetes. 2001;50(3):609-13.

29. Campbell RK, White JR. More choices than ever before: emerging therapies for type 2 diabetes. Diabetes Educ. 2008;34(3):518-34.

30. Drucker DJ. Biologic actions and therapeutic potential of the proglucagon-derived peptides. Nat Clin Pract Endocrinol Metab. 2005;1(1):22-31.

31. Holst JJ. Incretin hormones and the satiation signal. Int J Obes (Lond). 2013;37(9):11618.

32. Gomez N, Touihri K, Matheeussen V, Mendes Da Costa A, Mahmoudabady M, Mathieu $M$, et al. Dipeptidyl peptidase IV inhibition improves cardiorenal function in overpacing-induced heart failure. Eur J Heart Fail. 2012;14(1):14-21.

33. Takashima S, Fujita H, Fujishima H, Shimizu T, Sato T, Morii T, et al. Stromal cell-derived factor-1 is upregulated by dipeptidyl peptidase-4 inhibition and has protective roles in progressive diabetic nephropathy. Kidney Int. 2016;90(4):783-96.

34. Farah LX, Valentini V, Pessoa TD, Malnic G, McDonough AA, Girardi AC. The physiological role of glucagon-like peptide-1 in the regulation of renal function. Am J Physiol Renal Physiol. 2016;310(2):F123-7.

35. Holst JJ, Deacon CF. Glucagon-like peptide-1 mediates the therapeutic actions of DPP-IV inhibitors. Diabetologia. 2005;48(4):612-5.

36. Salles TA, dos Santos L, Barauna VG, Girardi ACC. Potential role of dipeptidyl peptidase IV in the pathophysiology of heart failure. International Journal of Molecular Sciences. 2015;16(2):4226-49.

37. Girardi AC, Degray BC, Nagy T, Biemesderfer D, Aronson PS. Association of $\mathrm{Na}(+)-\mathrm{H}(+)$ exchanger isoform NHE3 and dipeptidyl peptidase IV in the renal proximal tubule. J Biol Chem. 2001;276(49):46671-7.

38. Girardi AC, Knauf F, Demuth HU, Aronson PS. Role of dipeptidyl peptidase IV in regulating activity of $\mathrm{Na}+/ \mathrm{H}+$ exchanger isoform NHE3 in proximal tubule cells. Am J Physiol Cell Physiol. 2004;287(5):C1238-45.

39. Girardi AC, Fukuda LE, Rossoni LV, Malnic G, Rebouças NA. Dipeptidyl peptidase IV inhibition downregulates $\mathrm{Na}+-\mathrm{H}+$ exchanger NHE3 in rat renal proximal tubule. Am J Physiol Renal Physiol. 2008;294(2):F414-22.

40. Eligar VS, Bain SC. A review of sitagliptin with special emphasis on its use in moderate to severe renal impairment. Drug Des Devel Ther. 2013;7:893-903.

41. Hattori S. Sitagliptin reduces albuminuria in patients with type 2 diabetes. Endocr J. 2011;58(1):69-73. 
42. Kawasaki I, Hiura Y, Tamai A, Yoshida Y, Yakusiji Y, Ikuno Y, et al. Sitagliptin reduces the urine albumin-to-creatinine ratio in type 2 diabetes through decreasing both blood pressure and estimated glomerular filtration rate. J Diabetes. 2015;7(1):41-6.

43. Mori H, Okada Y, Arao T, Tanaka Y. Sitagliptin improves albuminuria in patients with type 2 diabetes mellitus. J Diabetes Investig. 2014;5(3):313-9.

44. Kanasaki K, Shi S, Kanasaki M, He J, Nagai T, Nakamura Y, et al. Linagliptin-mediated DPP4 inhibition ameliorates kidney fibrosis in streptozotocin-induced diabetic mice by inhibiting endothelial-to-mesenchymal transition in a therapeutic regimen. Diabetes. 2014;63(6):2120-31. 45. Joo KW, Kim S, Ahn SY, Chin HJ, Chae DW, Lee J, et al. Dipeptidyl peptidase IV inhibitor attenuates kidney injury in rat remnant kidney. BMC Nephrol. 2013;14:98.

46. Foley RN. Clinical epidemiology of cardiovascular disease in chronic kidney disease. J Ren Care. 2010;36 Suppl 1:4-8.

47. Johnson DW, Craven AM, Isbel NM. Modification of cardiovascular risk in hemodialysis patients: an evidence-based review. Hemodial Int. 2007;11(1):1-14.

48. Cowan BR, Young AA. Left ventricular hypertrophy and renin-angiotensin system blockade. Curr Hypertens Rep. 2009;11(3):167-72.

49. Frey N, Katus HA, Olson EN, Hill JA. Hypertrophy of the heart: a new therapeutic target? Circulation. 2004;109(13):1580-9.

50. Chaykovska L, von Websky K, Rahnenführer J, Alter M, Heiden S, Fuchs $\mathrm{H}$, et al. Effects of DPP-4 inhibitors on the heart in a rat model of uremic cardiomyopathy. PLoS One. 2011;6(11):e27861.

51. Dos Santos L, Salles TA, Arruda-Junior DF, Campos LCG, Pereira AC, Barreto ALT, et al. Circulating dipeptidyl peptidase IV activity correlates with cardiac dysfunction in human and experimental heart failure. Circulation: Heart Failure. 2013;6(5):1029-38.

52. Arruda-Junior DF, Martins FL, Dariolli R, Jensen L, Antonio EL, Dos Santos L, et al. Dipeptidyl Peptidase IV Inhibition Exerts Renoprotective Effects in Rats with Established Heart Failure. Front Physiol. 2016;7:293.

53. Aroor A, Zuberek M, Duta C, Meuth A, Sowers JR, Whaley-Connell A, et al. Angiotensin II Stimulation of DPP4 Activity Regulates Megalin in the Proximal Tubules. Int J Mol Sci. 2016;17(5).

54. Kawase H, Bando YK, Nishimura K, Aoyama M, Monji A, Murohara T. A dipeptidyl peptidase-4 inhibitor ameliorates hypertensive cardiac remodeling via angiotensin-II/sodiumproton pump exchanger-1 axis. J Mol Cell Cardiol. 2016;98:37-47.

55. Cingolani $\mathrm{HE}$, Camilión de Hurtado $\mathrm{MC}$. $\mathrm{Na}(+)-\mathrm{H}(+)$ exchanger inhibition: a new antihypertrophic tool. Circ Res. 2002;90(7):751-3.

56. Patel VB, Zhong JC, Grant MB, Oudit GY. Role of the ACE2/Angiotensin 1-7 Axis of the Renin-Angiotensin System in Heart Failure. Circ Res. 2016;118(8):1313-26.

57. Griffin KA, Picken M, Bidani AK. Method of renal mass reduction is a critical modulator of subsequent hypertension and glomerular injury. J Am Soc Nephrol. 1994;4(12):2023-31.

58. Griffin KA, Picken MM, Churchill M, Churchill P, Bidani AK. Functional and structural correlates of glomerulosclerosis after renal mass reduction in the rat. J Am Soc Nephrol. 2000;11(3):497-506.

59. Svíglerová J, Kuncová J, Nalos L, Tonar Z, Rajdl D, Stengl M. Cardiovascular parameters in rat model of chronic renal failure induced by subtotal nephrectomy. Physiol Res. 2010;59 Suppl 1:S81-8.

60. Zhang $Y$, Kompa AR. A practical guide to subtotal nephrectomy in the rat with subsequent methodology for assessing renal and cardiac function. Nephrology (Carlton). 2014;19(9):552-61.

61. Shimizu MH, Coimbra TM, de Araujo M, Menezes LF, Seguro AC. N-acetylcysteine attenuates the progression of chronic renal failure. Kidney Int. 2005;68(5):2208-17. 
62. Iliescu R, lonut T, Maranduca M, Gabriel D. Experimental models for renal disease Reduction in renal mass.

63. Bagshaw SM, Cruz DN, Aspromonte N, Daliento L, Ronco F, Sheinfeld G, et al. Epidemiology of cardio-renal syndromes: workgroup statements from the 7th ADQI Consensus Conference. Nephrol Dial Transplant. 2010;25(5):1406-16.

64. Filippatos G, Farmakis D, Parissis J. Renal dysfunction and heart failure: things are seldom what they seem. Eur Heart J. 2014;35(7):416-8.

65. Segall L, Nistor I, Covic A. Heart failure in patients with chronic kidney disease: a systematic integrative review. Biomed Res Int. 2014;2014:937398.

66. Tanaka Y, Kume S, Chin-Kanasaki M, Araki H, Araki S, Ugi S, et al. Renoprotective effect of DPP-4 inhibitors against free fatty acid-bound albumin-induced renal proximal tubular cell injury. Biochem Biophys Res Commun. 2016;470(3):539-45.

67. Eun Lee J, Kim JE, Lee MH, Song HK, Ghee JY, Kang YS, et al. DA-1229, a dipeptidyl peptidase IV inhibitor, protects against renal injury by preventing podocyte damage in an animal model of progressive renal injury. Lab Invest. 2016;96(5):547-60.

68. Picatoste B, Ramírez E, Caro-Vadillo A, Iborra C, Ares-Carrasco S, Egido J, et al. Sitagliptin reduces cardiac apoptosis, hypertrophy and fibrosis primarily by insulin-dependent mechanisms in experimental type-II diabetes. Potential roles of GLP-1 isoforms. PLoS One. 2013;8(10):e78330.

69. Sauvé M, Ban K, Momen MA, Zhou YQ, Henkelman RM, Husain M, et al. Genetic deletion or pharmacological inhibition of dipeptidyl peptidase-4 improves cardiovascular outcomes after myocardial infarction in mice. Diabetes. 2010;59(4):1063-73.

70. Lin CH, Lin CC. Sitagliptin attenuates inflammatory responses in lipopolysaccharidestimulated cardiomyocytes via nuclear factor-KB pathway inhibition. Exp Ther Med. 2016;11(6):2609-15.

71. Barretti DL, Magalhães FeC, Fernandes T, do Carmo EC, Rosa KT, Irigoyen MC, et al. Effects of aerobic exercise training on cardiac renin-angiotensin system in an obese Zucker rat strain. PLoS One. 2012;7(10):e46114.

72. Varagic J, Ahmad S, Nagata S, Ferrario CM. ACE2: angiotensin II/angiotensin-(1-7) balance in cardiac and renal injury. Curr Hypertens Rep. 2014;16(3):420.

73. Fernandes T, Hashimoto NY, Magalhães FC, Fernandes FB, Casarini DE, Carmona AK, et al. Aerobic exercise training-induced left ventricular hypertrophy involves regulatory MicroRNAs, decreased angiotensin-converting enzyme-angiotensin ii, and synergistic regulation of angiotensin-converting enzyme 2-angiotensin (1-7). Hypertension. 2011;58(2):182-9.

74. Zhang LH, Pang XF, Bai F, Wang NP, Shah Al, McKallip RJ, et al. Preservation of GlucagonLike Peptide-1 Level Attenuates Angiotensin II-Induced Tissue Fibrosis by Altering AT1/AT 2 Receptor Expression and Angiotensin-Converting Enzyme 2 Activity in Rat Heart. Cardiovasc Drugs Ther. 2015;29(3):243-55.

75. Gonzalez-Gronow M, Misra UK, Gawdi G, Pizzo SV. Association of plasminogen with dipeptidyl peptidase IV and $\mathrm{Na}+/ \mathrm{H}+$ exchanger isoform NHE3 regulates invasion of human 1-LN prostate tumor cells. J Biol Chem. 2005;280(29):27173-8.

76. Reid AC, Mackins CJ, Seyedi N, Levi R, Silver RB. Coupling of angiotensin II AT1 receptors to neuronal NHE activity and carrier-mediated norepinephrine release in myocardial ischemia. Am J Physiol Heart Circ Physiol. 2004;286(4):H1448-54.

77. Costa-Pessoa JM, Figueiredo CF, Thieme K, Oliveira-Souza M. The regulation of $\mathrm{NHE}_{1}$ and $\mathrm{NHE}_{3}$ activity by angiotensin $\|$ is mediated by the activation of the angiotensin II type I receptor/phospholipase $\mathrm{C} /$ calcium/calmodulin pathway in distal nephron cells. Eur J Pharmacol. 2013;721(1-3):322-31.

78. Putney LK, Barber DL. Na-H exchange-dependent increase in intracellular $\mathrm{pH}$ times G2/M entry and transition. J Biol Chem. 2003;278(45):44645-9. 
79. Wu KL, Khan S, Lakhe-Reddy S, Jarad G, Mukherjee A, Obejero-Paz CA, et al. The NHE1 $\mathrm{Na}+/ \mathrm{H}+$ exchanger recruits ezrin/radixin/moesin proteins to regulate Akt-dependent cell survival. J Biol Chem. 2004;279(25):26280-6.

80. Karmazyn M, Gan XT, Humphreys RA, Yoshida H, Kusumoto K. The myocardial $\mathrm{Na(+)-}$ $\mathrm{H}(+)$ exchange: structure, regulation, and its role in heart disease. Circ Res. 1999;85(9):777-86.

81. de Almeida Salles T, Zogbi C, de Lima TM, de Godoi Carneiro C, Garcez AT, Barbeiro HV, et al. The contributions of dipeptidyl peptidase IV to inflammation in heart failure. Am J Physiol Heart Circ Physiol. 2016;310(11):H1760-72.

82. Nistala R, Habibi J, Lastra G, Manrique C, Aroor AR, Hayden MR, et al. Prevention of obesity-induced renal injury in male mice by DPP4 inhibition. Endocrinology. 2014;155(6):226676.

83. Koibuchi N, Hasegawa $\mathrm{Y}$, Katayama T, Toyama K, Uekawa K, Sueta D, et al. DPP-4 inhibitor linagliptin ameliorates cardiovascular injury in salt-sensitive hypertensive rats independently of blood glucose and blood pressure. Cardiovasc Diabetol. 2014;13:157.

84. MacDonald MR, Petrie MC, Varyani F, Ostergren J, Michelson EL, Young JB, et al. Impact of diabetes on outcomes in patients with low and preserved ejection fraction heart failure: an analysis of the Candesartan in Heart failure: Assessment of Reduction in Mortality and morbidity (CHARM) programme. Eur Heart J. 2008;29(11):1377-85.

85. Turnbull FM, Abraira C, Anderson RJ, Byington RP, Chalmers JP, Duckworth WC, et al. Intensive glucose control and macrovascular outcomes in type 2 diabetes. Diabetologia. 2009;52(11):2288-98.

86. Yamada H, Tanaka A, Kusunose K, Amano R, Matsuhisa M, Daida H, et al. Effect of sitagliptin on the echocardiographic parameters of left ventricular diastolic function in patients with type 2 diabetes: a subgroup analysis of the PROLOGUE study. Cardiovasc Diabetol. 2017;16(1):63.

87. Scirica BM, Bhatt DL, Braunwald E, Steg PG, Davidson J, Hirshberg B, et al. Saxagliptin and cardiovascular outcomes in patients with type 2 diabetes mellitus. $\mathrm{N}$ Engl J Med. 2013;369(14):1317-26.

88. Green JB, Bethel MA, Paul SK, Ring A, Kaufman KD, Shapiro DR, et al. Rationale, design, and organization of a randomized, controlled Trial Evaluating Cardiovascular Outcomes with Sitagliptin (TECOS) in patients with type 2 diabetes and established cardiovascular disease. Am Heart J. 2013;166(6):983-9.e7.

89. White $W B$, Bakris GL, Bergenstal RM, Cannon CP, Cushman WC, Fleck $P$, et al. EXamination of CArdiovascular outcoMes with alogliptIN versus standard of carE in patients with type 2 diabetes mellitus and acute coronary syndrome (EXAMINE): a cardiovascular safety study of the dipeptidyl peptidase 4 inhibitor alogliptin in patients with type 2 diabetes with acute coronary syndrome. Am Heart J. 2011;162(4):620-6.e1.

90. Kim YG, Yoon D, Park S, Han SJ, Kim DJ, Lee KW, et al. Dipeptidyl Peptidase-4 Inhibitors and Risk of Heart Failure in Patients With Type 2 Diabetes Mellitus: A Population-Based Cohort Study. Circ Heart Fail. 2017;10(9). 